CFD ANALYSIS OF A NOTEBOOK COMPUTER THERMAL

MANAGEMENT SOLUTION

\begin{abstract}
A THESIS SUBMITTED TO
THE GRADUATE SCHOOL OF NATURAL AND APPLIED SCIENCES

$\mathrm{OF}$

MIDDLE EAST TECHNICAL UNIVERSITY
\end{abstract}

BY

FIDAN SEZA YALÇIN

IN PARTIAL FULFILLMENT OF THE REQUIREMENTS

FOR

THE DEGREE OF MASTER OF SCIENCE

IN

MECHANICAL ENGINEERING

MAY 2008 
Approval of the thesis:

\section{CFD ANALYSIS OF A NOTEBOOK COMPUTER THERMAL MANAGEMENT SOLUTION}

submitted by FIDAN SEZA YALÇIN in partial fulfillment of the requirements for the degree of Master of Science in Mechanical Engineering Department, Middle East Technical University by,

Prof. Dr. Canan ÖZGEN

Dean, Graduate School of Natural and Applied Sciences

Prof. Dr. S. Kemal İDER

Head of Department, Mechanical Engineering

Assist. Prof. Dr. İlker TARI

Supervisor, Mechanical Engineering Dept., METU

Assist. Prof. Dr. Cüneyt SERT

Co-Supervisor, Mechanical Engineering Dept., METU

\section{Examining Committee Members:}

Prof. Dr. M. Haluk AKSEL

Mechanical Engineering Dept., METU

Assist. Prof. Dr. İlker TARI

Mechanical Engineering Dept., METU

Assist. Prof. Dr. Cüneyt SERT

Mechanical Engineering Dept., METU

Assist. Prof. Dr. Derek K. BAKER

Mechanical Engineering Dept., METU

Assoc. Prof. Dr. Cemal Niyazi SÖKMEN

Nuclear Energy Engineering Dept., Hacettepe Univ.

Date: $05 / 05 / 2008$ 
I hereby declare that all information in this document has been obtained and presented in accordance with academic rules and ethical conduct. I also declare that, as required by these rules and conduct, I have fully cited and referenced all material and results that are not original to this work.

Name, Last Name: Fidan Seza YALÇIN

Signature:

iii 


\title{
ABSTRACT \\ CFD ANALYSIS OF A NOTEBOOK COMPUTER THERMAL MANAGEMENT SOLUTION
}

\author{
Yalçın, Fidan Seza \\ M.S., Department of Mechanical Engineering \\ Supervisor: Assist. Prof. Dr. İlker Tarı \\ Co-Supervisor: Assist. Prof. Dr. Cüneyt Sert
}

May 2008, 92 pages

In this study, the thermal management system of a notebook computer is investigated by using a commercial finite volume Computational Fluid Dynamics (CFD) software. After taking the computer apart, all dimensions are measured and all major components are modeled as accurately as possible. Heat dissipation values and necessary characteristics of the components are obtained from the manufacturer's specifications. The different heat dissipation paths that are utilized in the design are investigated. Two active fans and aluminum heat dissipation plates as well as the heat pipe system are modeled according to their specifications. The first and second order discretization schemes as well as two different mesh densities are investigated as modeling choices. Under different operating powers, adequacy of the existing thermal management system is observed. Average and maximum temperatures of the internal components are reported in the form of tables. Thermal resistance networks for five different operating conditions are obtained from the analysis of the CFD simulation results. Temperature distributions on the top surface of the chassis where the keyboard and touchpad are located are investigated considering the user comfort. 
Keywords: Notebook Thermal Management; CPU Cooling; Computational Fluid Dynamics (CFD); Heat Pipe. 


\title{
ÖZ
}

\section{DİZÜSTÜ BİLGISSAYARLARIN ISI YÖNETIM ÇÖZÜMÜNÜN HESAPLAMALI AKIŞKANLAR DINAMIĞİ ANALIZİ}

\author{
Yalçın, Fidan Seza \\ Yüksek Lisans, Makina Mühendisliği Bölümü \\ Tez Yöneticisi: Yard. Doç. Dr. İlker Tarı \\ Ortak Tez Yöneticisi: Yard. Doç. Dr. Cüneyt Sert
}

Mayıs 2008, 92 Sayfa

\begin{abstract}
$\mathrm{Bu}$ çalışmada bir dizüstü bilgisayarın 1sıl yönetim sisteminin sayısal çözümlemesi, ticari bir hesaplamalı akışkanlar dinamiği (HAD) programı ile yapılmıştır. Bilgisayar parçalara ayrıldıktan sonra, tüm boyutları ölçülmüş ve tüm ana bileşenler olabildiğince hassas modellenmiştir. Bileşenlerin 1s1 yayılımı değerleri ve gerekli özellikleri üretici teknik özelliklerinden temin edilmiştir. Tasarımda kullanılmış farklı ısı yayılımı yolları incelenmiştir. İki adet etkin fan ve alüminyum 1sı yayma plakaları, 1sıl tüp sistemiyle birlikte; teknik özelliklerine göre modellenmiştir. Tek ve çift hassasiyetli çözüm şemalarının yanında iki farklı eleman yoğunluğu, modelleme seçimi için incelenmiştir. Farklı çalışma güçlerinde 1sıl yönetim sisteminin yeterliliği gözlemlenmiştir. İç bileşenlerin ortalama ve azami sıcaklıkları tablolar halinde sunulmuştur. HAD benzetim sonuçlarının analizinden ısıl direnç ağları beş farklı çalışma koşulu için elde edilmiştir. Klavye ve dokunmatik farenin bulunduğu şase üst yüzeyindeki 1sı dağılımı kullanıcı konforu göz önünde tutularak incelenmiştir.
\end{abstract}


Anahtar Kelimeler: Dizüstü Bilgisayar Isıl Yönetimi; İşlemci Soğutulması; Hesaplamalı Akışkanlar Dinamiği (HAD); Isıl Tüp. 
To My Family 


\section{ACKNOWLEDGEMENTS}

I would like to express my deepest gratitude to my supervisor Assist. Prof. Dr. İlker Tarı and co-supervisor Assist. Prof. Dr. Cüneyt Sert for their great guidance, advice, criticism, encouragements, patience and insight throughout the research.

I am very thankful to Tufan Tolga, Erdoğan Yunusoğlu and all my colleagues in Kozmos Engineering for their support and understanding throughout my studies.

I am grateful to my friends, especially Banu Çomak, Meltem Yıldız, Sevgi Saraç and Pınar Ünsal for the care with which they helped me prepare this thesis; and for conversations that clarified my thinking on this and other matters.

A number of colleagues allowed me to use some of their materials and made comments that encouraged me to revise and improve my studies. In this regard, I am indebted to Bora Timurkutluk, Metehan Erdoğan and especially Ender Özden.

At last but not least; I am deeply indebt to Yalçın, Kırcı and Tuğcu families for their never-ending love and spiritual support at critical and opportune times.

As always, it was my parents and my sister who provided the shelter conditions under which the work could take place: thanks to them for this and many other things. 


\section{TABLE OF CONTENTS}

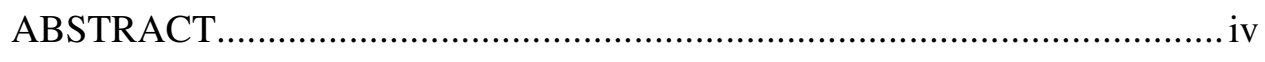

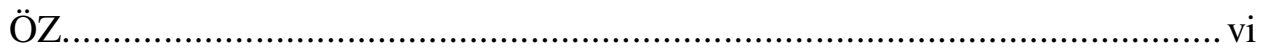

ACKNOWLEDGEMENTS ............................................................... ix

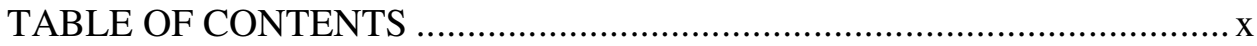

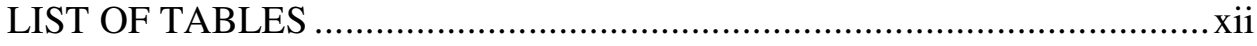

LIST OF FIGURES ........................................................................ xiv

CHAPTER

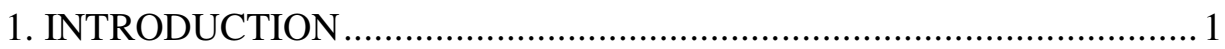

1.1 Thermal Management of Notebooks......................................... 1

1.2 Conventional Thermal Solutions ….......................................... 3

1.2.1 Heat Sinks ................................................................ 3

1.2.2 Heat Pipes.............................................................. 4

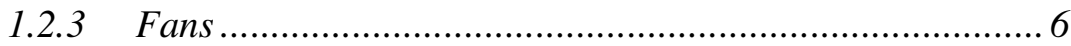

1.2.4 Interface materials .................................................. 6

1.3 The Use of Heat Pipes in Notebook Cooling .............................. 7

1.4 System Description and Parameters............................................. 10

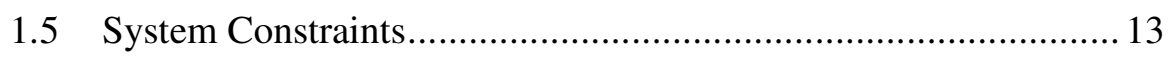

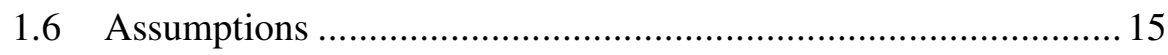

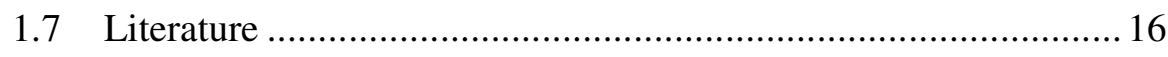

2. COMPUTATIONAL MODELS AND EQUATIONS SOLVED............. 19

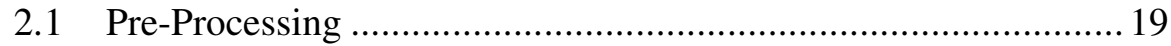

2.1.1 Computational Domain ............................................... 20

2.1.2 Details of Computational Domain ................................. 20

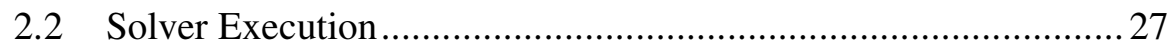

2.2.1 Governing Equations of Fluid Flow............................. 27

2.2.2 Flow Configuration and Boundary Conditions................ 29

2.2.3 Governing Equations to be Solved ................................ 35 


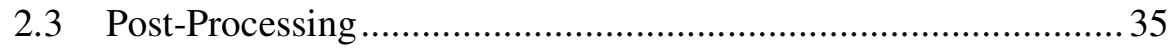

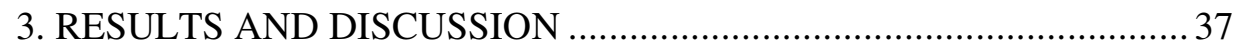

3.1 Sources of Errors in CFD Calculations ....................................... 37

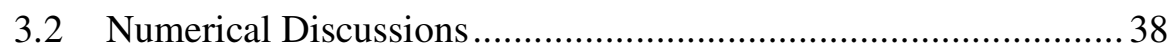

3.2.1 Convergence Criteria .................................................. 38

3.2.2 Mesh Selection ............................................................... 38

3.2.3 Discretization ............................................................. 44

3.3 Thermal Management Results …..............................................5 50

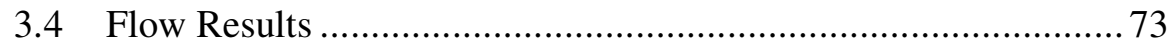

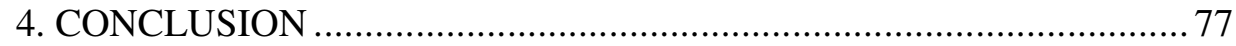

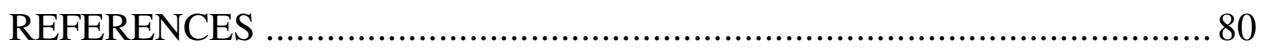

APPENDICES

A. HEAT PIPE THERMAL CONDUCTIVITY …..................................... 84

B. HEAT EXCHANGER GRID INDEPENDENCY .............................. 88

C. ENHANCEMENT IN THE THERMAL MANAGEMENT SYSTEM BY

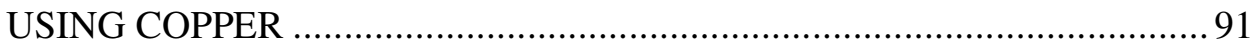




\section{LIST OF TABLES}

\section{TABLES}

Table 1.1 Thermal conductivities of interface materials .................................7

Table 1.2 Heat dissipation of the components .............................................13

Table 1.3 Maximum operating temperatures of the notebook components .....14

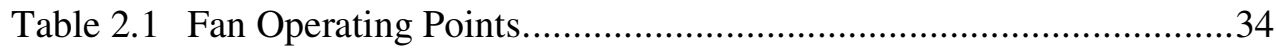

Table 3.1 Average temperature values for the components for the fine and the coarse mesh configurations

Table 3.2 Average temperature values of the components for the first order discretization scheme and the second order discretization scheme.....

Table 3.3 Heat dissipation rates of the components for Case I, Case II, Case III, Case IV, and Case V.

Table 3.4 Comparison of the maximum allowable temperatures and the calculated average temperatures of the components for Case I, Case II, Case III, Case IV, and Case V....

Table 3.5 Comparison of the maximum allowable temperatures and the calculated maximum temperatures of the components for Case I, Case II, Case III, Case IV, and Case V.

Table 3.6 Heat dissipation methods of the notebook and the components for Case I, Case II, Case III, Case IV, and Case V .

Table A.1 Comparison of the average temperature values of the components.

Table A.2 Comparison of the average temperature values of the evaporator and the condenser section of the heat pipes

Table A.3 Comparison of the heat loads on the heat transfer paths . .87 
Table B.1 Comparison of the average temperature values of the evaporator and the condenser section of the heat pipe for the coarse and the fine mesh configurations ........................................8

Table B.2 Average temperature values of the components for the coarse and the fine mesh configuration .............................................. 90

Table C.1 Comparison of the maximum temperature of the components ......92 


\section{LIST OF FIGURES}

\section{FIGURES}

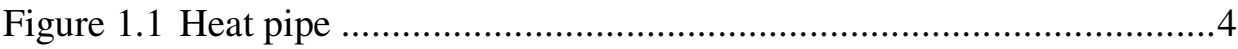

Figure 1.2 Heat pipe with heat spreader plate ............................................8

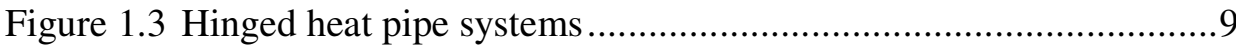

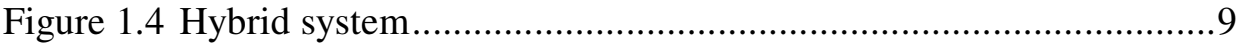

Figure 1.5 Inside of Sony Vaio PCG-GRX 316 MP notebook ..................... 10

Figure 1.6 CPU cooling system of the notebook.........................................11

Figure 1.7 Heat pipe configuration of the notebook....................................12

Figure 2.1 Computational domain of the notebook...................................21

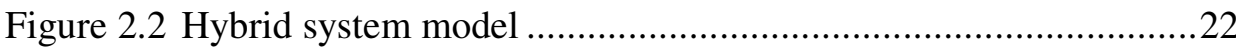

Figure 2.3 Heat exchanger model.........................................................23

Figure 2.4 Secondary fan attached with a heat sink ...................................24

Figure 2.5 Vents and Keyboard Locations..............................................26

Figure 2.6 Fan Performance curves of the primary fan and the secondary

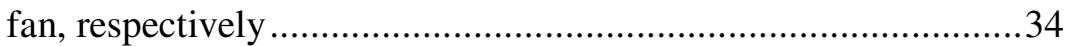

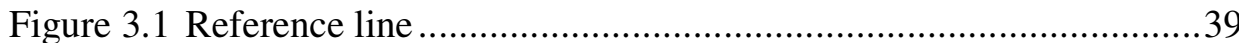

Figure 3.2 Temperature plots on the reference line for the coarse and the fine mesh configurations

Figure 3.3 Temperature distributions of the top surface of the CPU for the coarse mesh (top) and the fine mesh (bottom)

Figure 3.4 Temperature distributions of the top surface of the PCB for the coarse mesh (top) and the fine mesh (bottom)

Figure 3.5 Temperature plots on the reference line for the first order discretization scheme and the second order discretization scheme 
Figure 3.6 Temperature distributions of the top surface of the CPU for the first order discretization (top) and the second order discretization (bottom) solutions

Figure 3.7 Temperature distributions of the top surface of the PCB for the first order discretization (top) and the second order discretization (bottom) solutions

Figure 3.8 Temperature plots on the reference line for the first order and the second order discretization schemes with the coarse mesh configuration, and the first order discretization scheme with the fine mesh configuration ................................ 49

Figure 3.9 Thermal path diagram for Case I ............................................56

Figure 3.10 Thermal path diagram for Case II ....................................... 57

Figure 3.11 Thermal path diagram for Case III........................................ 58

Figure 3.12 Thermal path diagram for Case IV ..................................... 59

Figure 3.13 Thermal path diagram for Case V..........................................6 60

Figure 3.14 The active heat transfer path of the CPU ................................ 61

Figure 3.15 Temperature distributions of the PCB top surface for Case I, Case II, Case III, Case IV, and Case V .................................. 64

Figure 3.16 Temperature distributions of the top surface of the chassis for Case I, Case II, Case III, Case IV, and Case V .

Figure 3.17 Temperature distributions of the top surface of the chassis for Case I, Case II, Case III, Case IV, and Case V which exceeds the comfort limit ....................................................... 70

Figure 3.18 Contours of velocity on different planes in $z$ axis .................... 74

Figure 3.19 Path lines for primary fan .................................................. 75

Figure 3.20 Path lines for secondary fan.............................................. 76

Figure A.1 Heat pipe thermal resistance model ....................................... 84

Figure B.1 Temperature plots on the reference line for the coarse and the fine mesh configurations. 


\section{CHAPTER 1}

\section{INTRODUCTION}

The notebook technology has been improving since its first introduction into the market in 1980's. Customer demands push the companies to design thinner, lighter and higher performance notebooks. Higher performance central processing units (CPU), larger hard disk drives, more memory (RAM), and all the new features that have been added lead to high heat dissipation rates inside the notebook. Due to weight and space limitations, high performance notebooks have greater thermal challenges compared to desktops. The main contributor to this high heat dissipation is the CPU. The new generation CPUs are smaller and more powerful, hence they create higher heat fluxes. A high speed CPU has on the average $25 \mathrm{~W}$ heat load [1]. These high heat loads have to be dissipated by efficient thermal management techniques.

\subsection{Thermal Management of Notebooks}

Component level cooling and system level cooling are the main mechanisms in thermal management of notebook computers. In the component level cooling, the cooling solution is attached on the component. A system, in which a fan attached on the CPU, is an example to this type of cooling. In the system level cooling, heat dissipation is maximized from the system walls to the environment [2].

In thermal management, the main objective is to keep the components at or below their maximum junction temperature $\left(T_{j}\right)$ while operating at the 
Thermal Design Power (TDP). TDP of a component is the maximum power consumption of the component. This is the worst case scenario which is very rarely realized by an average user.

A typical cooling solution for a notebook is much more complex than that for a desktop system. The notebook cooling solutions differ among the manufacturers, since the internal design, layout, and the location of CPU are not the same. There are two types of cooling solutions classified according to the heat transfer mechanisms: passive cooling method and active cooling method [2]. In the thermal management of notebooks, either one or both of these cooling methods are used.

The passive cooling method is simply using natural convection and conduction paths within the notebook to cool it. The driving force for the natural convection is the temperature difference caused by the heat dissipating parts. The aim of the passive cooling method is to provide sufficient conduction paths in order to increase heat dissipation rates by decreasing total thermal resistance. Designing the conduction paths for the CPU is the main issue in passive cooling, since it is the main heat dissipation contributor. In most of the passive cooling methods, there are two conduction paths for the CPU. One of them is through motherboard, an aluminum or copper heat spreader plate attached to the motherboard and the bottom chassis wall; the other one is through the heat sink attached to the top of CPU. Thermal greases are commonly used to decrease the contact resistance in a conduction path.

In an active cooling method fans that are attached to the component, are used to supply airflow over the component or the heat sink, to increase the heat transfer rate. Passive cooling methods are much more silent, reliable and cheaper compared to the active cooling solutions. Also, they do not require extra power. However, for cooling higher performance CPUs passive cooling 
methods may not be sufficient. For higher performance notebooks it is advisable to apply active cooling methods or both methods together.

The complexity of the thermal solutions which are applied in notebook systems has greatly increased, from simple methods such as metal plates, extruded heat sinks, to more complicated ones such as heat pipes, fans and fan-heat sinks.

In the 1980's, 286 and 386 notebooks used the surface area of the CPU and the printed circuit board (PCB) to spread heat. As the power dissipation levels started to increase, in the 1990's, 486 notebooks used more complex cooling techniques such as extruded heat sinks, aluminum plates, thermally conductive elastomers, and thermal tapes. In 1994, with the introduction of the high power Pentium $^{\mathrm{TM}}$ processors, heat pipes started to appear in notebooks [3]. The details of the heat pipe use in notebook computers are discussed in Section 1.3.

\subsection{Conventional Thermal Solutions}

In this section, recently used conventional thermal management solutions are discussed.

\subsubsection{Heat Sinks}

A heat sink is a thermally conductive material which is used for transferring heat from the heat source to the ambient by a relatively large surface area. Most of the heat sinks used in notebook computers are made out of aluminum or copper and attached to the heat sources using a thermal interface material. The total rate of heat dissipation, the dimensions, the attachment method, type of the convection, and the direction of the airflow are the major factors affecting the selection of heat sink. 


\subsubsection{Heat Pipes}

A heat pipe is a passive two-phase heat transfer device capable of transferring large quantities of heat with a minimal temperature drop. It is a simple device that can quickly transfer heat from one point to another. They are often referred to as the "superconductors" of heat as they possess an extraordinary heat transfer capacity with low temperature gradients [4].

All heat pipes have three physical elements in common [5]:

- Container: An evacuated and sealed vessel

- Working fluid: Differs due to operating conditions

- Wick structure: Provides the capillary forces for the liquid to travel in the pipe.

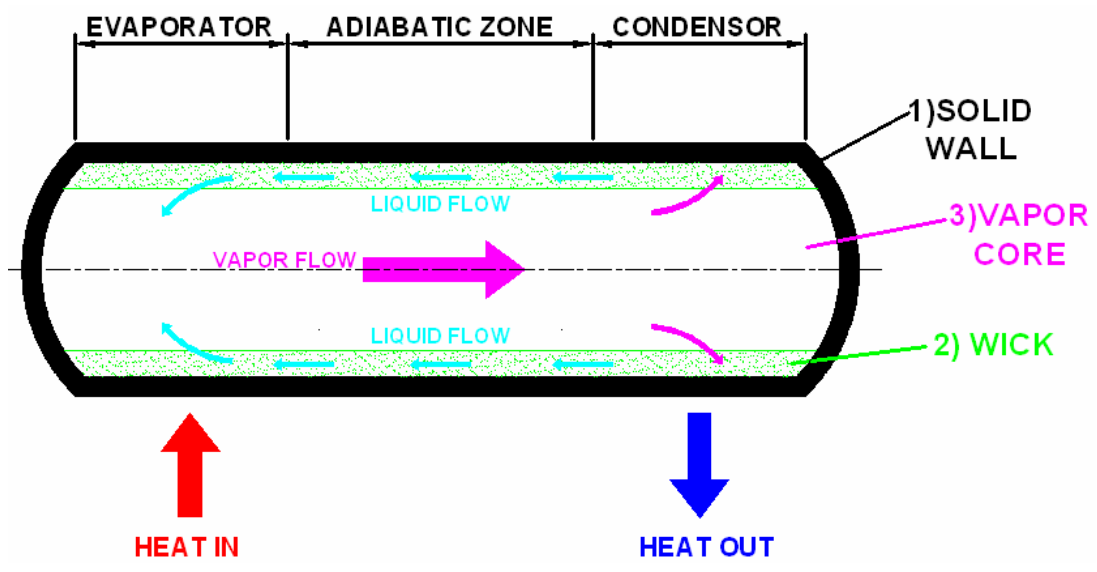

Figure 1.1 Heat pipe (adapted from [6])

As shown in Figure 1.1, a heat pipe in its simplest configuration is a closed and evacuated cylindrical vessel with the internal walls lined with a capillary structure or wick that is saturated with a working fluid. Since the heat pipe is 
evacuated and then charged with the working fluid prior to being sealed, the internal pressure is set by the vapor pressure of the fluid.

As heat is input at the evaporator, fluid is vaporized, creating a pressure gradient in the pipe. This pressure gradient forces the vapor to flow along the pipe to a cooler section where it condenses giving up its latent heat of vaporization. The working fluid is then returned to the evaporator by the capillary forces developed in the wick structure [6].

The thermal resistance of a heat pipe has three components [7]:

- The thermal resistances of the evaporator, heat source and working fluid

- The axial thermal resistance of working fluid

- The thermal resistances of the condenser, heat exchanger and ambient air

Typical thermal resistance values for a copper heat pipe with water as a working fluid are $0.2 \mathrm{~K} / \mathrm{W} . \mathrm{cm}^{2}$ for the end contacts and $0.02 \mathrm{~K} / \mathrm{W} . \mathrm{cm}^{2}$ for the axial thermal resistance. Overall thermal resistance is in the range of $0.05-0.2 \mathrm{~K} / \mathrm{W}$ which is extremely low when compared to pure metals [8].

Heat pipes have no power consumption and light weight which makes it preferable to use in a notebook. Another important benefit to use a heat pipe in a notebook computer appears when there is not enough space to install a heat sink on the component which dissipates heat. In this situation, a heat pipe can be used to transport heat to a place where it can be dissipated through a heat sink. 


\subsubsection{Fans}

Fans provide the airflow velocity in forced convection thermal management solutions and improve the thermal performance of the system. The rapid increase in the heat dissipation of notebook CPU's makes it inevitable to use fans for thermal solutions.

In an ideal notebook thermal solution it is not desired to use fans, however when the total system heat dissipation cannot be managed by natural convective methods, it is a must. As notebook computers become smaller, the external case surface area decreases and the surface area available for natural convection will not be sufficient.

Another common problem in notebook computers is the concentration of heat at certain 'hot spots' in the system. These hot spots are the major challenge while designing the thermal solutions. The use of fan simplifies the solution of hot spot problems without mechanically redesigning the entire system [8].

\subsubsection{Interface materials}

In a thermal design, the interface material between the thermal solution and the heat source is very important. The air gaps between contacts and the surface irregularities cause an increase in thermal resistance.

There is a large variety of thermal interface materials in the market to use in different applications, such as thermal greases, thermal compounds, phase change materials, elastomers, thermal adhesives, and gap fillers. Thermal conductivities of some of these materials are given in Table 1.1. 
Table 1.1 Thermal conductivities of interface materials [9]

\begin{tabular}{|l|c|}
\hline Interface Materials & $\begin{array}{c}\text { Thermal Conductivity } \\
\text { (W/m.K) }\end{array}$ \\
\hline Thermal grease & 0.75 \\
Thermal adhesive & 0.85 \\
Gap filler & 6 \\
\hline
\end{tabular}

\subsection{The Use of Heat Pipes in Notebook Cooling}

Although the first heat pipe was made in 1963, it was not until 1994 that a heat pipe was used in a notebook computer. After 1994, there have been several different methods to use heat pipes in notebook systems [2]. The details of some methods are as follows:

Heat Pipe with a Heat Spreader Plate: Heat pipe is used to transfer heat from the CPU to a plate dissipating the heat, usually made of aluminum. The position of the heat spreading plate changes according to the design of the notebook. It can be under the keyboard or on the chassis which can be seen in Figure 1.2 (a) and (b), respectively. Kobayashi et al. [10] worked on a cooling system for CPU by using the bottom chassis as a heat spreader combining with an aluminum heat transfer plate. The TDP of CPU is $3.9 \mathrm{~W}$, and the thermal management system managed to succeed in an ambient temperature of $35{ }^{\circ} \mathrm{C}$ and CPU operating temperature of $70{ }^{\circ} \mathrm{C}$. 


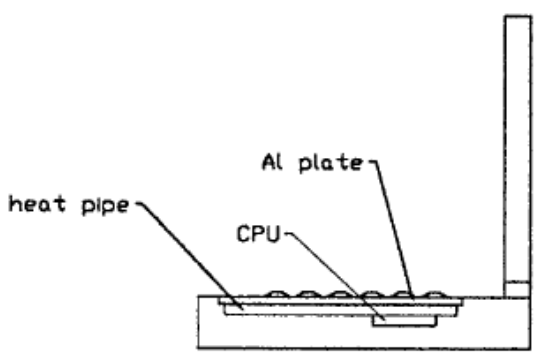

(a)

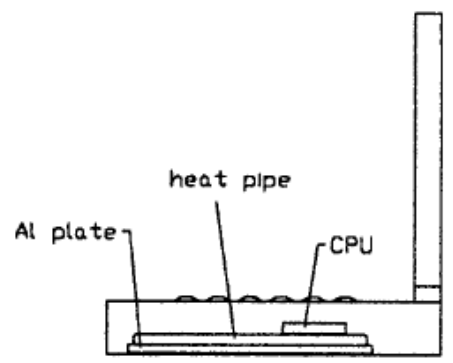

(b)

Figure 1.2 Heat pipe with heat spreader plate (adapted from [11])

Hinged Heat Pipe System: The heat pipe with heat spreader plate under the keyboard or on the chassis has limitations. High keyboard temperature or notebook chassis temperature is ergonomically undesirable. At this point thermal hinge concept will be an alternative solution. Mochizuki et al. [11] designed and tested a hinged heat pipe cooling system. Basically this system consisted of two heat pipes and a thermal hinge. The primary heat pipe is fixed and is in contacted with the CPU, transferring heat to the secondary heat pipe via thermal hinge that joined the two heat pipes together. The second heat pipe is used to transfer heat onto the aluminum heat spreader plate which is positioned at the back of display screen. An illustration of hinged heat pipe system is shown in Figure 1.3. The experiments showed that this system has $10-12 \mathrm{~W}$ range of heat dissipation capacity.

Hybrid System: This system is a combination of a heat pipe, a plate fin heat sink and a fan as shown in Figure 1.4. One end of the heat pipe is pressure fitted into a conductor block which is in contact with the CPU through thermal interface material, and the other end was mechanically attached to the heat exchanger. The heat exchanger assembly consists of a finned heat sink and a fan which provides air to the heat sink. Nguyen et al. [13] studied a hybrid system consisting of $6 \mathrm{~mm}$ round heat pipe attached to a heat block $(30 \mathrm{~mm} \mathrm{x}$ 
$30 \mathrm{~mm} \times 3 \mathrm{~mm})$ on one end and to a plate heat sink on the other $\left(100 \mathrm{~cm}^{2}\right.$ total fins surface area). A $50 \mathrm{~mm} \times 50 \mathrm{~mm} \times 7 \mathrm{~mm}$ fan provides 2 CFM airflow to the heat sink. The heat dissipation capacity of this system is $20 \mathrm{~W}$, if the temperature limit for the $\mathrm{CPU}$ is $90{ }^{\circ} \mathrm{C}$ and the ambient temperature is $40{ }^{\circ} \mathrm{C}$.

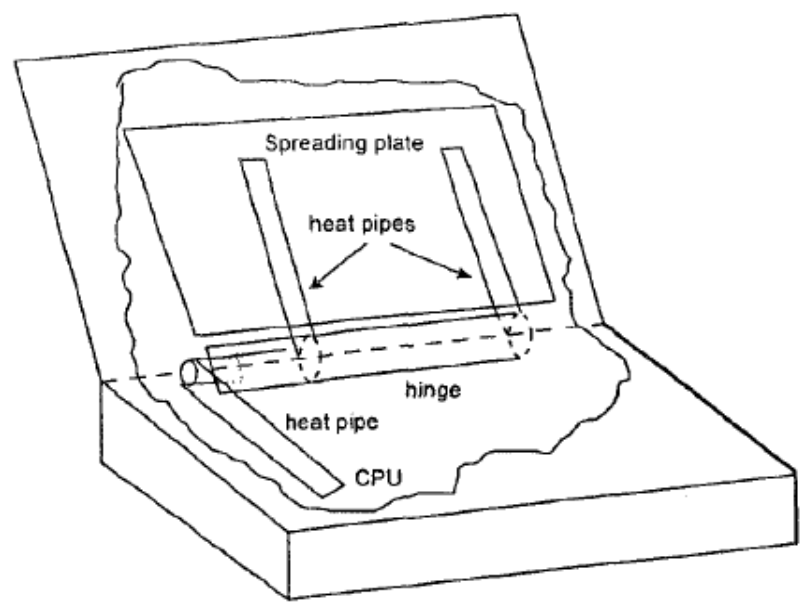

Figure 1.3 Hinged heat pipe systems (adapted from [12])

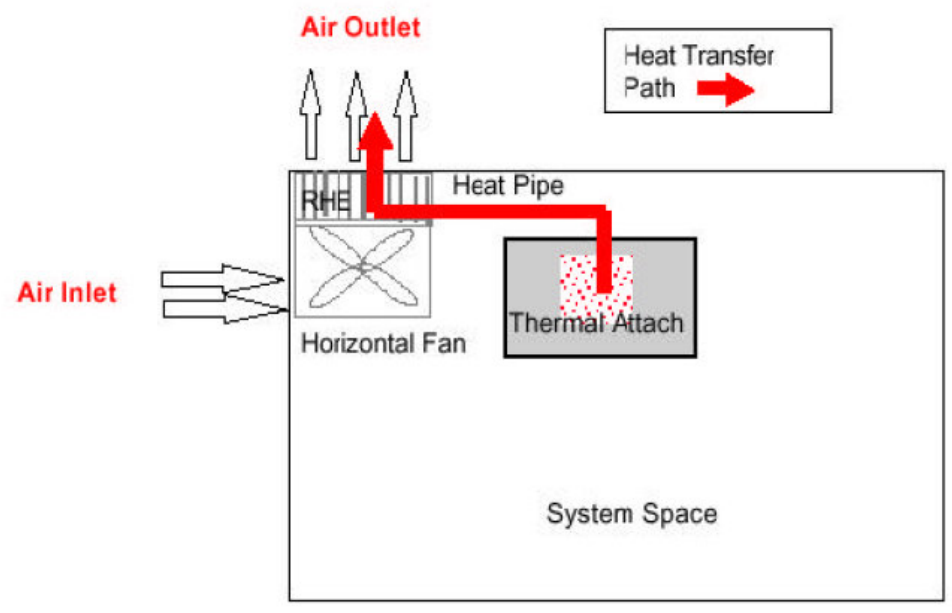

Figure 1.4 Hybrid system (adapted from [2]) 
Thermal solutions for the notebook computers improved from simple heat spreaders to micro heat pipes and miniature fans. Continuous development in the computer technologies will maintain this improvement for the following years.

In this study, a hybrid thermal management system is investigated for a specific notebook.

\subsection{System Description and Parameters}

The notebook considered in this study is SONY VAIO PCG-GRX316MP (TFT16.1UXGA, 1.60GHz - M Mobile Pentium IV, HDD 30GB,RAM 256MB) on which a hybrid thermal management system is used.

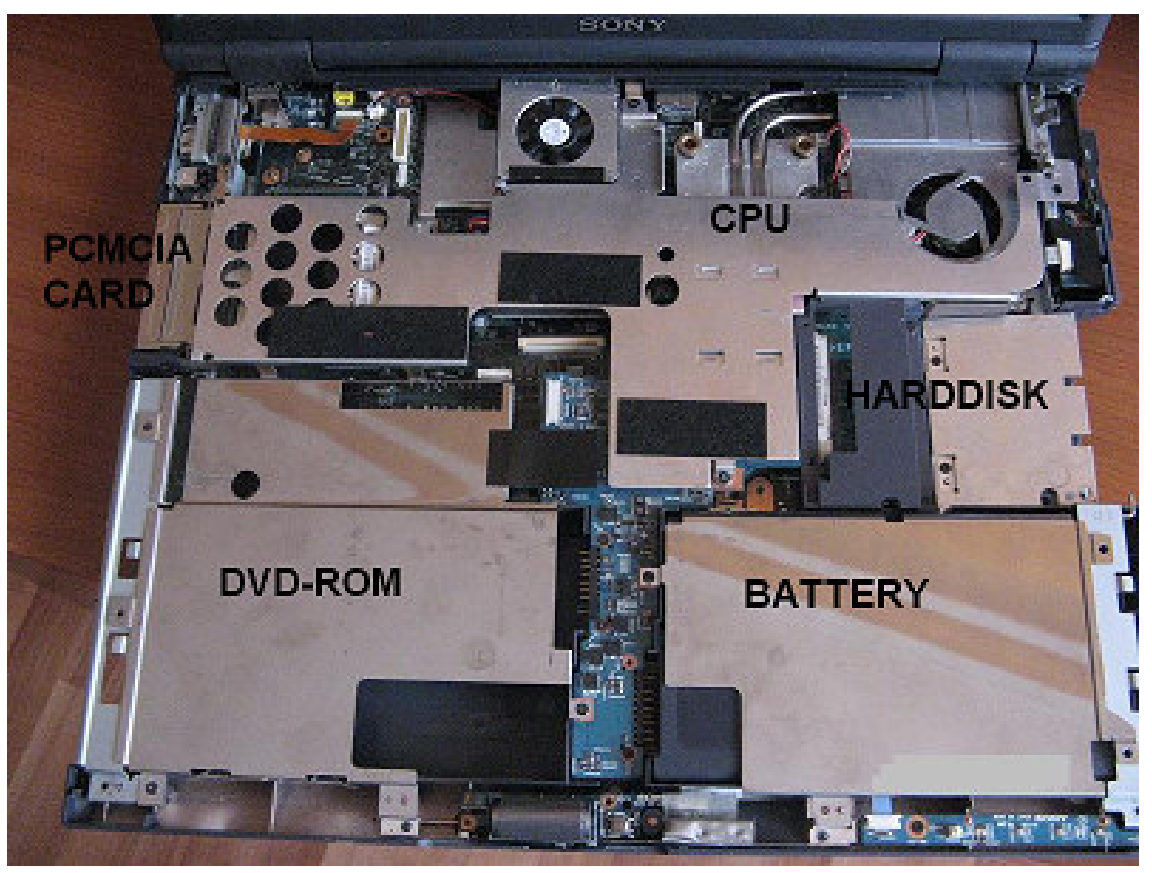

Figure 1.5 Inside of Sony Vaio PCG-GRX 316 MP notebook 
The external base dimensions of the notebook are $356 \mathrm{~mm}$ × $294 \mathrm{~mm}$ x $27 \mathrm{~mm}$. The chassis of the notebook is made of $3 \mathrm{~mm}$ thick ABS resin. There is a $3 \mathrm{~mm}$ gap between the table on which the notebook stands and the bottom of the notebook.

The CPU is placed on the upper right side of the case; on the top of the CPU there is an aluminum block attached with a thermal adhesive. There are two $4 \mathrm{~mm}$ diameter heat pipes on the top of the heat sink which is also attached by thermal adhesives. The heat pipes transfer heat to a fin-tube type heat exchanger at the other end. The heat exchanger has a fan placed nearby it. In Figures 1.6 and 1.7, the hybrid thermal management system that is used in this system is shown.

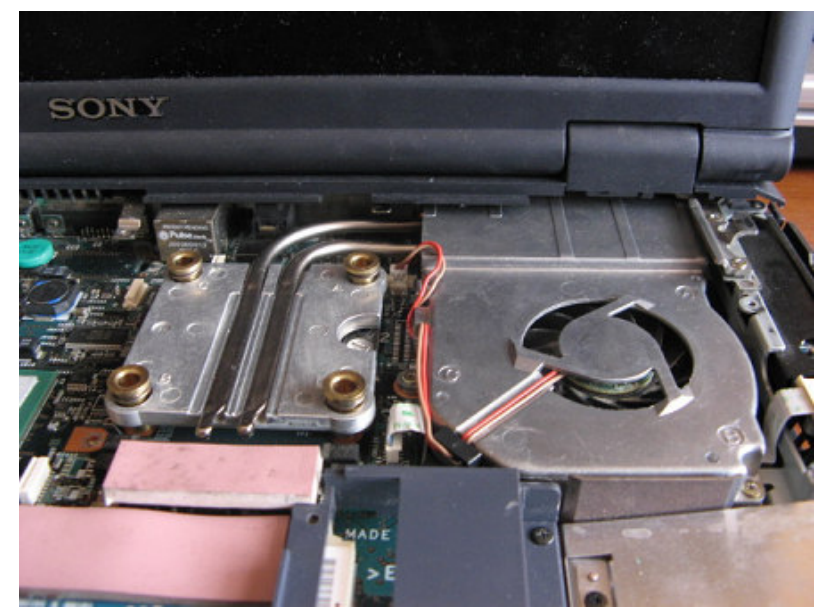

Figure 1.6 CPU cooling system of the notebook 


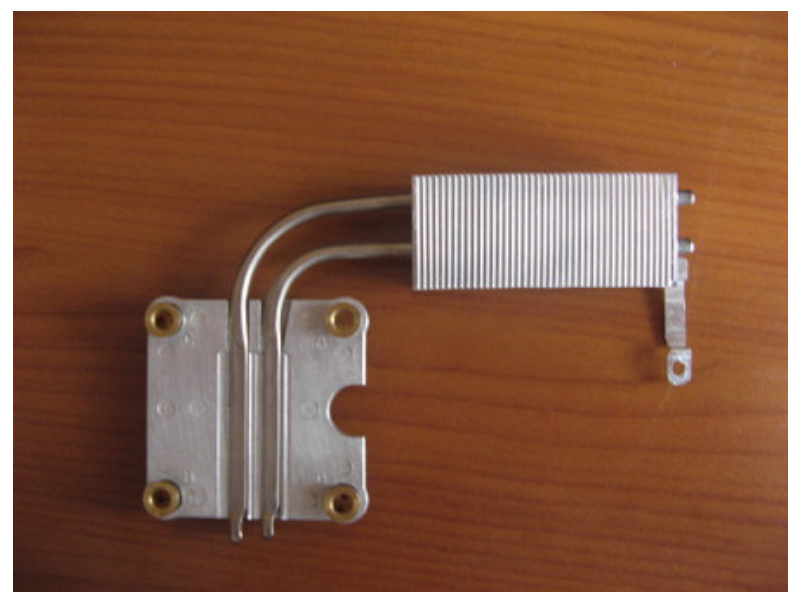

Figure 1.7 Heat pipe configuration of the notebook

There is a second, smaller fan in the notebook which is attached to an aluminum heat sink that is in contact with the graphics chip and the south bridge chip. There are thermal gap fillers between the aluminum heat sink and the chips.

The DVD-ROM and battery is placed in the front side of the notebook, to the left and the right respectively. The hard disk drive (HDD) is on the right side and the PCMCIA card is on the left side. On all of these components there are $0.5 \mathrm{~mm}$ thick aluminum plates that are placed to increase the heat transfer rate.

The keyboard base is made of a layer of $0.5 \mathrm{~mm}$ thick aluminum that is surrounded by a $1 \mathrm{~mm}$ thick insulation layer rubber on the top and $0.2 \mathrm{~mm}$ thick lamination layer of plastic underneath. The dimensions of the keyboard are $300 \mathrm{~mm} \times 115 \mathrm{~mm} \times 7 \mathrm{~mm}$.

Defining the heat dissipation rates of the components is an important issue. Although a notebook does not dissipate a constant rate of heat, in this study heat dissipation rates are taken as constant average values. The heat dissipation 
rate of CPU, which is the main source of heat in a notebook, is taken as $21 \mathrm{~W}$. This value is given by the manufacturer as the thermal design power [1]. Karabuto [14] discussed the heat dissipation rates of HDDs, and gave the values for different brands in idle, write and read modes. He also suggested a formula to calculate the average heat dissipation rates of these three modes. The average heat dissipation of HDD is calculated from this formula. The heat dissipation rates of the RAM, the PCMCIA card, the graphics card and the south bridge chip are taken from the thermal design guide written by Transmeta [8]. Table 1.2 shows the heat dissipation values of the components in the notebook at standard operating conditions. According to these values, the total amount of heat dissipated is $30 \mathrm{~W}$.

Table 1.2 Heat dissipation of the components

\begin{tabular}{|l|c|}
\hline Component & $\begin{array}{c}\text { Heat Dissipation } \\
\text { (W) }\end{array}$ \\
\hline Processor (CPU) & 21 \\
RAM & 0.5 \\
Hard disk & 5 \\
Graphics card & 2 \\
South bridge & 0.5 \\
PCMCIA card & 1 \\
\hline TOTAL & $\mathbf{3 0}$ \\
\hline
\end{tabular}

\subsection{System Constraints}

A notebook with specified geometrical properties and configuration can dissipate finite amount of heat which depends on the notebook surface area, material properties, and the surface and air temperatures. 
The heat generated inside the notebook is dissipated passively by the outside surface of the chassis; and actively using the fans attached to the heat exchanger, and the aluminum plate on the graphics card and the south bridge chip. There is certain rate of heat dissipation through the fan. The rest is dissipated passively. The passive dissipation of heat means an increase in the surface temperature of the notebook. For the ergonomic reasons, there are some limits for the surface temperatures.

The ambient air temperature around the notebook is assumed to be $25^{\circ} \mathrm{C}$. Intel recommends the notebook surface temperature can be $15^{\circ} \mathrm{C}$ over the ambient temperature, which leads us to $40{ }^{\circ} \mathrm{C}$ surface temperature for the assumed ambient temperature. The human body temperature is normally $37.1{ }^{\circ} \mathrm{C}$, so notebook user will not feel the warm surface [15].

There is also temperature limit for the components inside the notebook. The main aim of a thermal management system is to assure that the components are working below their maximum operating temperatures $\left(T_{\max }\right)$. Maximum operating temperatures are defined by the manufacturers. The typical values for the maximum operating temperatures are presented in Table 1.3 [8].

Table 1.3 Maximum operating temperatures of the notebook components

\begin{tabular}{|l|c|}
\hline Component & $\boldsymbol{T}_{\max }\left({ }^{\circ} \mathbf{C}\right)$ \\
\hline Processor (CPU) & 100 \\
Hard Disk & 60 \\
Battery & 55 \\
Graphics chip and south bridge & 85 \\
Memory (RAM) & 70 \\
PCMCIA card & 70 \\
\hline
\end{tabular}




\subsection{Assumptions}

In the solution, the altitude where the notebook is used is assumed to be at sea level. The ambient temperature is $25^{\circ} \mathrm{C}$. The table on which the notebook is placed is taken as a wooden desk.

In order to simplify the problem, the compressibility effects and the radiation heat transfer are neglected for heat transfer inside the notebook. Detailed information about the assumptions is given in Section 2.2.2.

The operating conditions are not stable in a notebook computer; which changes the heat dissipation rates of the components. In this study, an average operating condition is chosen for each analyzed case and the calculations are performed according to the steady state assumption.

There are thin air gaps between some components and the chassis walls. To reduce the computational time, it is assumed that the air in these gaps is stationary and behaves like a conduction or insulation path.

The heat transfer mechanism on the outside walls of the chassis is natural convection. The convective effects of the flow coming through the fan exits and the ventilation holes are neglected.

Although there are many components in the notebook, the modeling detail is chosen in order to obtain the best compromise between model complexity and accuracy. The components, which have no or little effect on the flow when compared to the other components, are not modeled. In Section 2.1.2, the details of the model are discussed. 


\subsection{Literature}

In the previous sections, the system is described together with its parameters and constraints. In this section, the methods that were used to solve the thermal management problems in the literature will be discussed.

The increasing heat dissipation rates of the components and shrinking system dimensions make the thermal management of notebook systems much more challenging than it was in 1980's. This complicated flow and heat transfer analysis for notebook systems is mainly preformed by using Computational Fluid Dynamics (CFD) software. In the first steps of the thermal design, during the selection of the cooling strategy, CFD analysis may be worthless; however, while performing the detailed analysis of the system thermal performance, the use of CFD complemented with experiments is very useful.

In 1996, Hisano et al. [16] divided the thermal analysis of a notebook into two stages to decrease the computational load. In the first stage, the thermal analysis of the components was preceded with experimental studies, and then the whole domain of the notebook was evaluated using the outputs of the first stage. The mesh that was used in the whole domain analysis was unstructured. Fine grids were applied to the region of CPU module, and relatively coarser grids were used for the other portions of the domain to decrease the computational load. Their experimental results showed that the computational results predicted the temperature of different locations within $3{ }^{\circ} \mathrm{C}$ error.

In the study of Viswanath et al. [17], numerical simulation of natural convection and radiation heat transfer in a notebook computer was conducted using FLOTHERM. To decrease the complexity of their model, smaller components were lumped together. The physical properties of the multilayer components such as PCB and CPU were determined by volume averaging the properties of the different layers. The other main components were represented 
as rectangular blocks with a thermal conductivity of $1 \mathrm{~W} / \mathrm{m} . \mathrm{K}$. The walls of the notebook were also modeled as cubical blocks. The prediction of all the temperatures of the system was within $10 \%$ of measured values. In addition to these, some thermal performance enhancements were suggested and analyzed in the study.

Kobayashi et al. [10] performed a CFD analysis in both the main body side and the display panel side of a notebook computer. The small components on the printed circuit board (PCB) were neglected. In their model, convection heat transfer was not taken into account while solving the energy equation by a finite volume method. In addition, the internal radiation was neglected since the temperature difference of the parts in the chassis was small.

In the study of Baek et al. [18], the numerical model for the whole domain of a notebook which is cooled by a hybrid thermal management system was presented. The total heat dissipation of the system was $19.35 \mathrm{~W}$; a turbulent model in which radiation was taken into account was created and analyzed using FLOTHERM. The components in the system were simplified like in many other papers for the ease of computational time. The keyboard was modeled as a plain plate and the PCB was modeled as a block having an anisotropic thermal conductivity. There is also an experimental analysis of the system which verified the results of the numerical solution.

Dallago and Venchi [19] studied the thermal behavior of a chosen notebook system, both numerically and experimentally. The heat dissipation of the components in the notebook was analyzed according to the best and worst case scenarios, which correspond to $8 \mathrm{~W}$ and $15 \mathrm{~W}$, respectively. The heat pipe in the thermal management system was modeled as a rod with $7100 \mathrm{~W} / \mathrm{mK}$ conductivity. In the study, using Mg-alloy chassis instead of ABS resin was suggested. This method decreases the temperature of the CPU $5{ }^{\circ} \mathrm{C}$, but in the mean time, the temperature of the chassis increases in an acceptable range. 
In the presented study, FLUENT is used to investigate the thermal management system of a specific notebook which consists of heat pipes, heat sinks and fans. The main objective is to understand the active and passive heat transfer paths and air flow inside the system. The main thermal paths in the system are defined to understand the heat transfer mechanisms. The system is analyzed for five different steady operating conditions and the effects of different heat dissipation rates of the components on the component temperatures are observed. The path lines within the system chassis and between the ventilation holes and the fans are visualized to investigate the air movement. 


\section{CHAPTER 2}

\section{COMPUTATIONAL MODELS AND EQUATIONS SOLVED}

The procedure that is followed in CFD calculations consists of three main steps; the pre-processing, the solver execution, and the post-processing.

The physical bounds of the problem are defined and the volume occupied by the fluid is divided into discrete cells in the pre-processing step. In the second step, numerical models and boundary conditions are set, so that the equations can be solved iteratively. Finally; when convergence is reached, the postprocessor is used for the analysis and visualization of the solution results.

\subsection{Pre-Processing}

The first step when starting a CFD calculation is defining the modeling goals. After defining the modeling goals, there are two main considerations in pre-processing: identifying the domain and designing the grid structure.

A numerical model is created in this study in order to analyze the cooling mechanism in a specific notebook. The computational domain is taken as the whole notebook chassis. The natural convection in the ambient air surrounding the notebook is also taken into account by defining average heat transfer coefficient values at the walls of the chassis. Although there is large number of components in the notebook, only the most important ones, which affect the temperature and flow field, are modeled in the system. The CPU, the PCB, the floppy and the hard disk drives, the heat sinks, the fans and the other parts 
which affect the flow regime are modeled. However the small details such as transistors, capacitors and wires are not taken into account. The details of the computational model are given in the sub-sections of this chapter.

Mesh generation is an important issue for the CFD analysis. In this study a non-conformal tetrahedral grid is created for the air volume inside the chassis, to decrease the computational time. A fine mesh size is applied for the portions near the heat and momentum sources, but a coarser mesh size is used for the other portions. The mesh generated in the heat exchanger has 3 cells in the air gaps between the fins and 1 cell in the fins, which is sufficient for the reliability of the results [20].

\subsubsection{Computational Domain}

The whole 3-D notebook chassis is the computational domain, which is shown in Figure 2.1. In this chassis, the CPU, the CPU heat sink, the heat pipes, the heat exchanger, the heat exchanger fan (Fan 1 in the figure), the heat sink of the graphics card and the south bridge chip, Fan 2 on this heat sink, the RAM modules, the DVD-Rom, the battery, the PCMCIA card, the hard disk drive (HDD), the speakers, the ventilation holes, the PCB and miscellaneous cards attached to the PCB are modeled.

\subsubsection{Details of Computational Domain}

In this section, the details of the modeled components in the computational domain are discussed. 


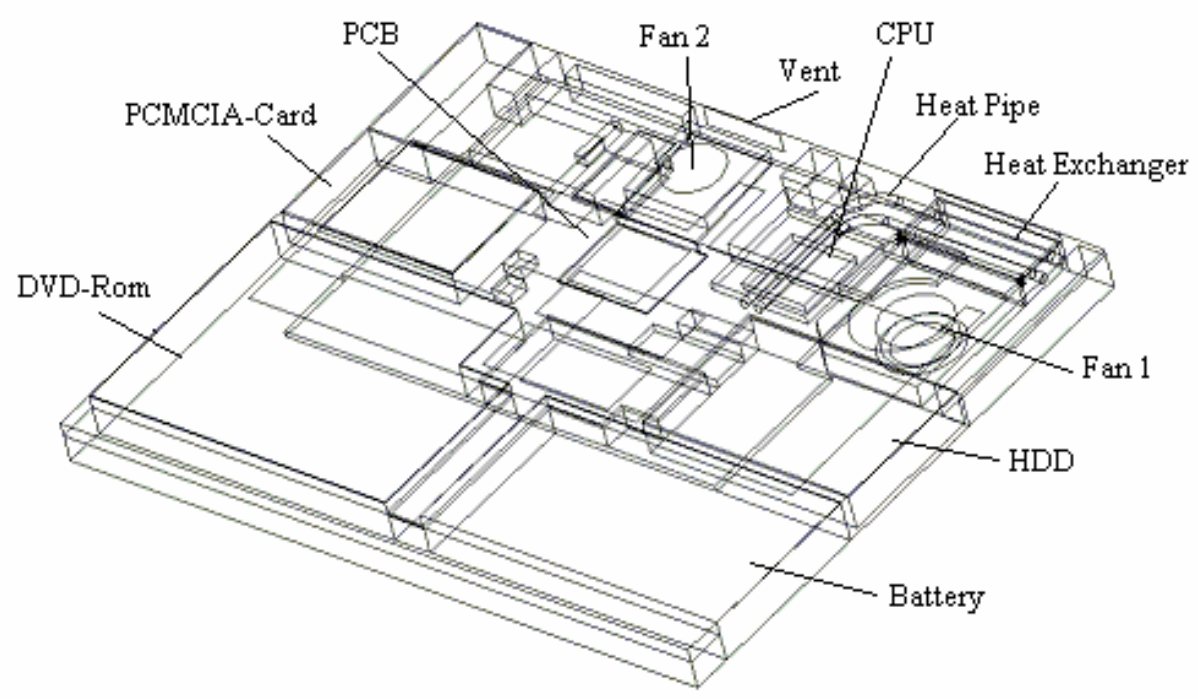

Figure 2.1 Computational domain of the notebook

\subsubsection{Chassis}

The outer boundary of the computational domain is defined by the chassis walls. Since there is heat transfer by natural convection to the environment from the walls, the heat transfer coefficient is applied as a boundary condition on the walls.

\subsubsection{CPU}

The CPU is the main heat source of the domain, dissipating $21 \mathrm{~W}$ of heat. The CPU is modeled as three blocks which represents the encapsulant, the polyamide and the die [17]. In Figure 2.2, the model of the CPU is shown with its main cooling system. 


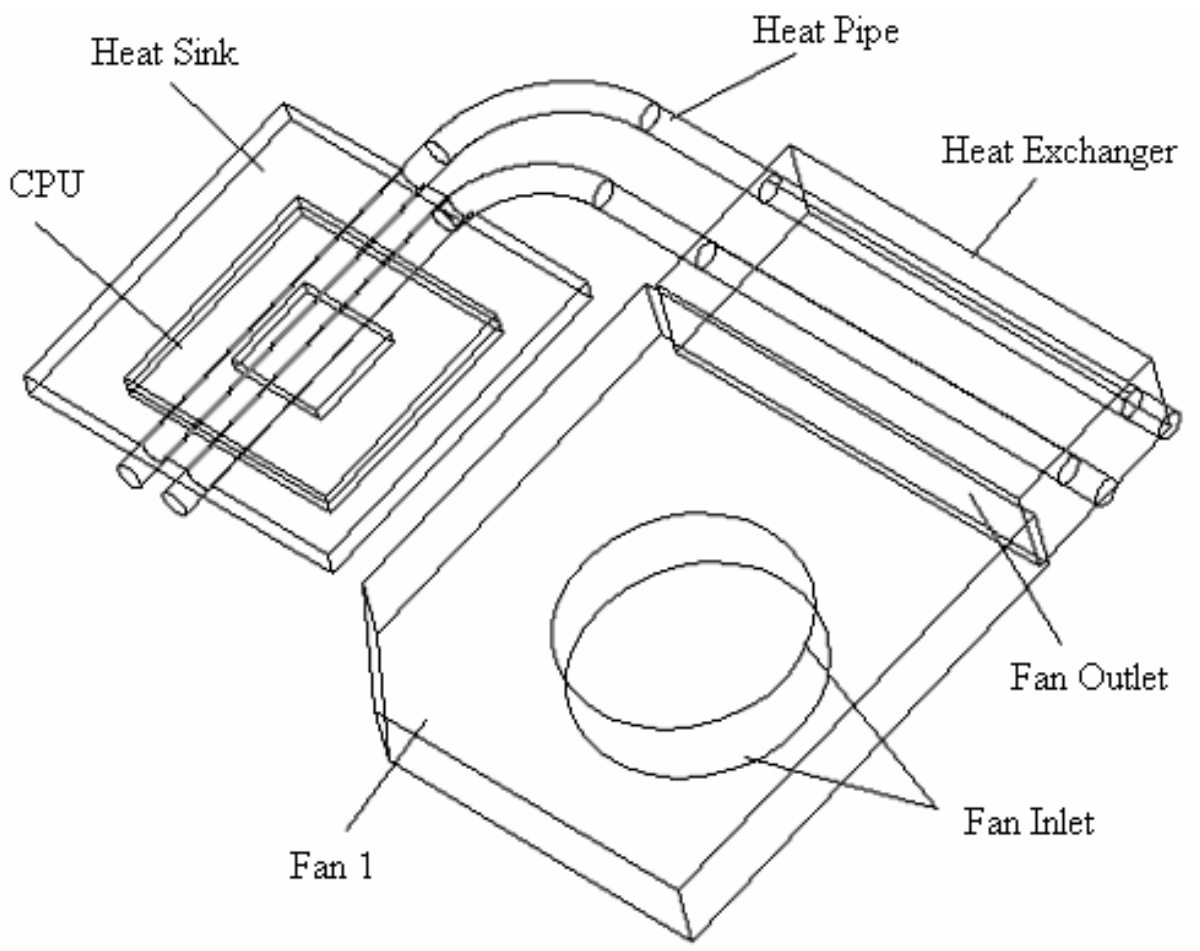

Figure 2.2 Hybrid system model

\subsubsection{CPU Heat Sink}

The heat sink on the top of the CPU is attached to the CPU with a thermal grease to decrease the thermal contact resistance. A contact resistance is set in the model according to the grease thermal conductivity. The dimensions of the heat sink are measured and the model is created as an aluminum block with these dimensions.

\subsubsection{Heat Exchanger}

At the condenser end of the heat pipes, $0.5 \mathrm{~mm}$ thick aluminum plates are attached with $1 \mathrm{~mm}$ spacing. There are 43 fins in the heat exchanger. This 
system is modeled according to its real dimensions and geometry as it is presented in Figure 2.3.

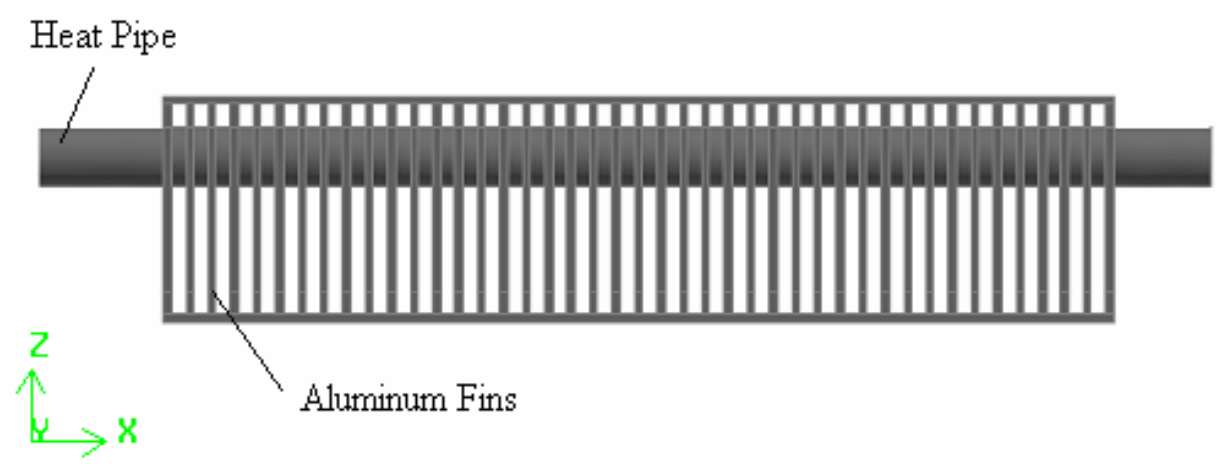

Figure 2.3 Heat exchanger model

\subsubsection{Heat Pipes}

The heat pipes are represented as solid rods having the same physical dimensions with the heat pipes and with a high thermal conductivity in axial direction. The thermal conductivity in radial direction is taken as the conductivity of pipe material, which is aluminum. In the axial direction the effective thermal conductivity is estimated as $40000 \mathrm{~W} / \mathrm{mK}$. The estimation of the thermal conductivity is discussed in Appendix A.

\subsubsection{Fans}

There are two fans in the system, one of them blows air through the heat exchanger (fan dimensions: $65 \mathrm{~mm} \times 65 \mathrm{~mm} \times 10 \mathrm{~mm}$ ) and the other one is attached to the heat sink of the graphics card and the south bridge chip (fan dimensions: $45 \mathrm{~mm}$ x $45 \mathrm{~mm} \times 8 \mathrm{~mm}$ ) which can be seen in Figures 2.2 and 
2.4. The fans are modeled as hollow blocks on which there are planes with exhaust and intake fan parameters defined. The properties of the fans are taken from the manufacturer's catalog [21] and the fan curves are defined to calculate the operating point.

\subsubsection{Graphics Card and South Bridge}

The graphics card and the south bridge chip are attached to the top of the PCB. There is an aluminum heat sink on them with an attached fan. The details can be seen in Figure 2.4. The graphics card and the south bridge chip are defined as 2-D heat sources.

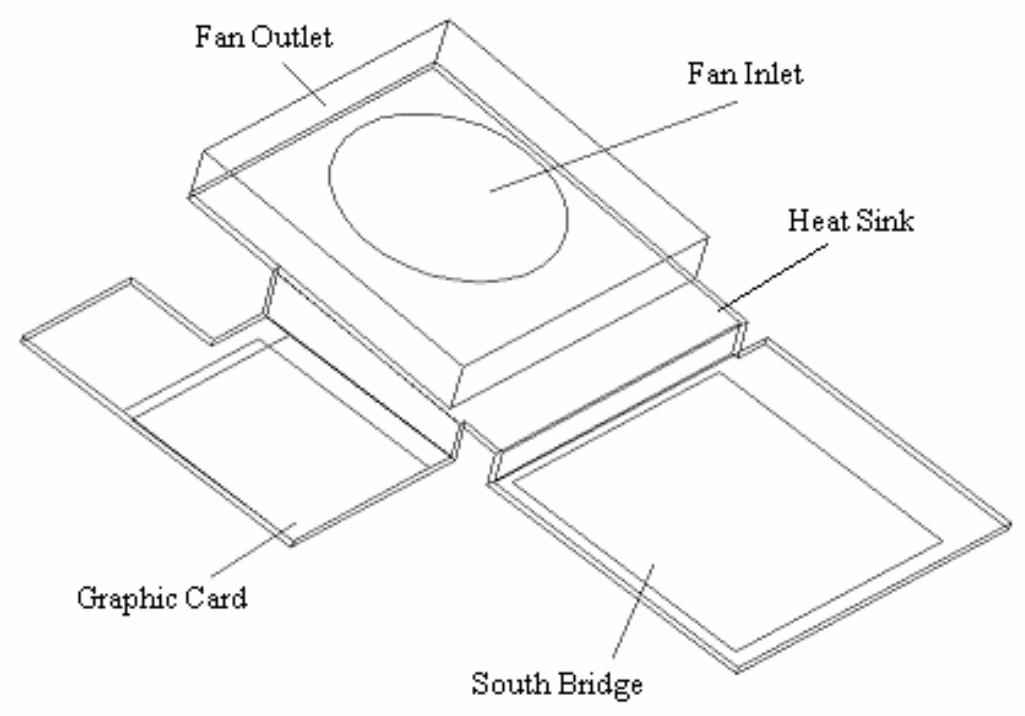

Figure 2.4 Secondary fan attached with a heat sink 


\subsubsection{PCB}

The PCB is modeled as a 3-D block with an anisotropic conductivity. The thermal conductivity is taken as $0.33 \mathrm{~W} / \mathrm{mK}$ along the thickness direction and $39.7 \mathrm{~W} / \mathrm{mK}$ in the other two directions [19].

\subsubsection{RAM Modules}

There are two slots for RAM modules on the PCB. The RAM modules are modeled as 3-D blocks with a heat generation value.

\subsubsection{Hard Disk Drive and PCMCIA card}

The hard disk drive and the PCMCIA card are modeled as 3-D blocks which generate heat. A thermal conductivity of $1 \mathrm{~W} / \mathrm{mK}$ is assumed for them [17].

\subsubsection{Aluminum Plates}

The aluminum plates, which are used to increase the heat transfer area and thermal conductivity, are modeled as 2-D planes.

\subsubsection{Vents}

There are four ventilation holes in the system. Two of them are inlet vents which provide the necessary air to fans; the other two are placed near the exits of the fans for the outlet flow of the air. The locations of the vents are shown in Figure 2.5. These vents are defined as planes with a loss coefficient [20]. 


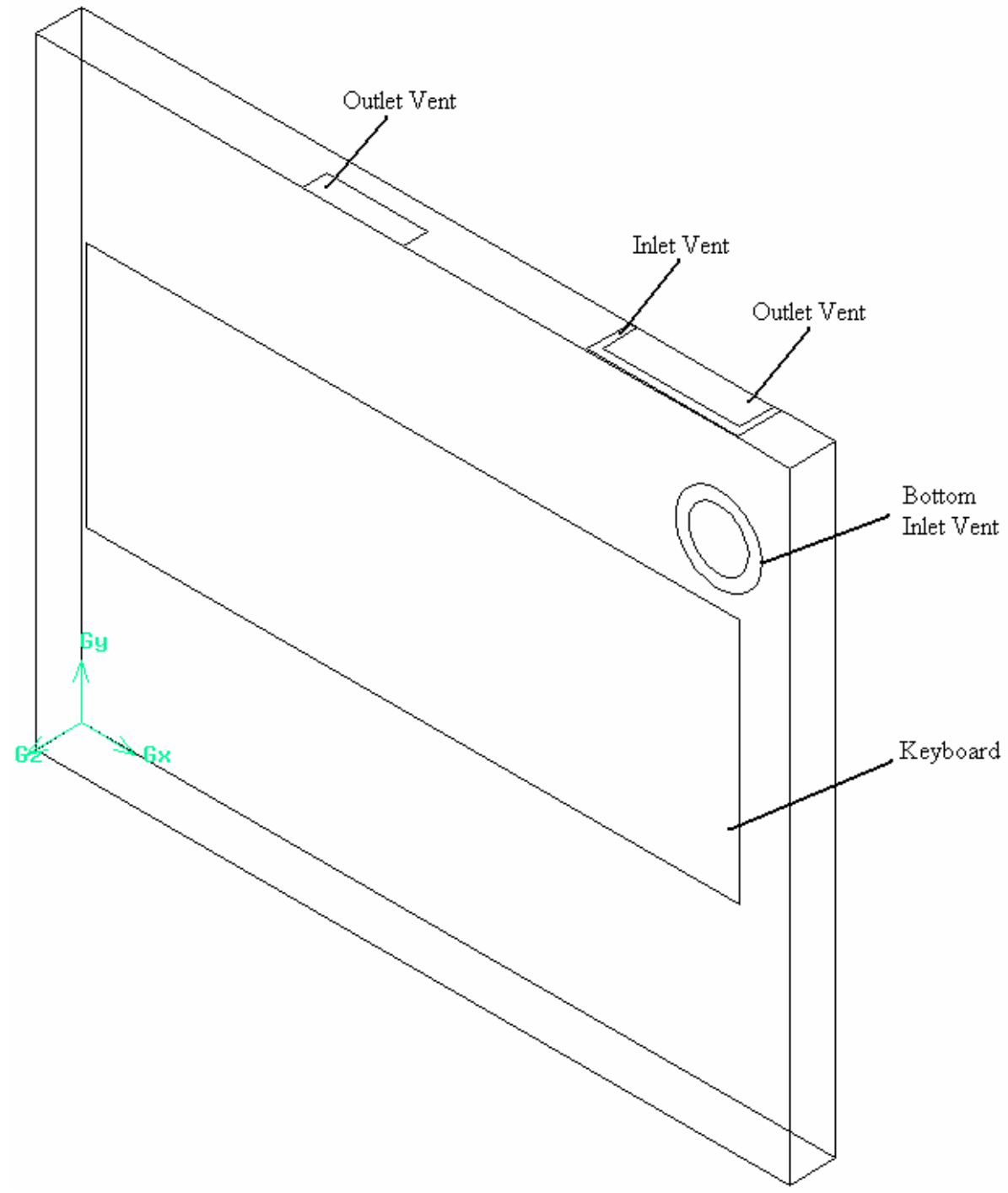

Figure 2.5 Vents and Keyboard Locations 


\subsubsection{Components with Low Heat Dissipation}

These components are the entities which will affect the flow and thermal analysis with negligible heat dissipation, such as the battery, the DVD-Rom, the speakers, the sockets and the ports. These components are modeled as 3-D blocks with an assumed thermal conductivity of $1 \mathrm{~W} / \mathrm{mK}$ [17].

\subsection{Solver Execution}

In this section the mathematical model for the problem will be presented with the governing equations, the flow properties and the boundary conditions.

\subsubsection{Governing Equations of Fluid Flow}

The general form of instantaneous governing equations for compressible Newtonian fluid is given as follows [22]:

Continuity: $\quad \frac{\partial \rho}{\partial t}+\nabla \cdot(\rho \vec{V})=0$

$x$-momentum: $\frac{\partial(\rho u)}{\partial t}+\nabla \cdot(\rho u \vec{V})=-\frac{\partial p}{\partial x}+\frac{\partial \tau_{x x}}{\partial x}+\frac{\partial \tau_{y x}}{\partial y}+\frac{\partial \tau_{z x}}{\partial z}+\rho f_{x}$

$y$-momentum: $\frac{\partial(\rho v)}{\partial t}+\nabla \cdot(\rho v \vec{V})=-\frac{\partial p}{\partial y}+\frac{\partial \tau_{x y}}{\partial x}+\frac{\partial \tau_{y y}}{\partial y}+\frac{\partial \tau_{z y}}{\partial z}+\rho f_{y}$

$z$-momentum: $\frac{\partial(\rho w)}{\partial t}+\nabla \cdot(\rho w \vec{V})=-\frac{\partial p}{\partial z}+\frac{\partial \tau_{x z}}{\partial x}+\frac{\partial \tau_{y z}}{\partial y}+\frac{\partial \tau_{z z}}{\partial z}+\rho f_{z}$

energy: $\quad \frac{\partial(\rho e)}{\partial t}+\nabla \cdot(\rho e \vec{V})=-p \nabla \cdot \vec{V}+\nabla \cdot(k \nabla T)+\Phi+q$

equation of state: $\quad p=\rho R T$ 
where $\rho$ is the density, $u, v$ and $w$ are the velocity components, $\vec{V}$ is the velocity vector, $p$ is the pressure, $f_{x}, f_{y}$ and $f_{z}$ are the body forces, $e$ is the internal energy, $k$ is the thermal conductivity, $q$ is the heat flux as a source term, $R$ is the gas constant.

$\tau$ is the viscous stress which can be defined for the Newtonian fluids as:

$$
\begin{aligned}
& \tau_{x x}=\lambda\left(\frac{\partial u}{\partial x}+\frac{\partial v}{\partial y}+\frac{\partial w}{\partial z}\right)+2 \mu \frac{\partial u}{\partial x} \\
& \tau_{y y}=\lambda\left(\frac{\partial u}{\partial x}+\frac{\partial v}{\partial y}+\frac{\partial w}{\partial z}\right)+2 \mu \frac{\partial v}{\partial y} \\
& \tau_{z z}=\lambda\left(\frac{\partial u}{\partial x}+\frac{\partial v}{\partial y}+\frac{\partial w}{\partial z}\right)+2 \mu \frac{\partial w}{\partial z} \\
& \tau_{x y}=\tau_{y x}=\mu\left(\frac{\partial u}{\partial y}+\frac{\partial v}{\partial x}\right) \\
& \tau_{x z}=\tau_{z x}=\mu\left(\frac{\partial u}{\partial z}+\frac{\partial w}{\partial x}\right) \\
& \tau_{z y}=\tau_{y z}=\mu\left(\frac{\partial w}{\partial y}+\frac{\partial v}{\partial z}\right)
\end{aligned}
$$

where $\mu$ represents the dynamic viscosity, and $\lambda$ is the second viscosity coefficient. The second viscosity coefficient is approximated by Stokes as follows:

$$
\lambda=-\frac{2}{3} \mu
$$

In the energy equation Eq.2.5, $\Phi$ is the viscous dissipation term which denotes the dissipation of mechanical energy into heat. This term is usually very small and negligible, except for high Mach numbers. 


$$
\Phi=\lambda(\nabla \cdot \vec{V})^{2}+\mu\left[\begin{array}{c}
2\left(\frac{\partial u}{\partial x}\right)^{2}+2\left(\frac{\partial v}{\partial y}\right)^{2}+2\left(\frac{\partial w}{\partial z}\right)^{2}+ \\
\left(\frac{\partial u}{\partial y}+\frac{\partial v}{\partial x}\right)^{2}+\left(\frac{\partial u}{\partial z}+\frac{\partial w}{\partial x}\right)^{2}+\left(\frac{\partial w}{\partial y}+\frac{\partial v}{\partial z}\right)^{2}
\end{array}\right]
$$

\subsubsection{Flow Configuration and Boundary Conditions}

In this section, the flow configuration of the system, which has an effect on the governing equations, and the boundary conditions, which are needed to solve the governing equations, will be discussed.

\subsubsection{Compressibility}

The compressibility effects of the air inside the computational domain are neglected since the velocity of air inside the chassis is low. In the system, there is a $65 \mathrm{~mm} \times 65 \mathrm{~mm} \times 10 \mathrm{~mm}$ fan with a flow cross sectional area $\left(A_{c}\right)$ of $0.7 \times 10^{-3} \mathrm{~m}^{2}$. Assuming the air flow $(G)$ of this fan as $20 \mathrm{CFM}$, the velocity of air $\left(V_{a}\right)$ can be calculated as:

$$
\begin{aligned}
V_{a} & =\frac{G}{A_{c}} \\
V_{a} & =13.5 \mathrm{~m} / \mathrm{s}
\end{aligned}
$$

Then Mach number $(M a)$ can be calculated as:

$$
\begin{aligned}
M a & =\frac{V_{a}}{c} \\
M a & =4.5 \times 10^{-2}
\end{aligned}
$$


In which $\mathrm{c}$ is the speed of sound and taken as $300 \mathrm{~m} / \mathrm{s}$. For Mach numbers smaller than 0.3 the compressible and incompressible results are nearly the same, therefore the flow can be assumed as incompressible [23].

\subsubsection{Turbulence}

The velocity of air inside the notebook chassis is small and laminar flow assumption can be adequate for this flow. However, since there are fans inside the computational domain, the swirling action of the fans may lead to a turbulent flow. In this study only laminar flow calculations are performed and the turbulent effects of fans are neglected [24].

\subsubsection{Radiation}

Radiative heat transfer is an important issue when there are high temperature gradients between the components in the same environment facing each other. In a notebook system if the only heat transfer mechanisms are natural convection and conduction, the radiation effect cannot be neglected. However; in this study, forced convection is the main heat transfer mechanism, therefore radiative heat transfer is neglected.

\subsubsection{Boundary Conditions}

No slip boundary condition is applied for the chassis and component walls in the domain. Therefore at all walls and surfaces:

$$
u=v=w=0
$$


As mentioned in Section 1.6, the heat transfer mechanism outside the notebook chassis is assumed to be natural convection only. An average heat transfer coefficient will be defined for the top and side surfaces of the chassis separately. Trial and error method is used to define the heat transfer coefficients for each case. The solution for Case I is presented in this section as an example.

Initially, a typical heat transfer coefficient of $5 \mathrm{~W} / \mathrm{m}^{2} \mathrm{~K}$ is selected for the walls and used in the first iteration. The average temperature $\left(T_{s}\right)$ of the side wall is obtained as $34{ }^{\circ} \mathrm{C}$ when the ambient temperature $\left(T_{\infty}\right)$ is assumed to be $25{ }^{\circ} \mathrm{C}$. The calculations for the average heat transfer coefficients are performed using this average surface temperature [25].

$$
R a_{L}=G r_{L} \operatorname{Pr}=\frac{g \beta\left(T_{s}-T_{\infty}\right) L^{3}}{v \alpha}
$$

Rayleigh number $\left(R a_{L}\right)$ is calculated for the natural convection coefficient, where gravity $(g)$ is $9.81 \mathrm{~m} / \mathrm{s}^{2}$, the volumetric thermal expansion coefficient ( $\beta$ ) calculated according to the film temperature $\left(T_{f}\right)$ of $302.5 \mathrm{~K}$ is $3.31 \times 10^{-3}$ $\mathrm{K}^{-1}$. The length $(L)$ of the side wall is $27 \mathrm{~mm}$, the kinematic viscosity $(v)$ is $16.14 \times 10^{-6} \mathrm{~m}^{2} / \mathrm{s}$ and the thermal diffusivity $(\alpha)$ is $22.87 \times 10^{-6} \mathrm{~m}^{2} / \mathrm{s}$ at $T_{f}$.

$$
R a_{L}=\frac{(9.81)\left(3.31 \times 10^{-3}\right)(34-25)(0.027)^{3}}{\left(16.14 \times 10^{-6}\right)\left(22.87 \times 10^{-6}\right)}=15583
$$

Since $R a_{L}<10^{9}$, the flow is laminar, then the average Nusselt number $(\overline{N u})$ can be calculated from: 


$$
\begin{aligned}
& \overline{N u_{L}}=0.68+\frac{0.670 R a_{L}{ }^{1 / 4}}{\left[1+(0.492 / \operatorname{Pr})^{9 / 16}\right]^{4 / 9}} \\
& \overline{N u_{L}}=0.68+\frac{0.670(15583)^{1 / 4}}{\left[1+(0.492 / 0.7)^{9 / 16}\right]^{4 / 9}}=6.416
\end{aligned}
$$

Then the average heat transfer coefficient can be found as $6.2 \mathrm{~W} / \mathrm{m}^{2} \mathrm{~K}$ from Eq.2.20 with the air thermal conductivity of $26 \times 10^{-3} \mathrm{~W} / \mathrm{mK}$.

$$
\bar{h}=\frac{\overline{N u_{L}} \cdot k}{L}
$$

Similarly, for the top wall of the chassis, which is at $34{ }^{\circ} \mathrm{C}, R a_{L}$ can be calculated from the Eq.2.18 where a characteristic length $\left(L_{c}\right)$ is used instead of $L$, which is:

$$
L_{c}=\frac{A}{P}=\frac{10.47 \times 10^{-2} \mathrm{~m}^{2}}{1.3 \mathrm{~m}}=8.05 \times 10^{-2} \mathrm{~m}
$$

where $A$ is the surface area and $P$ is the surface perimeter. Then $R a_{L}$ is:

$$
R a_{L}=\frac{(9.81)\left(3.31 \times 10^{-3}\right)(34-25)\left(8.05 \times 10^{-2}\right)^{3}}{\left(16.14 \times 10^{-6}\right)\left(22.87 \times 10^{-6}\right)}=4.13 \times 10^{5}
$$

Again $R a_{L}<10^{9}$ and the flow is laminar, then the average Nusselt number $(\overline{\mathrm{Nu}})$ can be calculated from the correlations for the upper surface of a heated plate.

$$
\overline{N u_{L}}=0.54 R a_{L}^{1 / 4}=0.54\left(4.13 \times 10^{5}\right)^{1 / 4}=13.7
$$


The average heat transfer coefficient is $4.4 \mathrm{~W} / \mathrm{m}^{2} \mathrm{~K}$, which is calculated from Eq.2.20. The analysis result gives average surface temperatures that are close to the assumptions; therefore the average heat transfer coefficients calculated above can be used for the system.

The heat transfer mechanism of the bottom wall of the chassis is conduction since $R a_{L}$ is calculated as 35 from Eq.2.18 for the $3 \mathrm{~mm}$ air gap, which is less than critical value 1700 . Therefore the thermal conductivity of air $\left(26 \times 10^{-3} \mathrm{~W} / \mathrm{mK}\right)$ is used for the heat transfer of the bottom wall.

\subsubsection{Interior Conditions}

The heat dissipation values for the standard operating condition of the notebook components are given in Table 1.2. In addition to this standard operating condition, four other operating conditions, which will be presented in Section 3.3, are analyzed in this study. The heat dissipation values defined for each case are entered into the calculations as the heat generation rates.

There are two fans in the notebook. The operating points of the fans are calculated according to the fan performance diagrams shown in Figure 2.6 and given in Table 2.1. 


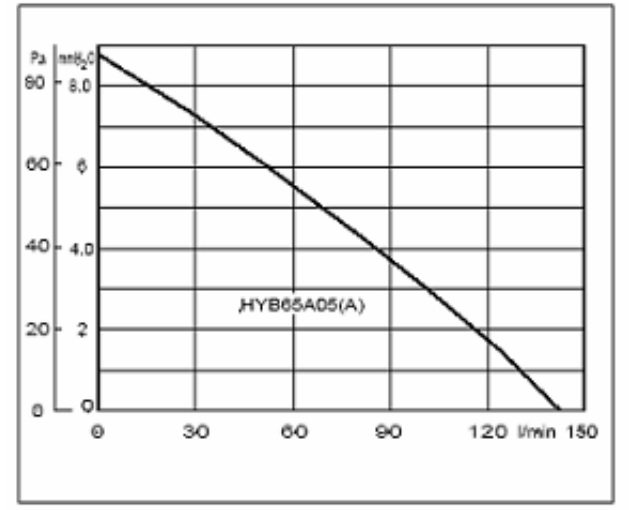

HYB65A05 FAN PERFORMANCE DLAGRAM

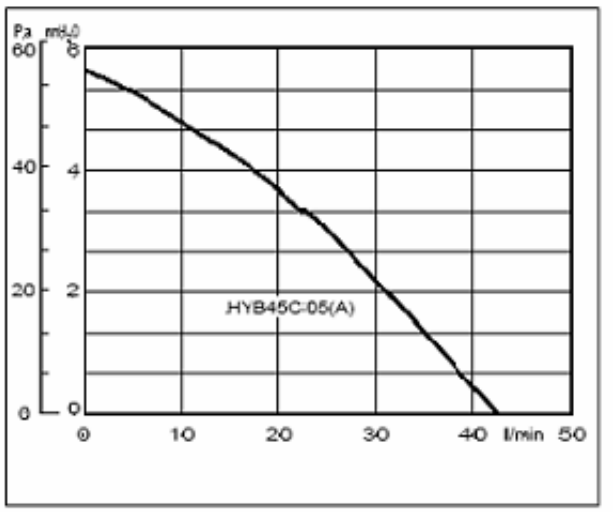

HYB45C05 FAN PERFORMANCE DLAGRAM

Figure 2.6 Fan Performance curves of the primary fan and the secondary fan, respectively (adapted from [21])

Table 2.1 Fan Operating Points

\begin{tabular}{|l|c|c|}
\hline Fan & $\begin{array}{c}\text { Pressure Rise } \\
(\mathbf{P a})\end{array}$ & $\begin{array}{c}\text { Volumetric Flow Rate } \\
\left(\mathbf{m}^{\mathbf{3}} / \mathbf{s}\right)-(\mathbf{C F M})\end{array}$ \\
\hline Fan 1 (65mm x 65mm x 10mm) & 33 & $0.00155-3.3$ \\
\hline Fan 2 (45mm x 45mm x 8mm) & 3.5 & $0.00068-1.4$ \\
\hline
\end{tabular}

In the numerical discussion section, Section 3.2; the heat exchanger medium, where the fins attached to the condenser end of the heat pipe, is modeled as a porous medium with a pressure drop and heat transfer. Since the flow in the heat exchanger system is laminar, the pressure drop equation for the heat exchanger is simplified to Darcy's law [26]. 


\subsubsection{Governing Equations to be Solved}

The governing equations are simplified according to the conditions and assumptions of the model analyzed in this study. As it is mentioned in the Section 1.6 the system is assumed to be steady state and incompressible, therefore time dependent parameters are dropped from the equations 2.1 to 2.5 and Eq.2.6 is omitted. In addition, the viscous dissipation term in Eq.2.5 is omitted since the Mach number of the system is small. The resulting equations are:

continuity: $\quad \nabla \cdot(\vec{V})=0$

$x$-momentum: $\nabla \cdot(\rho u \vec{V})=-\frac{\partial p}{\partial x}+\frac{\partial \tau_{x x}}{\partial x}+\frac{\partial \tau_{y x}}{\partial y}+\frac{\partial \tau_{z x}}{\partial z}+\rho f_{x}$

$y$-momentum: $\nabla \cdot(\rho v \vec{V})=-\frac{\partial p}{\partial y}+\frac{\partial \tau_{x y}}{\partial x}+\frac{\partial \tau_{y y}}{\partial y}+\frac{\partial \tau_{z y}}{\partial z}+\rho f_{y}$

$z$-momentum: $\nabla \cdot(\rho w \vec{V})=-\frac{\partial p}{\partial z}+\frac{\partial \tau_{x z}}{\partial x}+\frac{\partial \tau_{y z}}{\partial y}+\frac{\partial \tau_{z z}}{\partial z}+\rho f_{z}$

energy: $\quad \nabla \cdot(\rho e \vec{V})=-p \nabla \cdot \vec{V}+\nabla \cdot(k \nabla T)+q$

The energy equation used for the solid regions is simplified as:

$$
0=\nabla \cdot(k \nabla T)+q
$$

For the anisotropic solids the conductivity term in Eq.2.26 will be $\nabla .\left(k_{i j} \nabla T\right)$.

\subsection{Post-Processing}

The equations defined in the previous section are solved by Fluent using the previously discussed boundary conditions in Section 2.2.2.4 and the interior 
conditions in Section 2.2.2.5. In the post-processing phase of the study, these results are analyzed and visualized. The post-processing results will be presented in Chapter 3.

To begin with, it is aimed to understand the effects of heat transfer mechanisms, so the temperature values for the components will be analyzed and checked if they are within the limits or not. For the comfort of the user, the top surface temperature of the chassis is important, so the distribution of it will be also presented.

In addition to temperatures, the air flow inside the notebook which is affected from the fans is an important issue. The air flow around the fans will be analyzed in the results section.

The results will be presented by contours for temperature distributions and velocity magnitudes of the air flow. To understand the air movement, the path lines in the vicinity of the fans will be shown. The difference between two discretization schemes will be compared by plotting the temperature values for the same specific points. 


\section{CHAPTER 3}

\section{RESULTS AND DISCUSSION}

\subsection{Sources of Errors in CFD Calculations}

The results that are achieved from the numerical solution always have an error. The important thing is to understand the sources of errors and try to decrease them. Mainly, the sources of errors can be categorized into three titles: the modeling errors, the discretization errors and the convergence errors.

In the definition of a mathematical model for an actual flow, some approximations and assumptions are made for the boundary and the physical conditions. In order to have an accurate result, the numerical analysis has to be done for an appropriate model with reasonable approximations and assumptions.

The major source of error is the discretization errors due to the difference between the exact solution and the numerical solution of the selected numerical method. Fluent uses the Finite Volume Method in which the governing equations are solved on discrete control volumes. This method causes some errors like all the other methods (Finite Difference Method, Finite Element Method, etc).

Convergence is an important issue when finalizing the numerical solution. Fluent runs successive iterations until the residuals of the variables fall below a certain user defined value. However, this does not mean that the solution has converged: more iteration may be needed for convergence. To understand if the 
system has converged or not, some other variables such as velocity, pressure and temperature have to be monitored and checked for the critical locations of the domain.

\subsection{Numerical Discussions}

In this section of the study, the results of the numerical solution are reviewed considering the convergence criteria, the mesh configuration and the discretization scheme selection. The porous medium heat exchanger model is used in this section instead of the real dimension heat exchanger model.

\subsubsection{Convergence Criteria}

In this study, the convergence criteria are chosen as $10^{-3}$ for the continuity and the momentum equations and $10^{-7}$ for the energy equation. In addition to checking the residuals of the solution, average temperatures of the CPU and the graphics card are monitored.

\subsubsection{Mesh Selection}

In a numerical analysis, it is important to select a reasonable mesh and have a grid independent solution. In addition to the default case with 1,445,752 elements, a case with 2,465,780 elements is generated in this study, to show the grid independency. The results are compared for these two cases.

For comparison of the solution the two cases, a reference line is defined in a critical position which is in the center of the CPU heat sink in this case. The position of the reference line is shown in Figure 3.1. The static temperature on 
this reference line is calculated in both configurations and the results are plotted in Figure 3.2. The difference calculated from Figure 3.2, do not exceed $0.3{ }^{\circ} \mathrm{C}$ which corresponds to a maximum $0.4 \%$ difference where $\%$ difference is calculated by Equation 3.1.

$\%$ Diff. $=\frac{\text { AbsoluteDifference }}{\text { Max.AllowableTemp.ForCPU }- \text { AmbientTemp. }} \times 100$

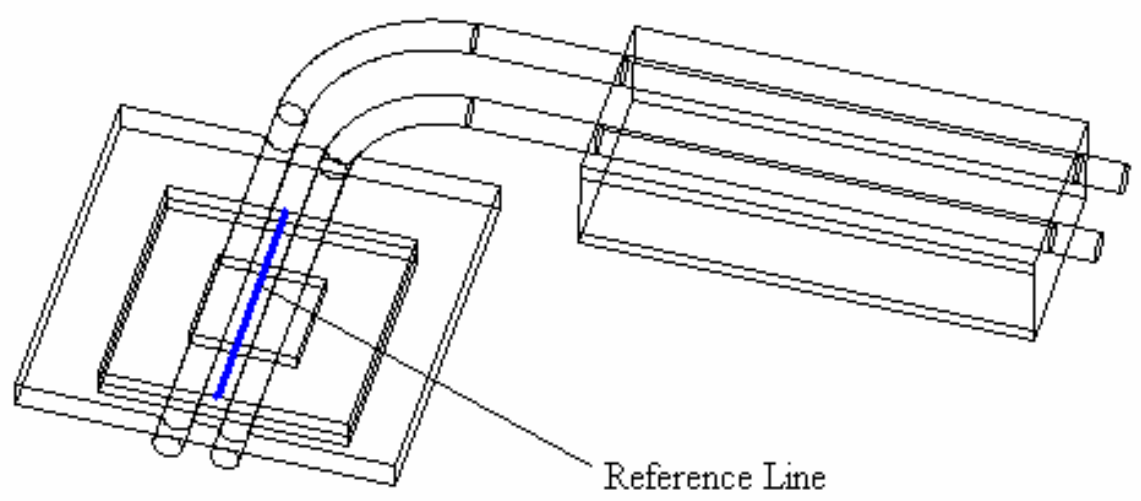

Figure 3.1 Reference line 


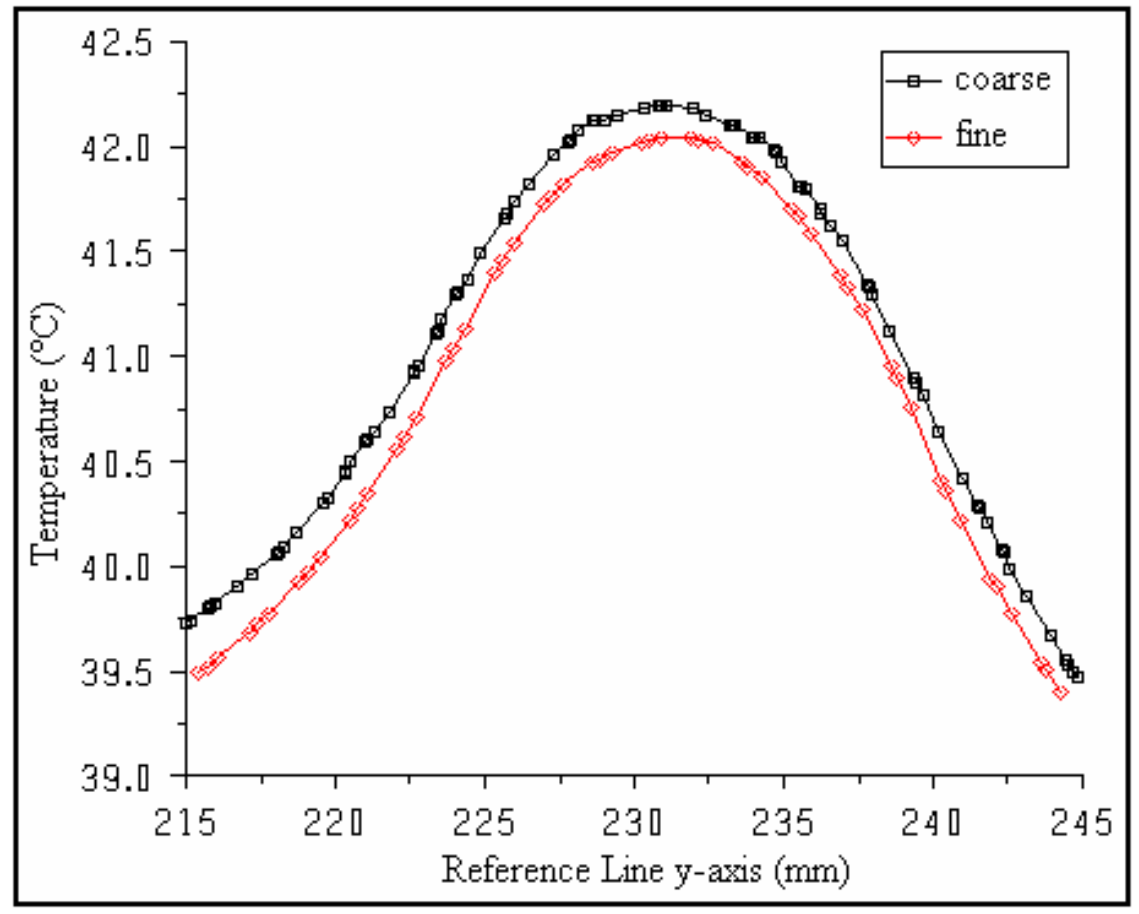

Figure 3.2 Temperature plots on the reference line for the coarse and the fine mesh configurations

In addition to this comparison, Table 3.1 presents the average temperature values for the components for both configurations. It can be seen that, there is no significant change in the average temperatures of the components. The maximum difference of $0.4{ }^{\circ} \mathrm{C}$ is in the RAM modules temperature. 
Table 3.1 Average temperature values for the components for the fine and the coarse mesh configurations

\begin{tabular}{|l|c|c|c|}
\hline Components & $\begin{array}{c}\text { Coarse Mesh } \\
\text { Average T }\left({ }^{\circ} \mathbf{C}\right)\end{array}$ & $\begin{array}{c}\text { Fine Mesh } \\
\text { Average T }\left({ }^{\circ} \mathbf{C}\right)\end{array}$ & $\begin{array}{c}\text { \% } \\
\text { Difference }\end{array}$ \\
\hline CPU & 49.5 & 49.5 & 0 \\
HDD & 46.2 & 46.3 & 0.1 \\
BATTERY & 34.3 & 34.3 & 0 \\
GC & 42.8 & 42.8 & 0 \\
RAM & 68.8 & 69 & 0.3 \\
PCMCIA & 41.4 & 41.8 & 0.5 \\
PCB & 39.3 & 39.5 & 0.1 \\
DVD & 41.3 & 41.5 & 0.1 \\
\hline
\end{tabular}

Figures 3.3 and 3.4 present the temperature distribution of the top surfaces of the CPU and the PCB in these two mesh configurations, respectively. The average temperature values are close and the difference between the contours of temperature can be neglected. Therefore the coarse mesh configuration is sufficient and it is selected in this study.

As it is mentioned before, the porous medium heat exchanger model is used in this section. In the real dimension heat exchanger model, the entire system mesh is generated with 1,883,191 elements. There are 3 cells in the air gaps between the fins of the heat exchanger and 1 cell in the fins. A finer mesh is generated for the heat exchanger to check the validity of these calculations and compared with the coarse one in Appendix B. 

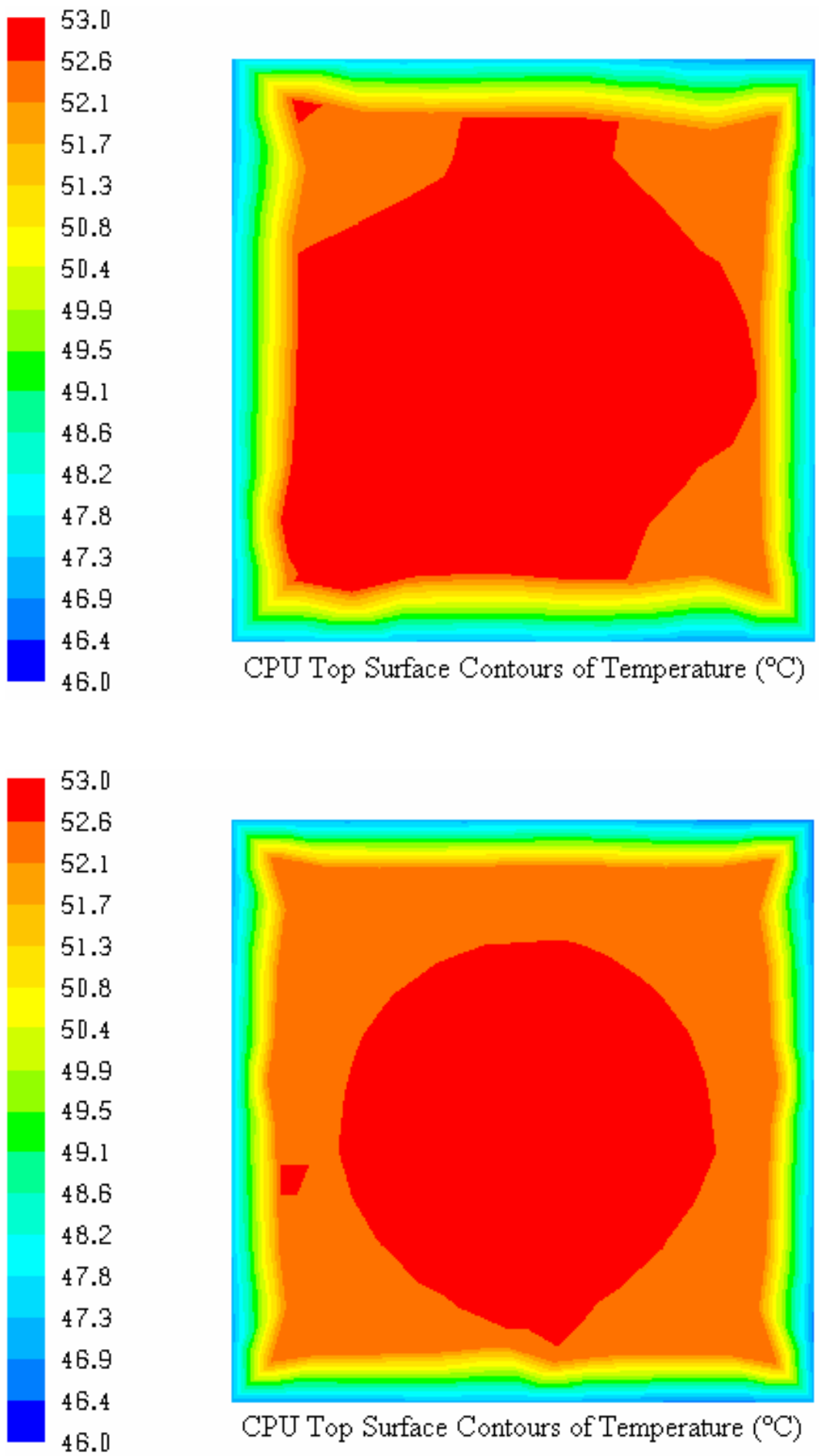

Figure 3.3 Temperature distributions of the top surface of the CPU for the coarse mesh (top) and the fine mesh (bottom) 

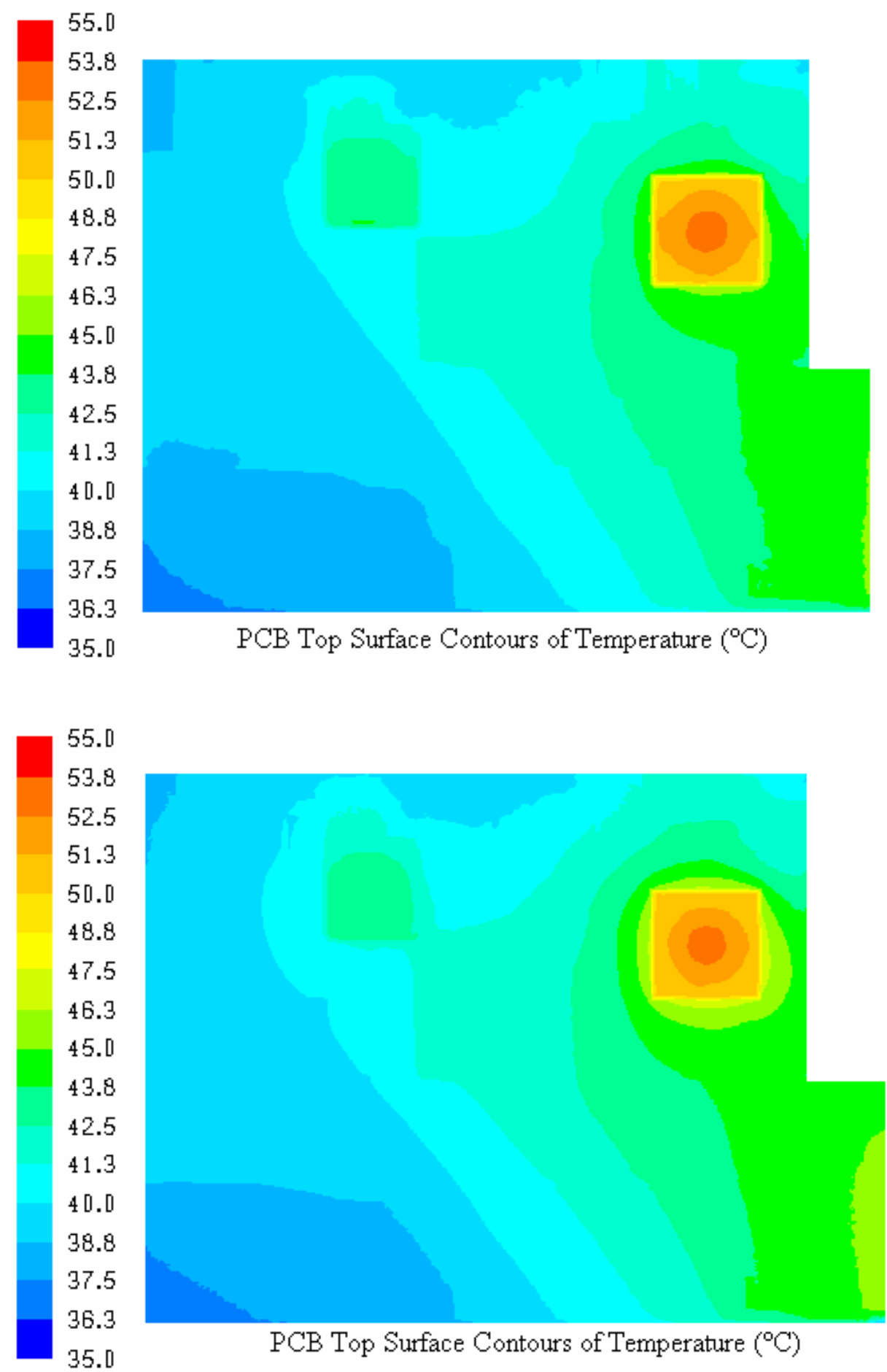

Figure 3.4 Temperature distributions of the top surface of the PCB for the coarse mesh (top) and the fine mesh (bottom) 


\subsubsection{Discretization}

The easiest discretization scheme offered by Fluent is the first order upwind scheme. This scheme is generally used when the flow is aligned with the grid. This situation can be achieved for the quadrilateral and the hexahedral grids. The first order upwind scheme yields faster convergence, but gives first order accuracy. When the flow is not aligned with the grid structure the first order scheme generally fails. For the triangular and the tetrahedral grids, since they cannot achieve this situation, the second order discretization is suggested.

In this study, the numerical solution is performed both with the first order upwind scheme and the second order scheme, and the solutions are compared. For both schemes the residuals converge. In addition to this, the velocity and the temperature values for the critical positions are checked in both schemes. They have steady values for successive iterations.

For the solution comparison of the two discretization scheme, the reference line shown in Figure 3.1 is used. The static temperature on this reference line is measured in both schemes and the results are plotted in Figure 3.5.

Figure 3.5 shows that the second order discretization scheme predicts slightly lower temperature values for the reference line than the first order one. The difference calculated from the figure, do not exceed $0.5{ }^{\circ} \mathrm{C}$ which means maximum $0.7 \%$ difference. 


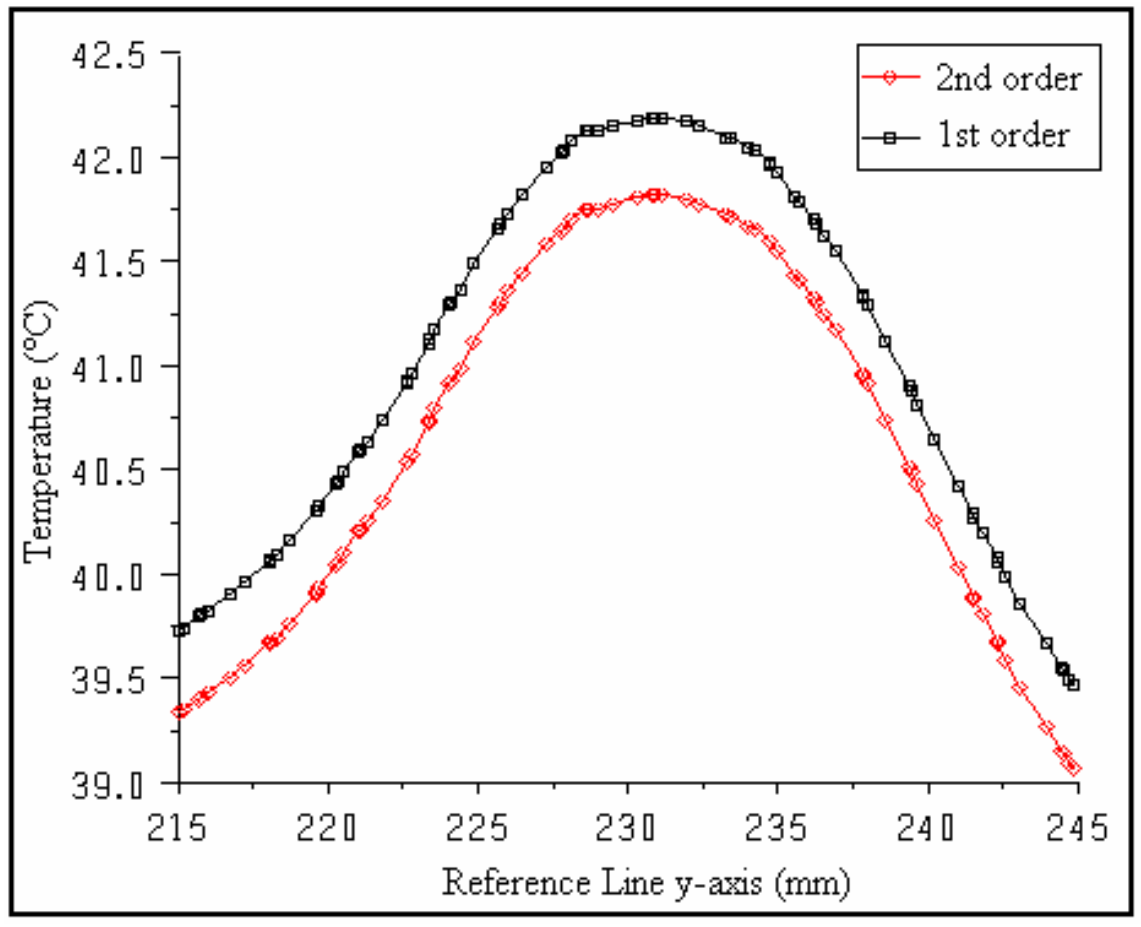

Figure 3.5 Temperature plots on the reference line for the first order discretization scheme and the second order discretization scheme

In addition to this comparison, Table 3.2 gives the average temperature values of the components for both of the schemes. The maximum difference of $0.5^{\circ} \mathrm{C}$ is calculated on the graphics card. 
Table 3.2 Average temperature values of the components for the first order discretization scheme and the second order discretization scheme

\begin{tabular}{|l|c|c|c|}
\hline Components & $\begin{array}{c}\mathbf{1}^{\text {st }} \text { Order } \\
\text { Average T }\left({ }^{\circ} \mathbf{C}\right)\end{array}$ & $\begin{array}{c}\mathbf{2}^{\text {nd }} \text { Order } \\
\text { Average T }\left({ }^{\circ} \mathbf{C}\right)\end{array}$ & $\begin{array}{c}\% \\
\text { Difference }\end{array}$ \\
\hline CPU & 49.5 & 49.2 & 0.4 \\
HDD & 46.2 & 46.5 & 0.4 \\
BATTERY & 34.3 & 34.3 & 0 \\
GC & 42.8 & 43.3 & 0.7 \\
SB & 41.8 & 42.2 & 0.5 \\
RAM & 41.4 & 41.6 & 0.3 \\
PCMCIA & 39.3 & 39.6 & 0.4 \\
PCB & 41.3 & 41.6 & 0.4 \\
DVD & 34.7 & 34.9 & 0.3 \\
\hline
\end{tabular}

Figures 3.6 and 3.7 present the temperature distribution of the top surface of the CPU and the PCB, respectively. The temperature distributions shown in these figures differ slightly for each scheme solution. 

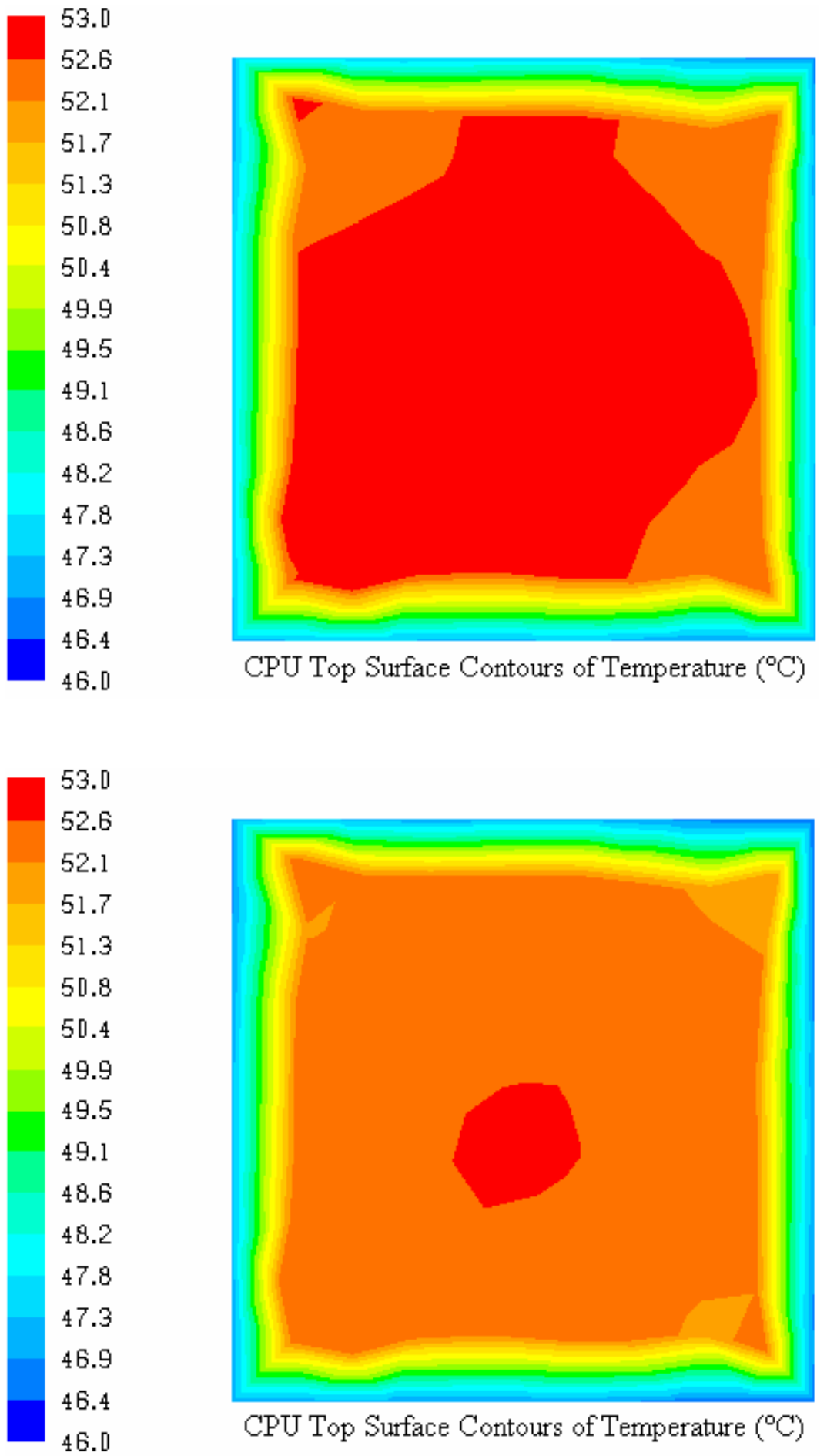

Figure 3.6 Temperature distributions of the top surface of the CPU for the first order discretization (top) and the second order discretization (bottom) solutions 

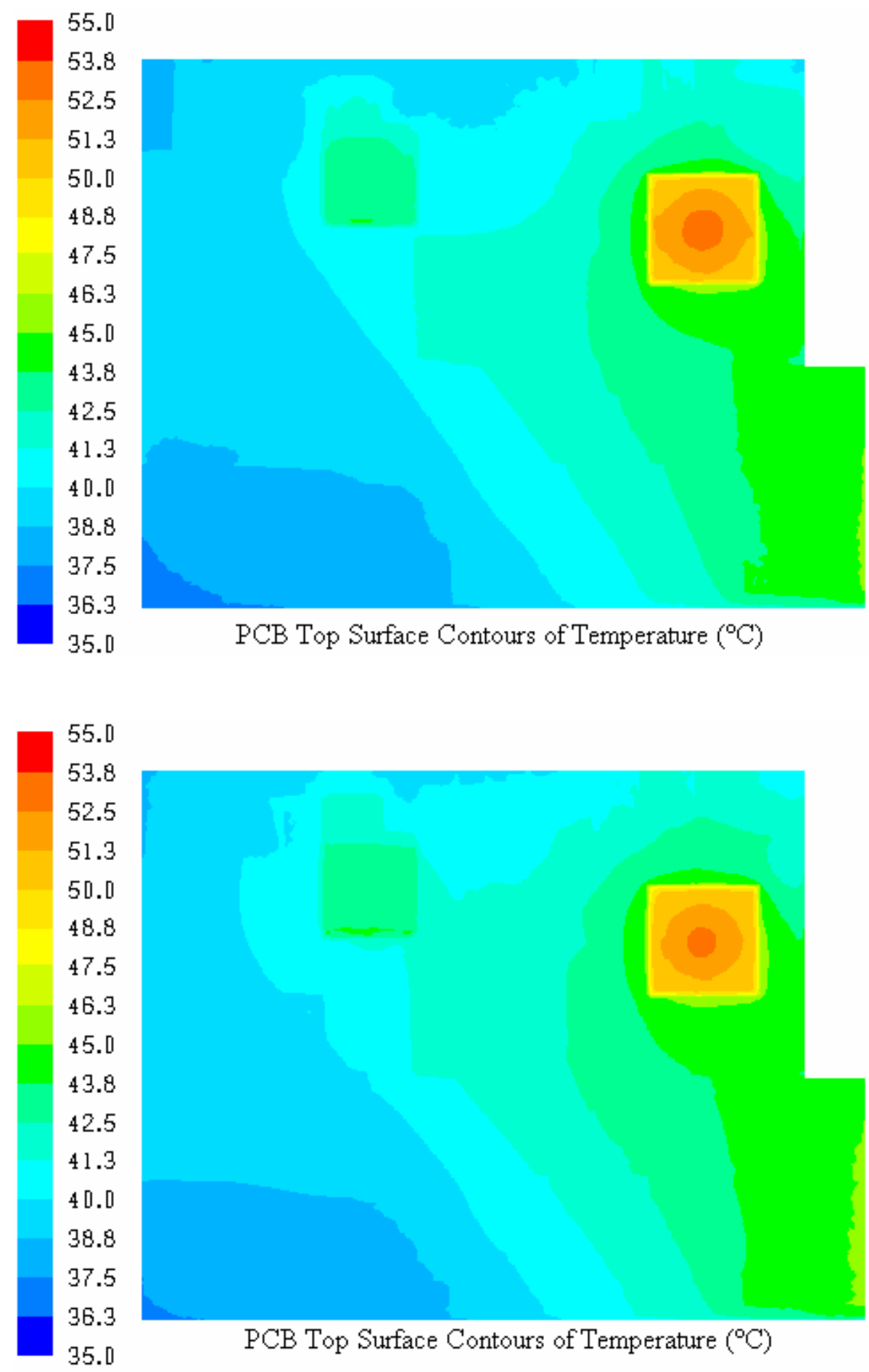

Figure 3.7 Temperature distributions of the top surface of the PCB for the first order discretization (top) and the second order discretization (bottom) solutions 
For the solution comparison of the two discretization schemes with the coarse mesh configuration and the first order discretization scheme with the fine mesh configuration, the static temperature on the reference line shown in Figure 3.1 is plotted and given in Figure 3.8.

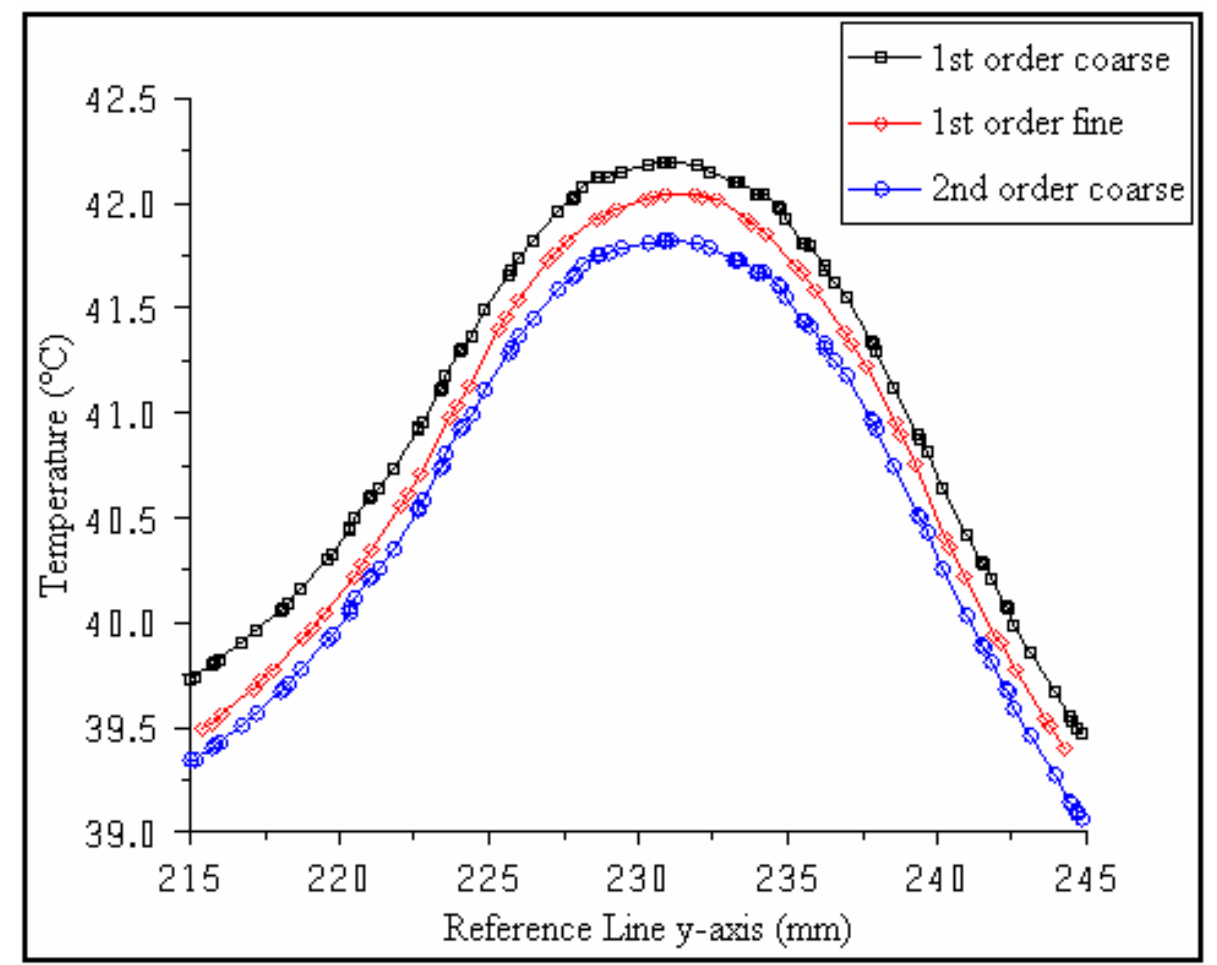

Figure 3.8 Temperature plots on the reference line for the first order and the second order discretization schemes with the coarse mesh configuration, and the first order discretization scheme with the fine mesh configuration

There is $0.4 \%$ difference between the fine mesh configuration with the first order discretization scheme and the coarse mesh configuration with the second order discretization scheme. Since the difference between the first order and the second order discretization schemes with the coarse mesh configuration is 
$0.7 \%$, the coarse mesh configuration with the first order discretization scheme solution is performed for the further analysis.

\subsection{Thermal Management Results}

In this section the results of five different operating conditions are given and the thermal paths of these cases are discussed. Also, the constraints of the system which are presented in Section 1.4 are checked.

The first case (Case I) is realized when the notebook is used for standard applications. In this study, Case I is chosen as the default case. In the second case (Case II), the battery is charging while the notebook is used for standard applications. The third case (Case III) occurs when the DVD is running while the notebook is used for standard applications. In the fourth case (Case IV), the CPU is working at full load and at the same time the HDD is reading or writing. The fifth case (Case V) is the simulation of an extreme case, which practically does not occur for an average user. In this case, the CPU and the HDD are working at full load, at the same time the DVD is running and the battery is charging. The heat dissipation values of the components for each case are given in Table 3.3. 
Table 3.3 Heat dissipation rates of the components for Case I, Case II, Case III, Case IV, and Case V

\begin{tabular}{|c|c|c|c|c|c|}
\hline Component & $\begin{array}{c}\text { CASE I } \\
\text { Heat Dissipation } \\
\text { (W) }\end{array}$ & $\begin{array}{c}\text { CASE II } \\
\text { Heat Dissipation } \\
\text { (W) }\end{array}$ & $\begin{array}{c}\text { CASE II } \\
\text { Heat Dissipation } \\
\text { (W) }\end{array}$ & $\begin{array}{c}\text { CASE IV } \\
\text { Heat Dissipation } \\
\text { (W) }\end{array}$ & $\begin{array}{c}\text { CASE V } \\
\text { Heat Dissipation } \\
\text { (W) }\end{array}$ \\
\hline Processor (CPU) & 21 & 21 & 21 & 30 & 30 \\
\hline RAM & 0.5 & 0.5 & 0.5 & 0.5 & 0.5 \\
\hline Hard disk & 5 & 5 & 5 & 9 & 9 \\
\hline Graphics card & 2 & 2 & 2 & 2 & 2 \\
\hline South bridge & 0.5 & 0.5 & 0.5 & 0.5 & 0.5 \\
\hline PCMCLA card & 1 & 1 & 1 & 1 & 1 \\
\hline DVD & 0 & 0 & 5 & 0 & 5 \\
\hline Battery & 0 & 2 & 0 & 0 & 2 \\
\hline TOTAL & 30 & 32 & 35 & 43 & 50 \\
\hline
\end{tabular}


The comparison between the average temperatures of the components for each case and the maximum allowable operating temperatures of the components is given in Table 3.4. All the average temperatures of the components listed are below the maximum allowable operating temperature limit, except from the HDD average temperature in Case IV and V. There is a considerable change in the average temperatures of the components which dissipate different amounts of heat in different cases. The average temperatures of the components in their close vicinity are also changed.

In Table 3.5, the maximum temperatures of the components are compared with the maximum allowable operating temperatures for each case. In Case IV and $\mathrm{V}$ both the HDD and the battery exceed the maximum allowable operating temperature limit. Additionally, in Case V the PCB exceeds the limit. The most excessive one is the HDD in Case V which exceeds the limit by $6.6^{\circ} \mathrm{C}$.

The difference between the average temperature values and the maximum temperature values is caused by the hot regions occurring within the components. 
Table 3.4 Comparison of the maximum allowable temperatures and the calculated average temperatures of the components for Case I, Case II, Case III, Case IV, and Case V

\begin{tabular}{|l|c|c|c|c|c|c|}
\hline & Maximum & \multicolumn{5}{|c|}{ Calculated Average Temperature $\left({ }^{\circ} \mathrm{C}\right)$} \\
\cline { 3 - 7 } Components & Allowable T( $\left.{ }^{\circ} \mathrm{C}\right)$ & CASE I & CASE II & CASE II & CASE IV & CASE V \\
\hline CPU & 100 & 53.5 & 53.9 & 54.6 & 65.6 & 67.1 \\
BDD & 60 & 47.9 & 49.5 & 49.9 & 61.2 & 64.3 \\
GC & 55 & 34.9 & 42 & 37.4 & 39.4 & 48.5 \\
SB & 85 & 44.8 & 45.3 & 47.7 & 49.9 & 53.4 \\
RAM & 85 & 43.8 & 44.5 & 46.9 & 49.9 & 53.6 \\
PCMCLA & 70 & 43.2 & 44.3 & 47.2 & 50 & 54.9 \\
PCB & 70 & 40.8 & 41.5 & 45.6 & 45.2 & 50.4 \\
DVD & 70 & 43.2 & 44.1 & 46.8 & 50 & 54.4 \\
\hline
\end{tabular}


Table 3.5 Comparison of the maximum allowable temperatures and the calculated maximum temperatures of the components for Case I, Case II, Case III, Case IV, and Case V

\begin{tabular}{|c|c|c|c|c|c|c|c|}
\hline & & Maximum & & Calculate & ximum $\mathrm{Te}$ & rature $\mathrm{f}^{\circ} \mathrm{C}$ & \\
\hline & Components & Allowable $\mathrm{T}\left({ }^{\circ} \mathrm{C}\right)$ & CASE I & CASE II & CASE III & CASE IV & CASE V \\
\hline & CPU & 100 & 57.8 & 58.2 & 58.9 & 71.8 & 73.2 \\
\hline & $\mathrm{HDD}$ & 60 & 49.1 & 50.7 & 50.9 & 63.6 & 66.6 \\
\hline & BATTERY & 55 & 45 & 47.3 & 47.3 & 55.6 & 59.9 \\
\hline r & $\mathrm{GC}$ & 85 & 45.2 & 45.7 & 48.3 & 50.4 & 53.9 \\
\hline & $\mathrm{SB}$ & 85 & 44.2 & 44.9 & 47.2 & 50.8 & 54.5 \\
\hline & RAM & 70 & 45.7 & 46.6 & 48.2 & 54.3 & 57.7 \\
\hline & PCMCLA & 70 & 41.4 & 42.1 & 46.1 & 46.2 & 51.4 \\
\hline & $\mathrm{PCB}$ & 70 & 57.1 & 57.6 & 58.2 & 69.8 & 72.3 \\
\hline & DVD & 60 & 41.3 & 42.9 & 48.5 & 48 & 54.4 \\
\hline
\end{tabular}


The simplified thermal path diagrams for all five cases are presented in Figures 3.9 - 3.13. In these diagrams, there are two types of heat dissipation paths given. One of them is the active heat transfer path, presented in red color, in which heat is dissipated by the active cooling methods. In this study, the active cooling methods are the two fans which are transferring heat from the CPU, the graphics card and the south bridge chip. The other type of path shown in the figures is the passive heat transfer path, presented in blue color. The main heat transfer mechanism for this path is conduction and natural convection. In the figures, some heat transfer paths are left colorless, because both active and passive methods are effective in these paths. The main heat sources, which are taken into account in this analysis, are presented in magenta.

The air inside the chassis is in contact with the components, the chassis walls, the keyboard and the fans. The heat transferred to the chassis air is dissipated to the ambient through the elements which are in contact with it. 


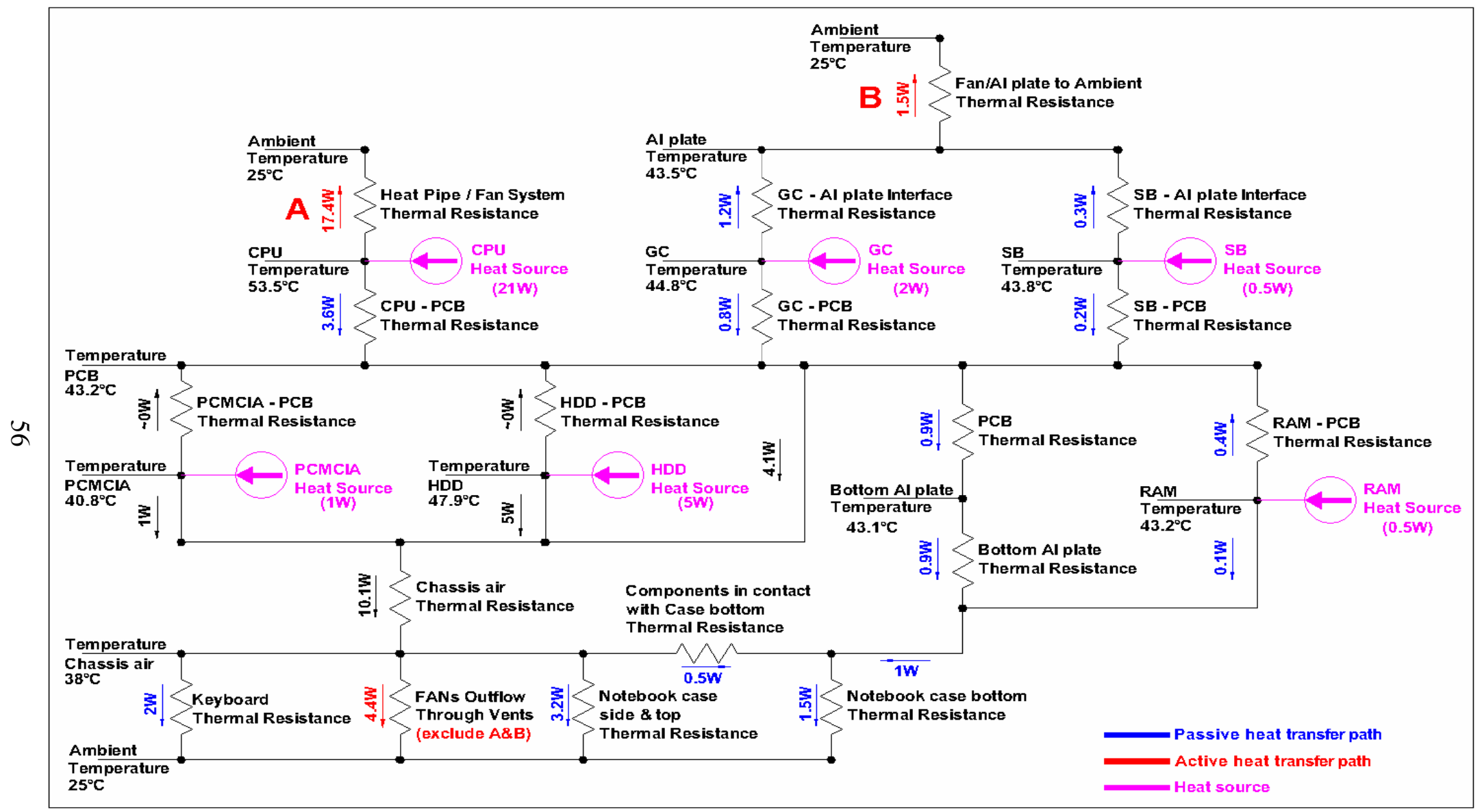

Figure 3.9 Thermal path diagram for Case I 


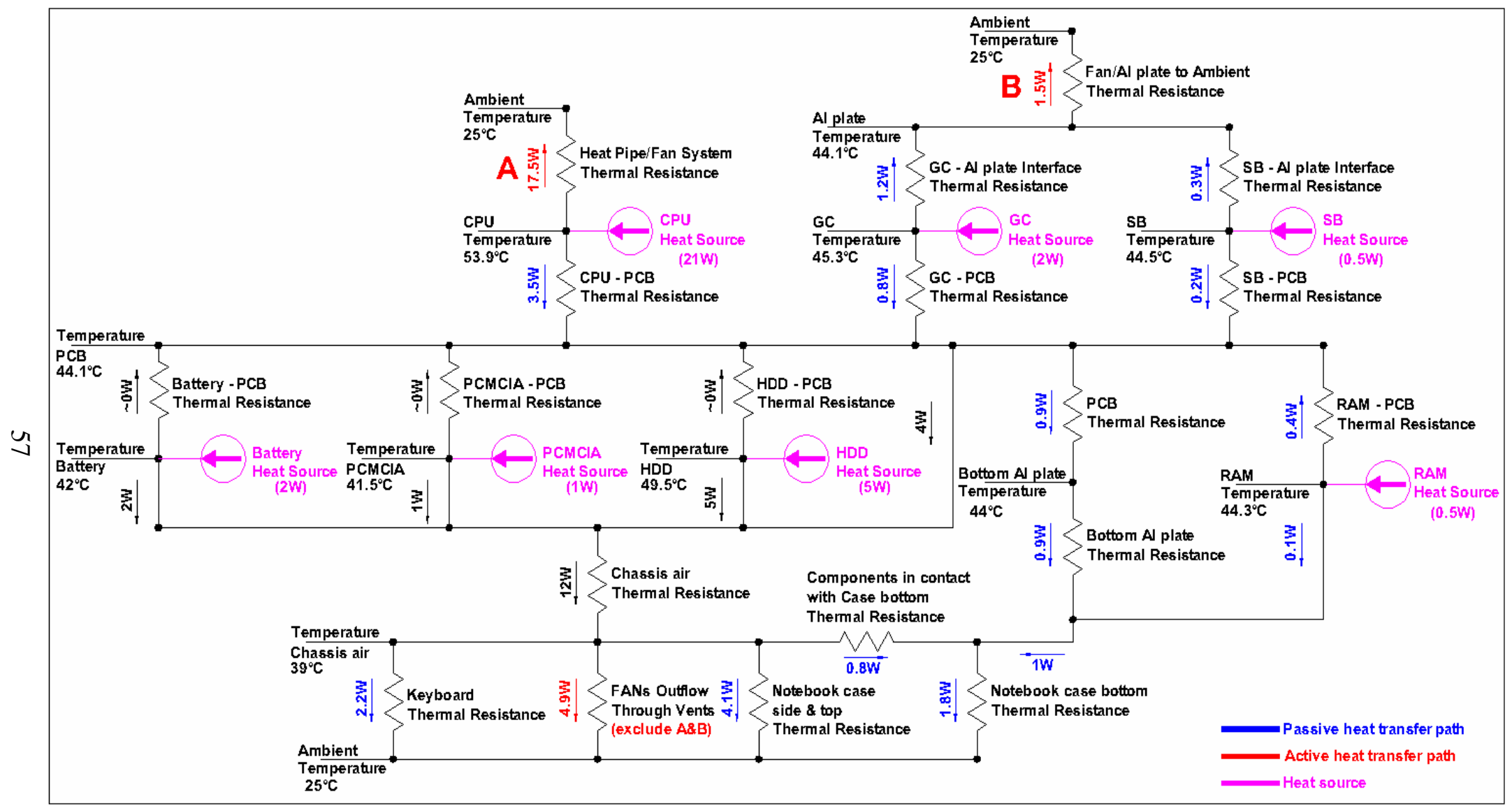

Figure 3.10 Thermal path diagram for Case II 


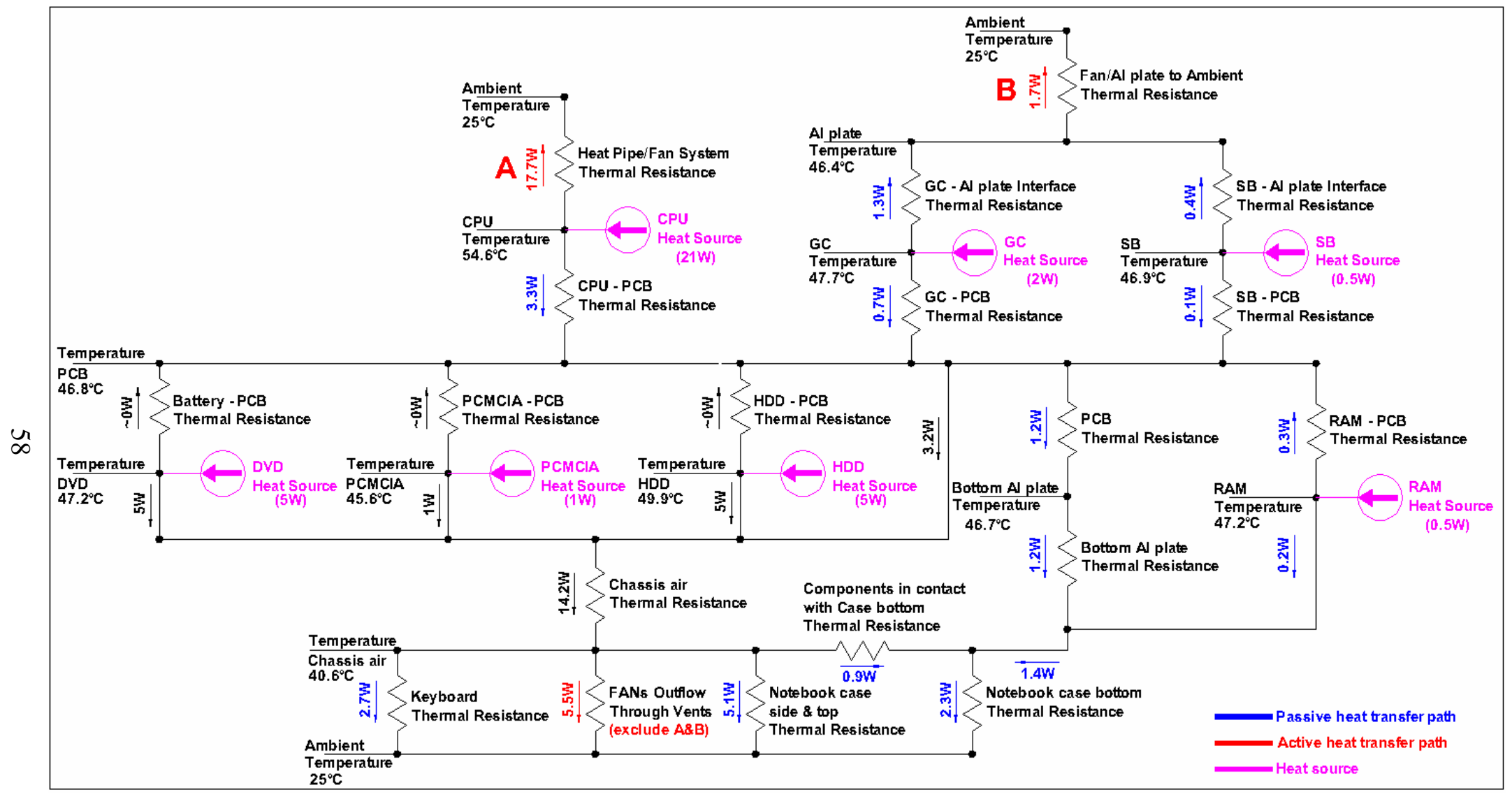

Figure 3.11 Thermal path diagram for Case III 


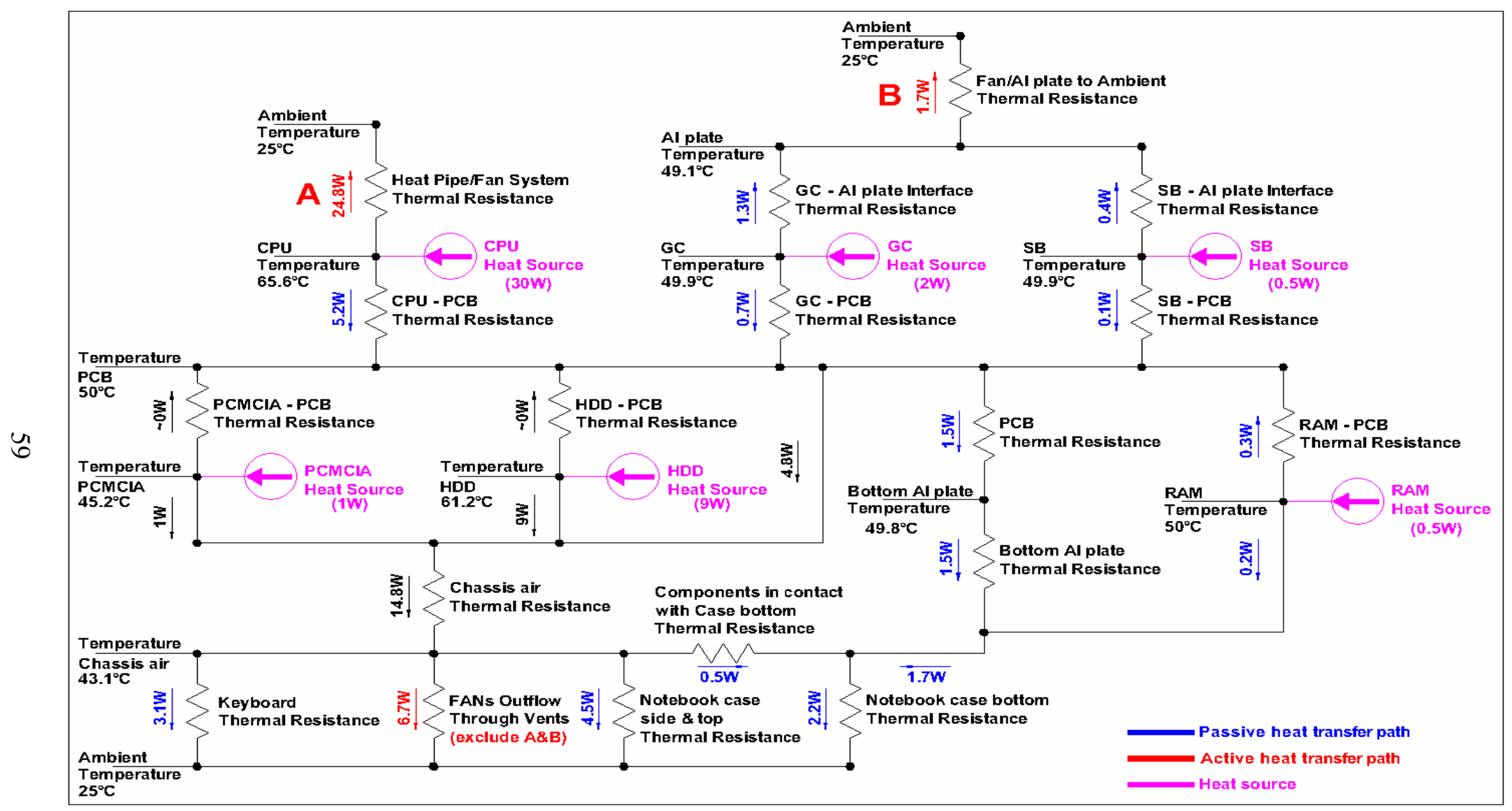

Figure 3.12 Thermal path diagram for Case IV 


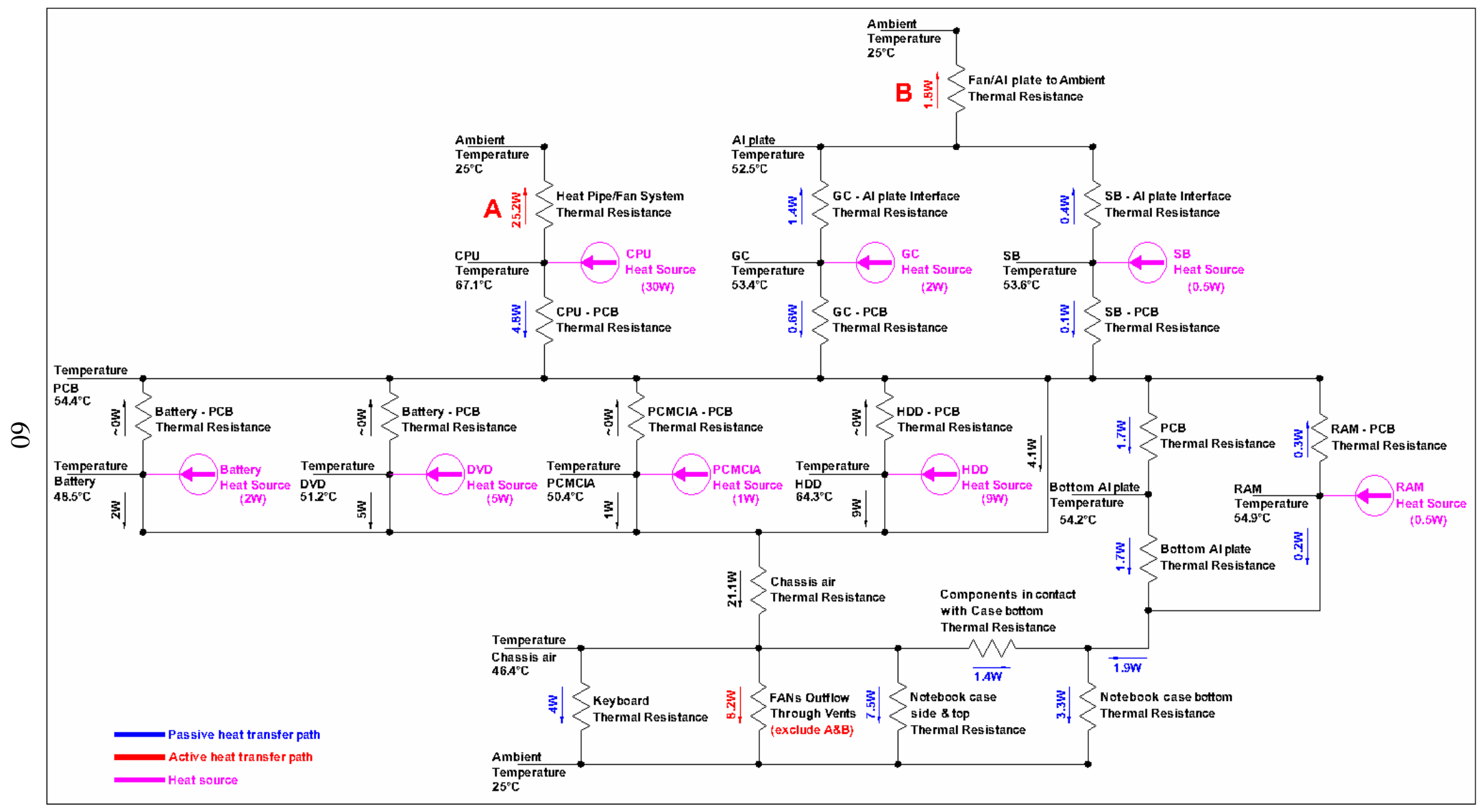

Figure 3.13 Thermal path diagram for Case V 
The heat transfer path from the CPU to the ambient through the hybrid system, which is named as "A" in Figure 3.9, is presented in Figure 3.14 in detail. The thermal resistances of the elements in the path are also mentioned in this figure. Although the temperature values and the heat transfer rates for Case I are given in this figure, the components and the thermal resistances are the same for all cases.

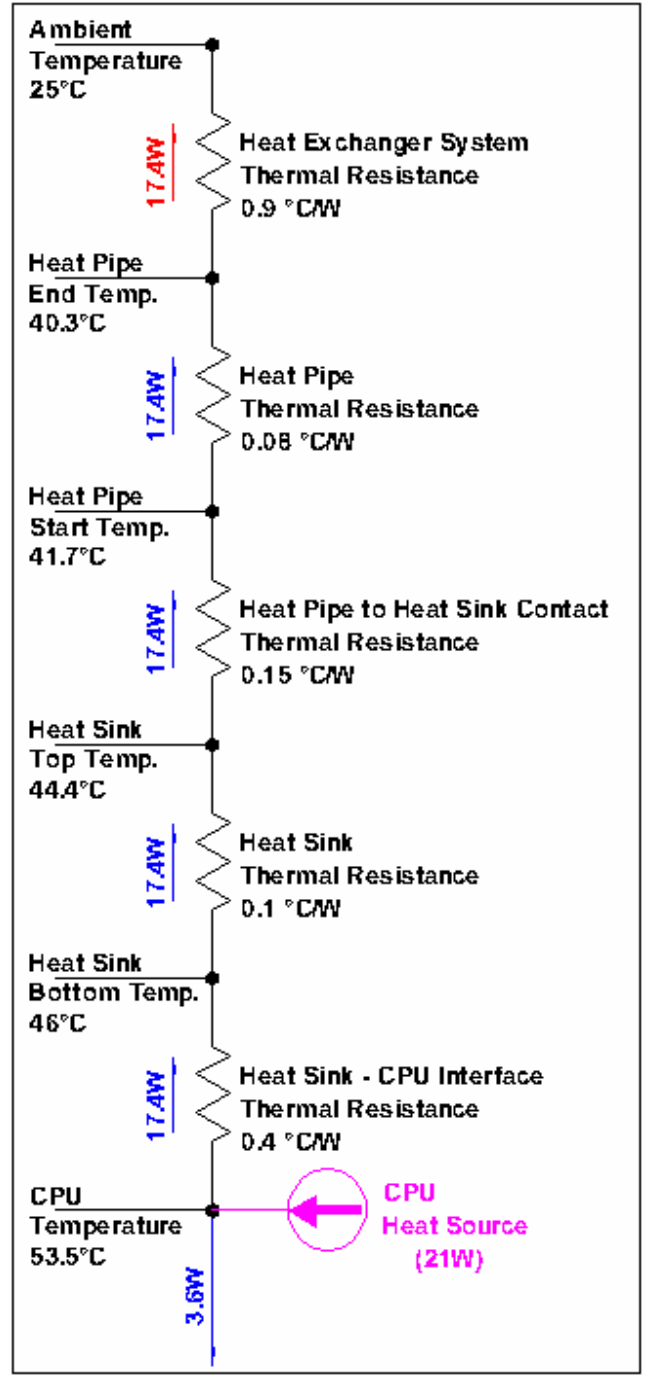

Figure 3.14 The active heat transfer path of the CPU 
The active and the passive heat dissipation rates for the five cases are summarized in Table 3.6. The percent usage of the cooling method preferred for the dissipation of the heat generated from the CPU does not have a significant change in different cases. On the other hand, the usage of active cooling methods increased for the graphics card and the south bridge in Case III, Case IV and Case V. This is because the increase in the PCB temperature is more than these components temperatures. The increasing PCB temperature does not affect the cooling path preference of the CPU since the CPU is the main component which affects the temperature of the PCB. 
Table 3.6 Heat dissipation methods of the notebook and the components for Case I, Case II, Case III, Case IV, and Case V

心

\begin{tabular}{|c|l|c|c|c|c|c|c|c|c|}
\cline { 3 - 10 } \multicolumn{2}{c|}{} & \multicolumn{2}{c|}{ NOTEBO OK } & \multicolumn{2}{c|}{ CPU } & \multicolumn{2}{c|}{ Graphics Card } & \multicolumn{2}{c|}{ South Bridge } \\
\hline \multicolumn{2}{|c|}{ Cooling Method } & Active & Passive & Active & Passive & Active & Passive & Active & Passive \\
\hline \hline \multirow{2}{*}{ CASE I } & Amount(W) & 23.3 & 6.7 & 17.4 & 3.6 & 1.2 & 0.8 & 0.3 & 0.2 \\
\cline { 2 - 11 } & Percent (\%) & 78 & 22 & 83 & 17 & 60 & 40 & 60 & 40 \\
\hline \multirow{2}{*}{ CASE II } & Amount(W) & 23.9 & 8.1 & 17.5 & 3.5 & 1.2 & 0.8 & 0.3 & 0.2 \\
\cline { 2 - 11 } & Percent (\%) & 75 & 25 & 83 & 17 & 60 & 40 & 60 & 40 \\
\hline \multirow{2}{*}{ CASE III } & Amount(W) & 24.9 & 10.1 & 17.7 & 3.3 & 1.3 & 0.7 & 0.4 & 0.1 \\
\cline { 2 - 11 }$y$ & Percent (\%) & 71 & 29 & 84 & 16 & 65 & 35 & 80 & 20 \\
\hline \multirow{2}{*}{ CASE IV } & Amount(W) & 33.2 & 9.8 & 24.8 & 5.2 & 1.3 & 0.7 & 0.4 & 0.1 \\
\cline { 2 - 11 } & Percent (\%) & 77 & 23 & 83 & 17 & 65 & 35 & 80 & 20 \\
\hline \multirow{2}{*}{ CASE V } & Amount(W) & 35.2 & 14.8 & 25.2 & 4.8 & 1.4 & 0.6 & 0.4 & 0.1 \\
\cline { 2 - 10 }$y$ & Percent (\%) & 70 & 30 & 84 & 16 & 70 & 30 & 80 & 20 \\
\hline
\end{tabular}


The temperature distributions of the top surface of the PCB in each case are shown in Figure 3.15. In this figure, the effect of the CPU which is on the upper right of the $\mathrm{PCB}$, the graphics card which is on upper left of the PCB, and the HDD which is on the lower right of the PCB can be clearly seen. There is a noticeable temperature difference between the position on which the CPU is attached and its vicinity. This is mainly caused by the difference between the in plane thermal conductivity of the PCB and the thermal conductivity of the thermal grease used under the CPU. The former one has a higher value.

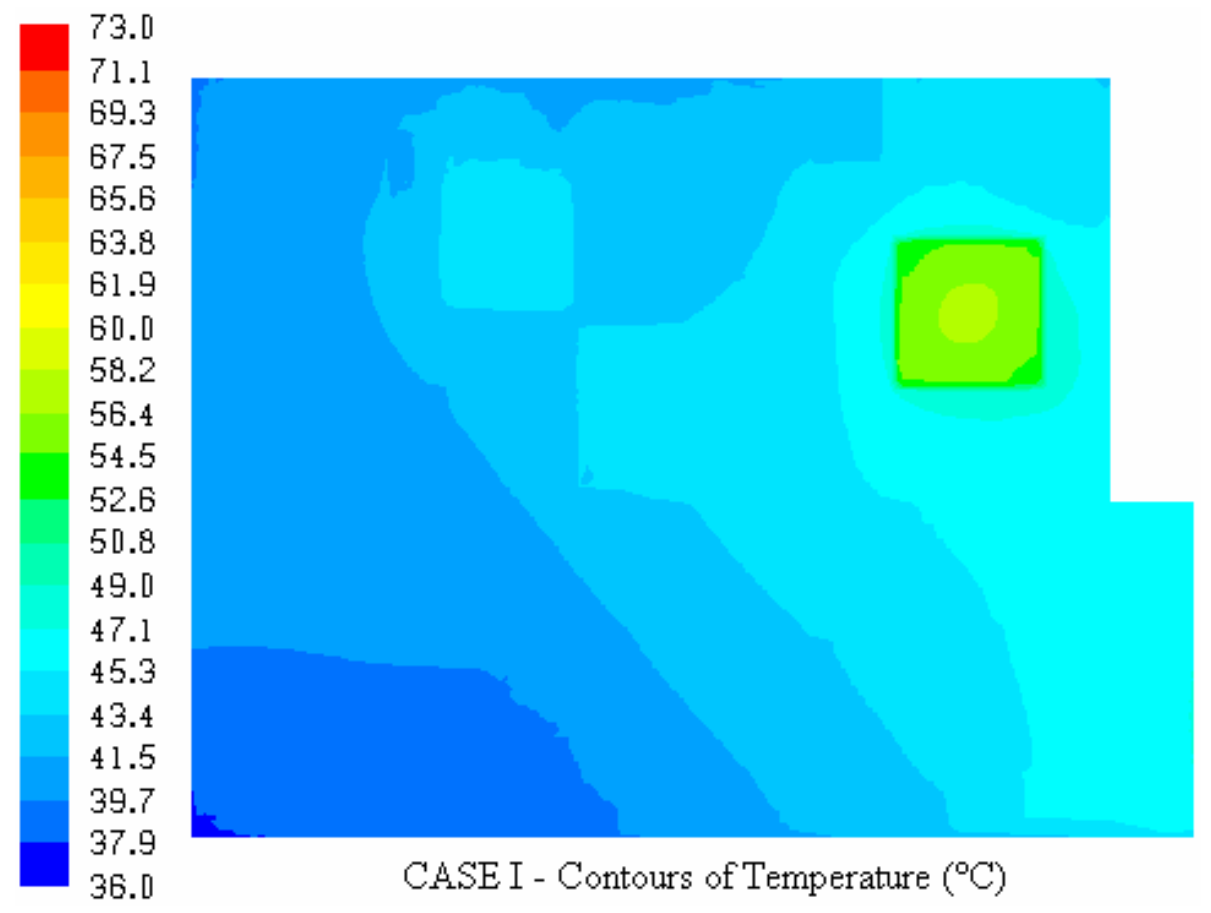

Figure 3.15 Temperature distributions of the PCB top surface for Case I, Case II, Case III, Case IV, and Case V 

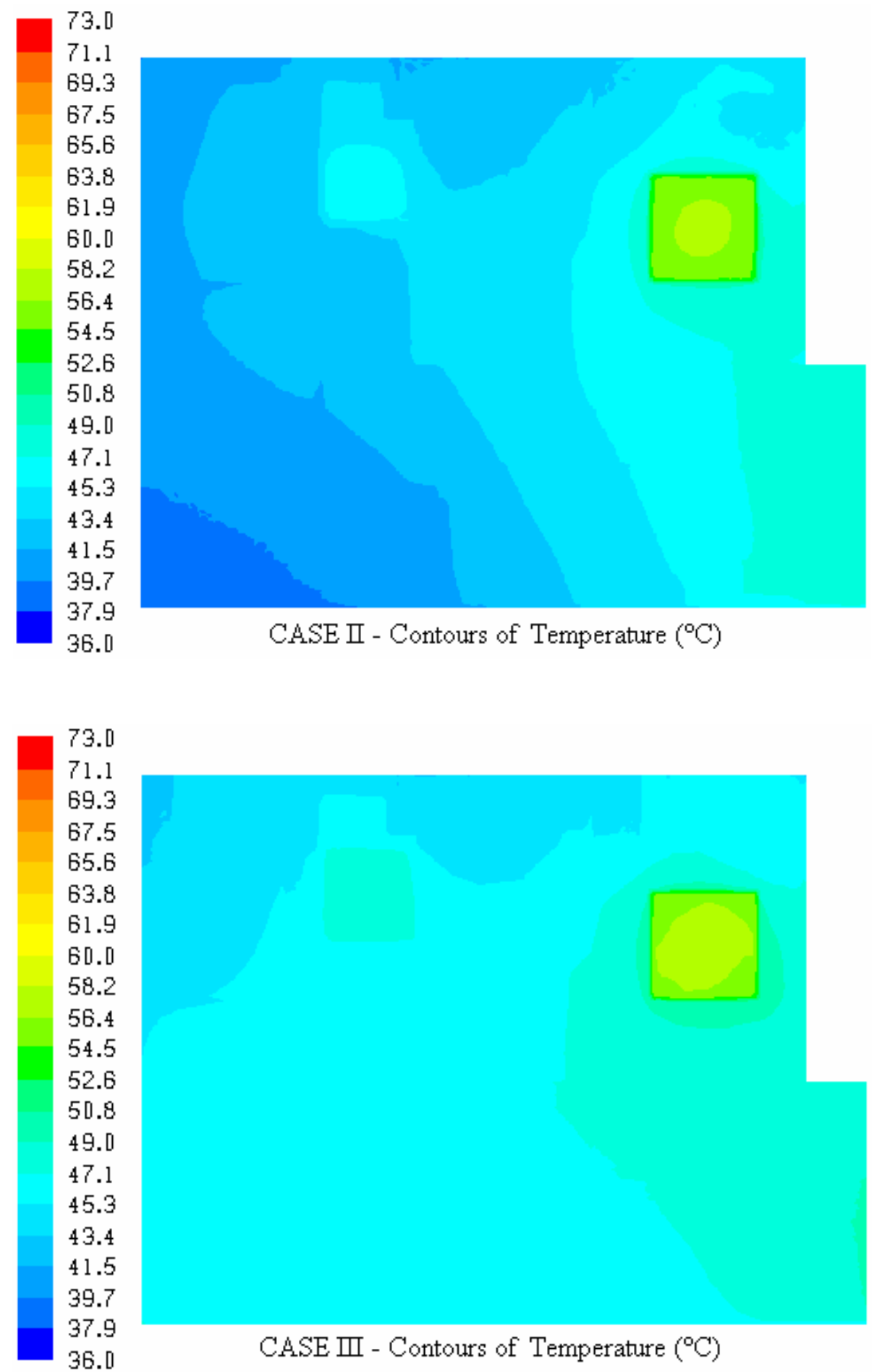

Figure 3.15 (continued) 

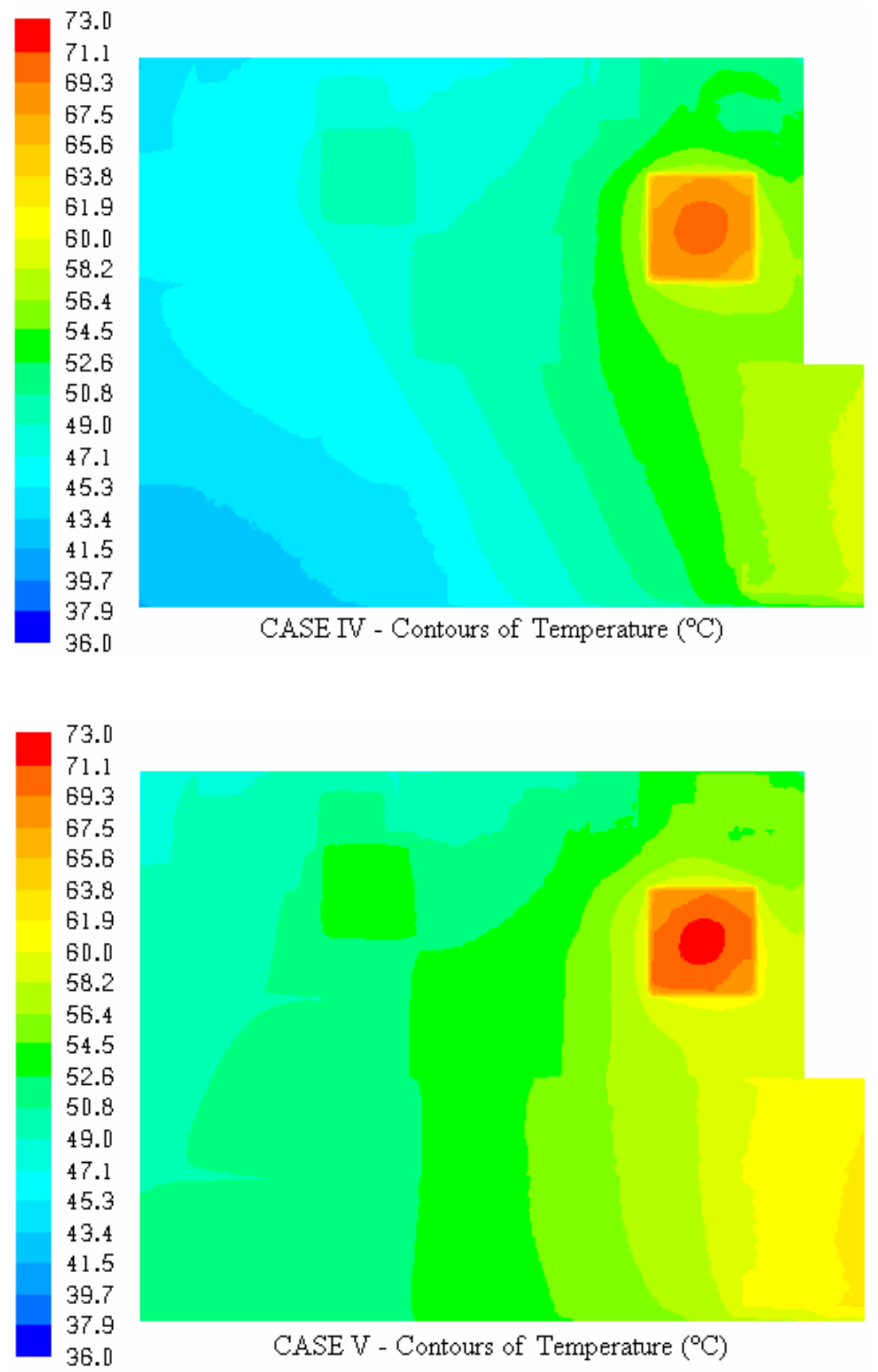

Figure 3.15 (continued) 
The temperature distribution of the top surface of the chassis is presented in Figure 3.16. In Case I, the effect of the CPU, the HDD and the graphics card can be clearly seen. The heat dissipation from the battery and the DVD affects the top surface temperature as shown in Case II and Case III, respectively. The effect of the increased heat dissipation rates of the CPU and the HDD, on the temperature distribution of the top surface of the chassis, can be seen when Case I and Case IV in Figure 3.16 are compared.

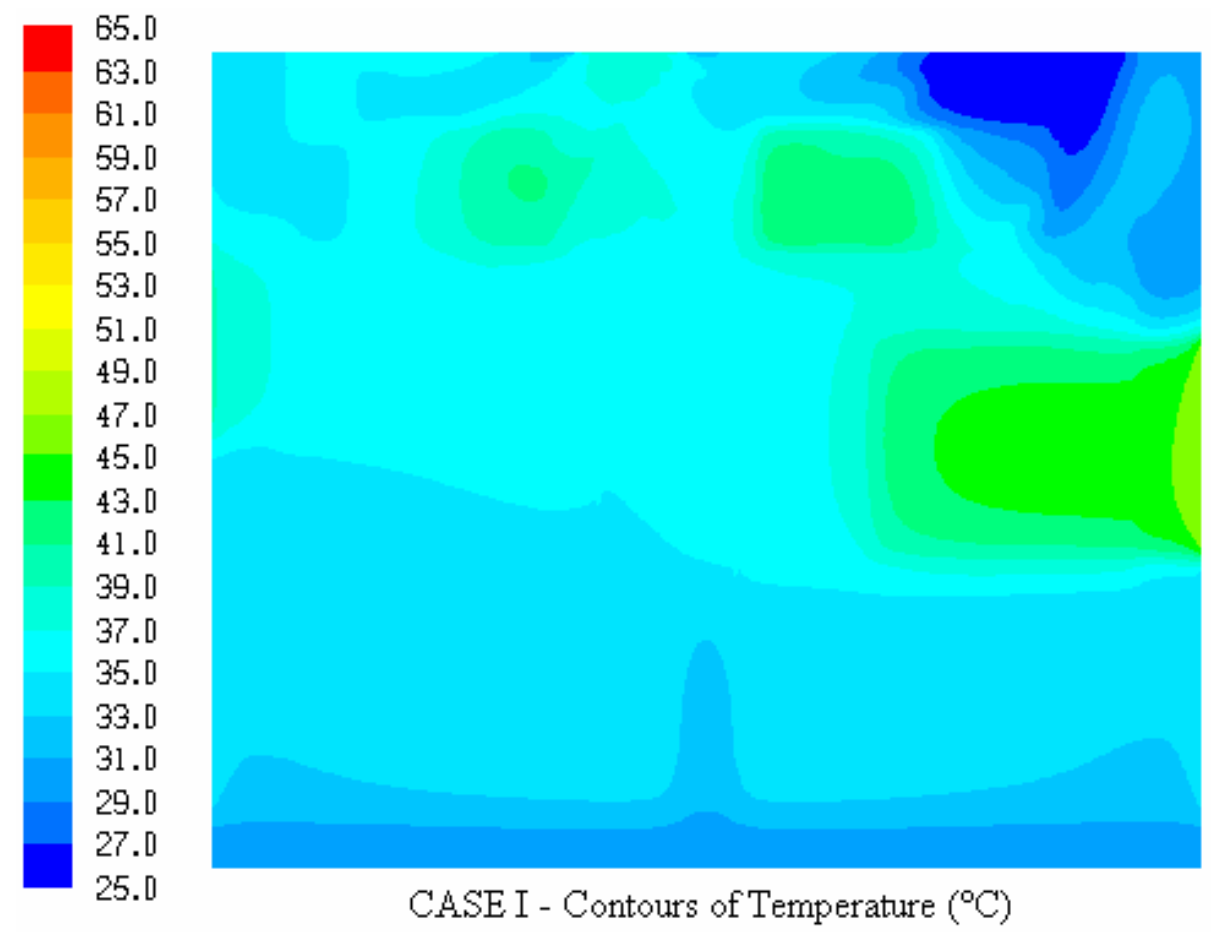

Figure 3.16 Temperature distributions of the top surface of the chassis for Case I, Case II, Case III, Case IV, and Case V 
65.0

63. 0

61.0

59.0

57.0

55.0

53.0

51.0

49.0

47.0

45 . 0

43.0

41.0

39.0

37.0

35.0

33.0

31.0

29.0

27.0

25 . 0

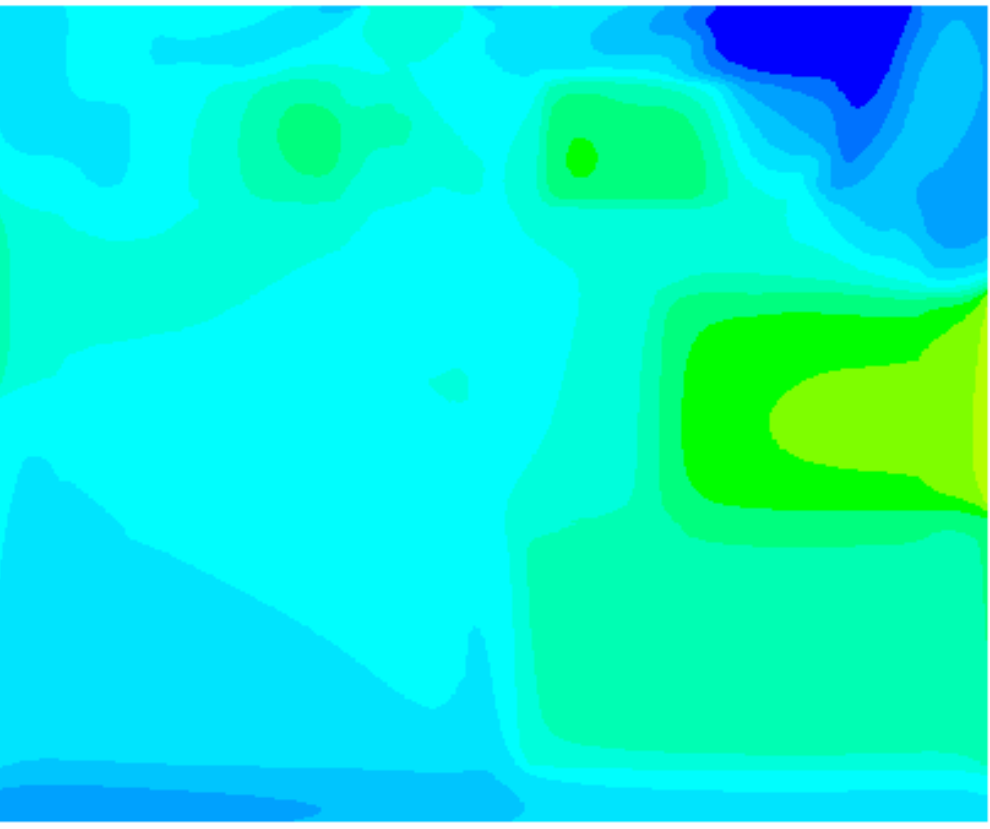

CASE II - Contours of Temperature $\left({ }^{\circ} \mathrm{C}\right)$

65. 0

63.0

61.0

59.0

57.0

55.0

53.0

51.0

49. 0

47.0

45 . 0

43.0

41 . 0

39.0

37.0

35.0

33.0

31.0

29.0

27.0

25.0

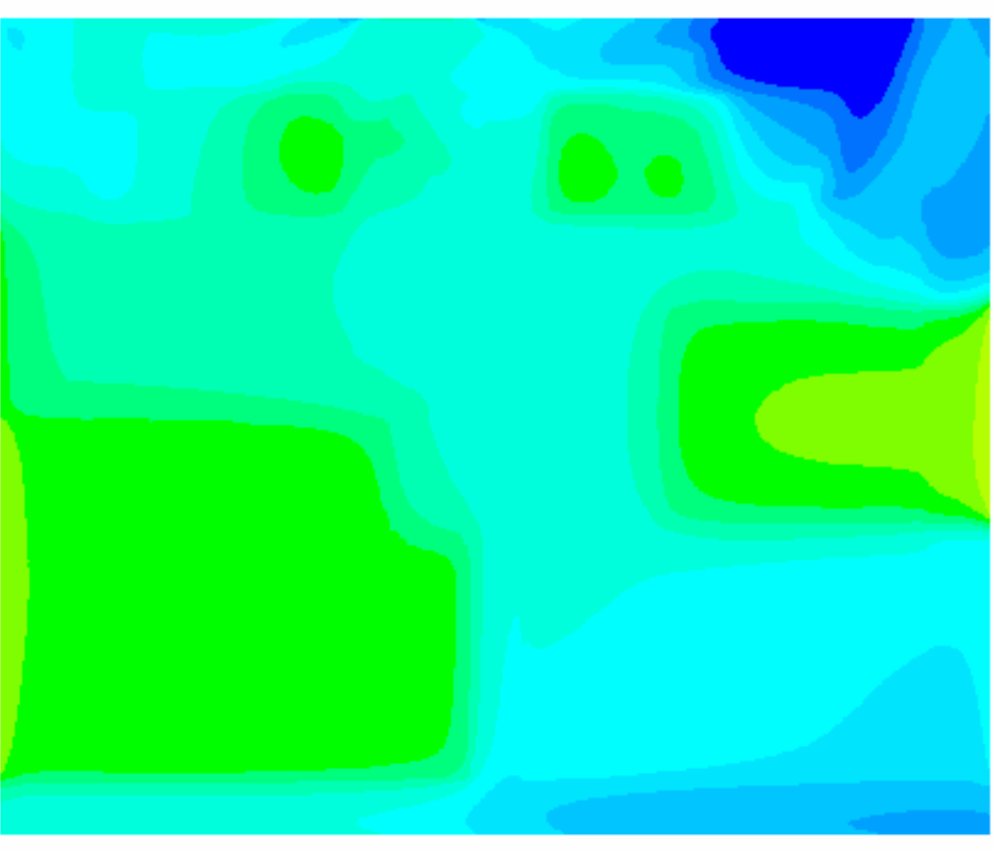

CASE II - Contours of Temperature $\left({ }^{\circ} \mathrm{C}\right)$

Figure 3.16 (continued) 
65.0

63.0

61.0

59.0

57.0

55. D

53.0

51.0

49. 0

47.0

45.0

43.0

41.0

39.0

37.0

35.0

33.0

31.0

29.0

27.0

25.0

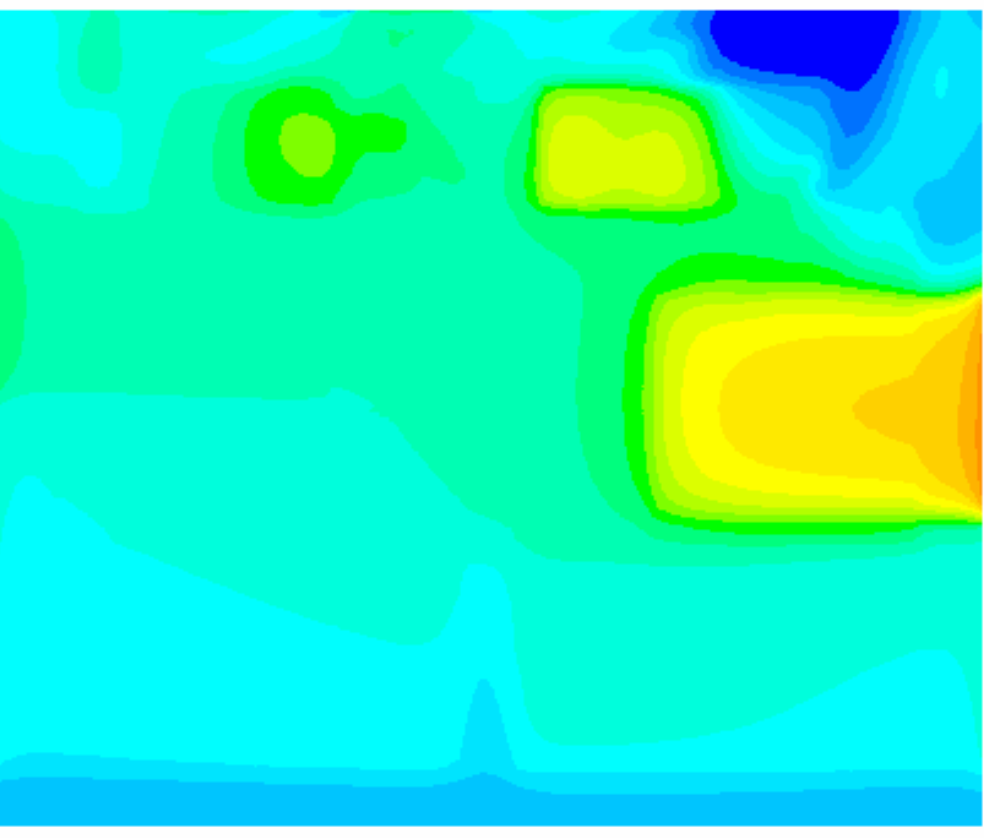

CASE TV - Contours of Temperature $\left({ }^{\circ} \mathrm{C}\right)$

65.0

63.0

61.0

59.0

57.0

55.0

53.0

51.0

49.0

47.0

45.0

43.0

41 . 0

39.0

37.0

35.0

33.0

31.0

29.0

27.0

25.0

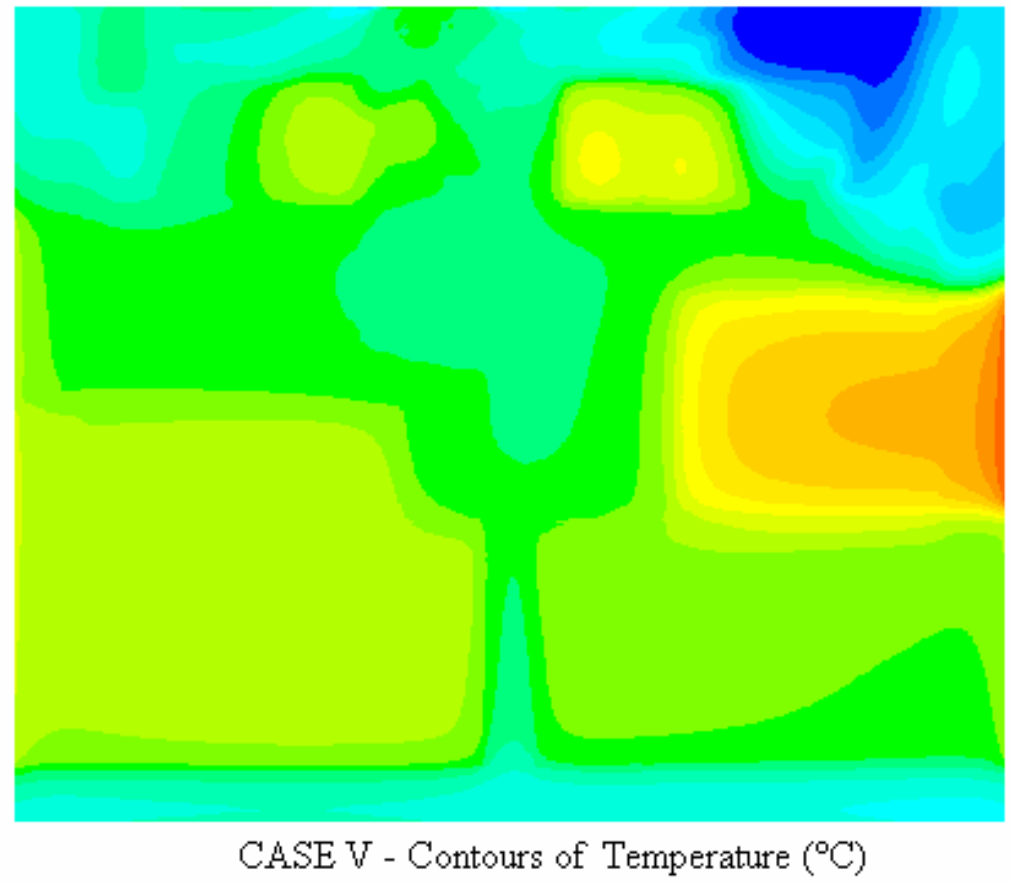

Figure 3.16 (continued) 
The user of the notebook will feel the heat on the parts surface where the temperature exceeds $40{ }^{\circ} \mathrm{C}$ [15]. These sections are shown in Figure 3.17 for each case. The rectangle shown in the figure represents the keyboard. The temperature contours that appear above, to the right and to the left of the keyboard do not affect the user since these regions are not used actively. However the high temperatures on the keyboard and below the keyboard disturb the user. In Case IV and Case V the temperature on the right side of the keyboard exceeds the limits more than $10{ }^{\circ} \mathrm{C}$, which will severely disturb the user.

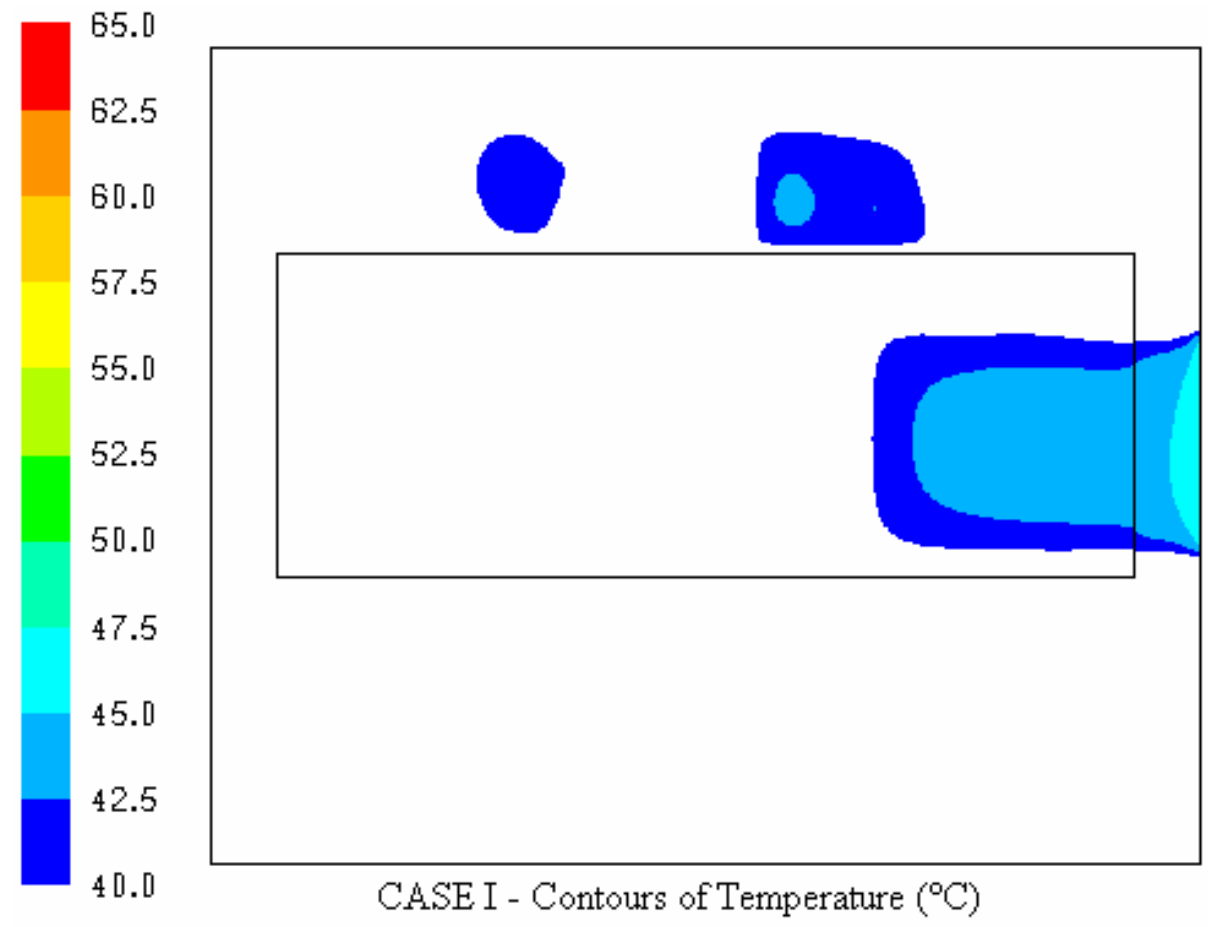

Figure 3.17 Temperature distributions of the top surface of the chassis for Case

I, Case II, Case III, Case IV, and Case V which exceeds the comfort limit 

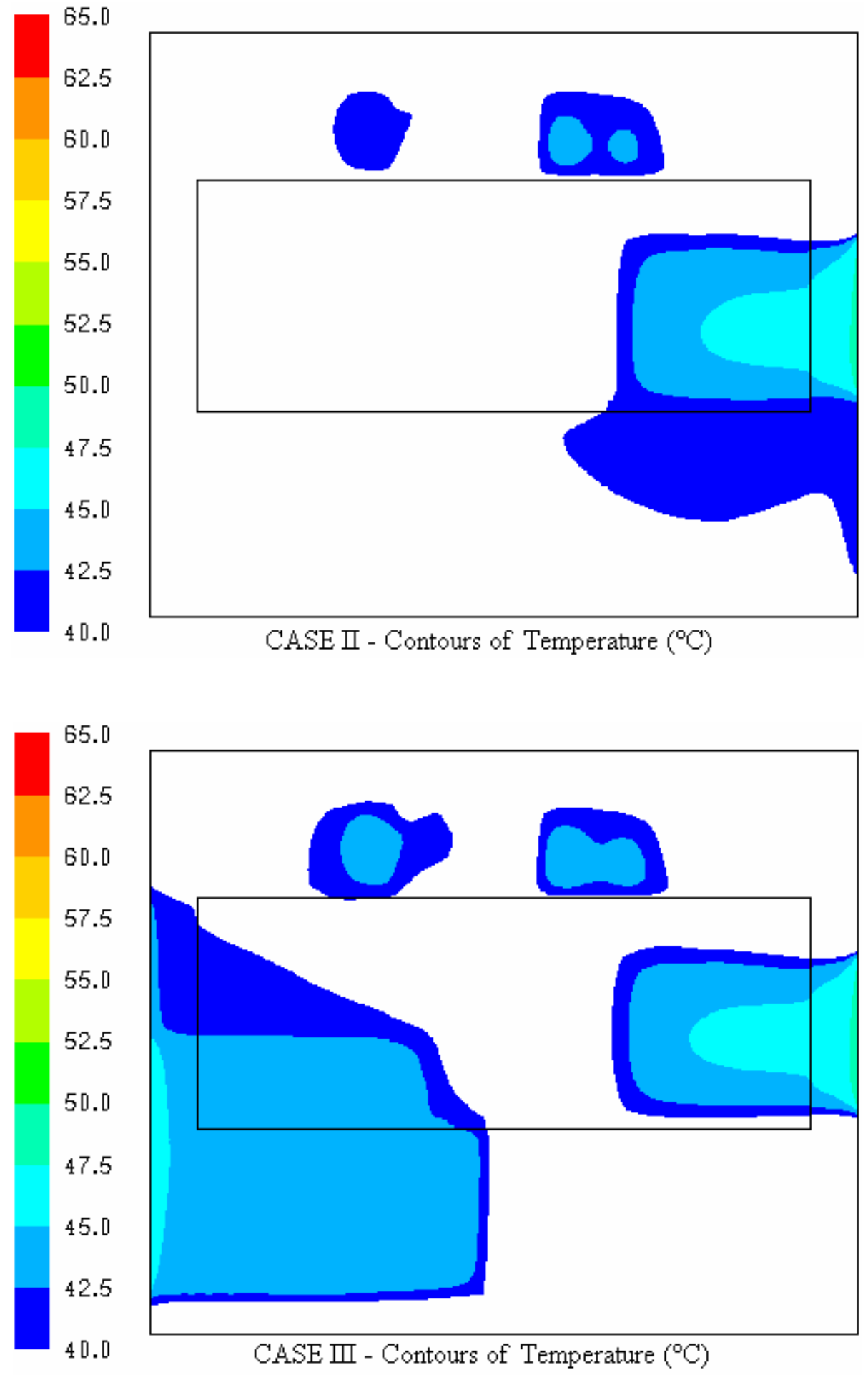

Figure 3.17 (continued) 

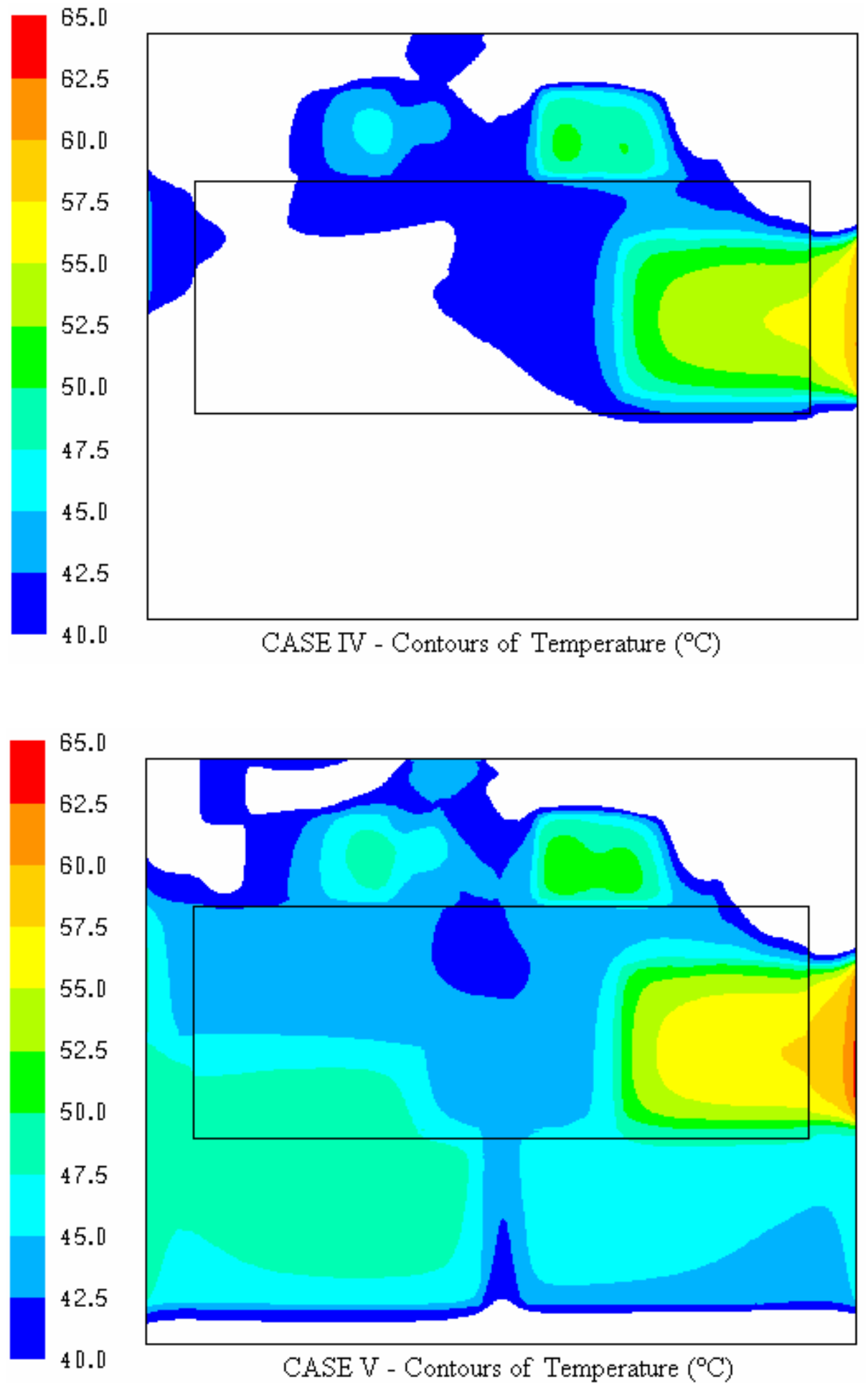

Figure 3.17 (continued) 


\subsection{Flow Results}

The results presented in this section are obtained from the solution of Case I. In the computational domain the maximum velocity of air is $5.2 \mathrm{~m} / \mathrm{s}$, which is at the entrance of the heat exchanger.

The contours of velocity on different planes on the $z$-axis are presented in Figure 3.18. The upper figure is at the position $z$ equals $4 \mathrm{~mm}$; this plane is 1 $\mathrm{mm}$ above the PCB. At this level, the velocity inside the heat exchanger can be seen. The velocity below the secondary fan is caused by the exhaust and suction of this fan.

The bottom figure is at the position $z$ equals $18 \mathrm{~mm}$; this plane is $5 \mathrm{~mm}$ above the primary fan and approximately $2 \mathrm{~mm}$ above the secondary fan. Since the secondary fan is tilted by six degrees, this plane intersects with the secondary fan. The velocity magnitude caused by the suction of the primary and the secondary fans can be seen in this figure. The air in the front part of the notebook chassis is stagnant. In addition to this, the air which is away from the fan inlet and outlet regions has very low velocities. 

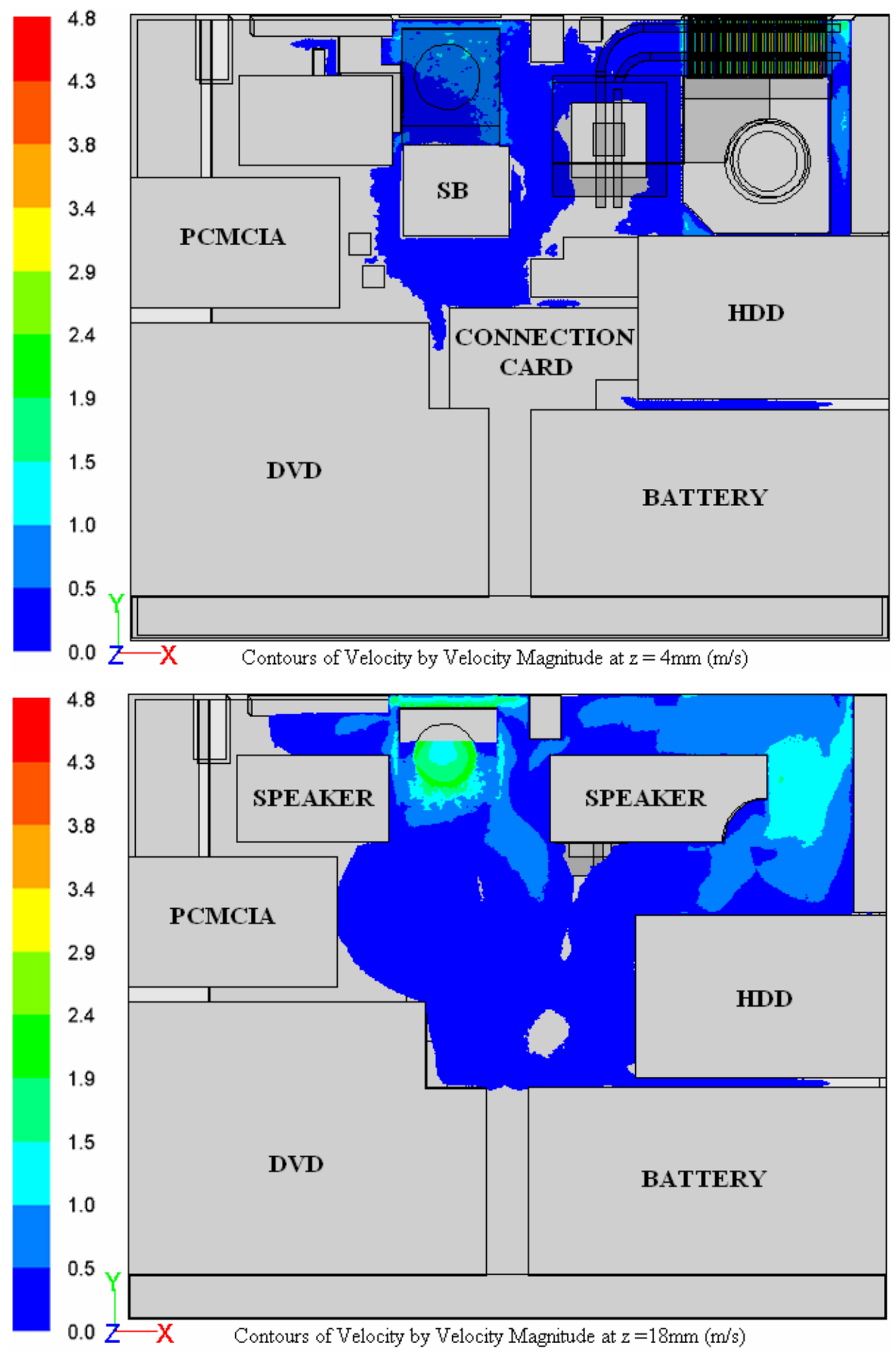

Figure 3.18 Contours of velocity on different planes in $z$ axis 
The path lines around the primary and the secondary fans are presented in Figures 3.19 and 3.20, respectively. The primary fan sucks air from the ventilation holes on the bottom and the side wall. Since it has two suction holes, it sucks from both of them. The bottom ventilation hole mainly supplies the air for the bottom suction hole, but it also supply air for the top suction hole. The path lines also show that the air supplied by the side ventilation hole not only feeds the primary fan, but also the secondary fan.

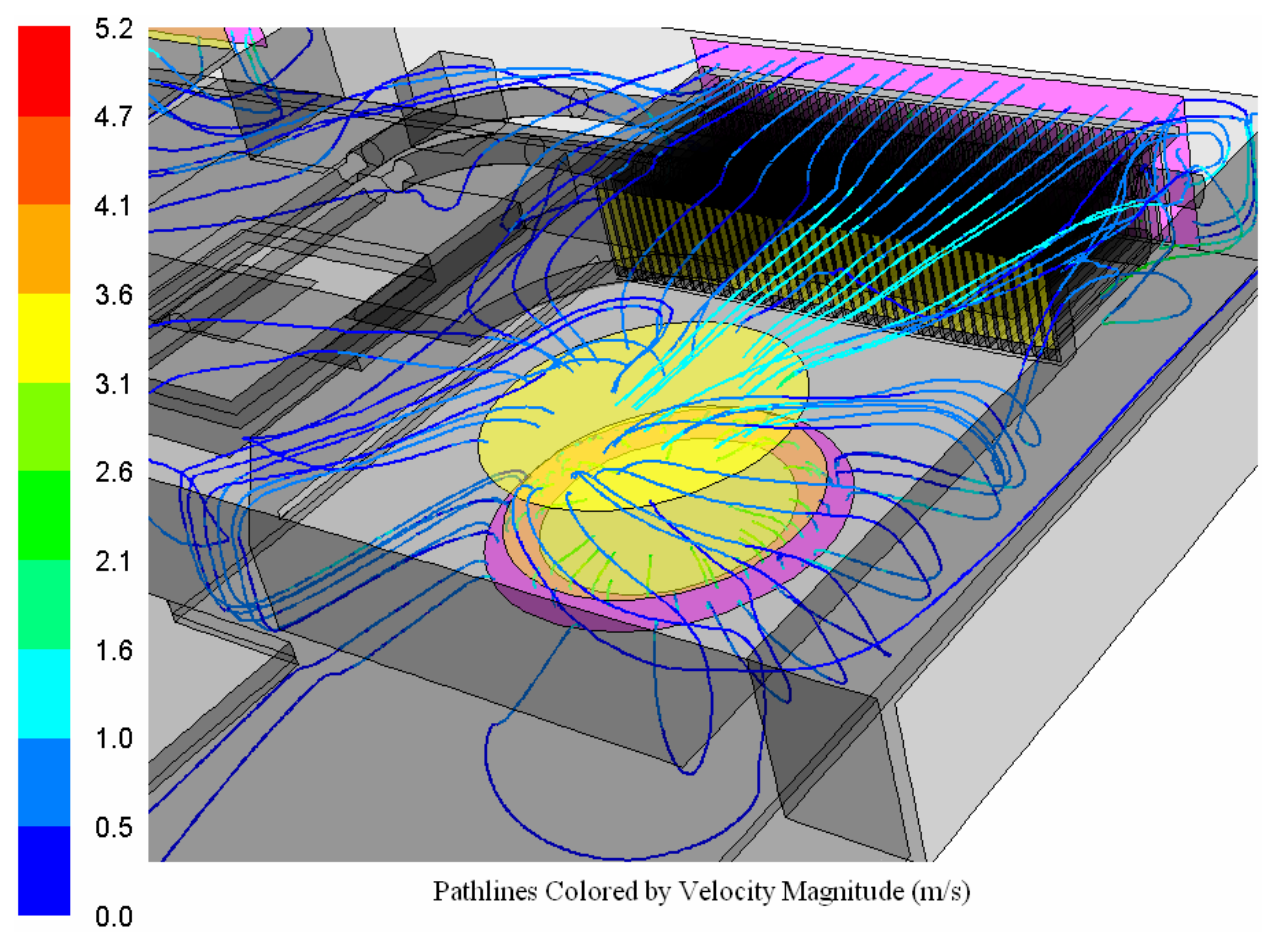

Figure 3.19 Path lines for primary fan

The secondary fan sucks air mainly from the ventilation hole on the side wall near it. At the same time, the side wall ventilation hole near the primary fan also supplies air for this fan. 


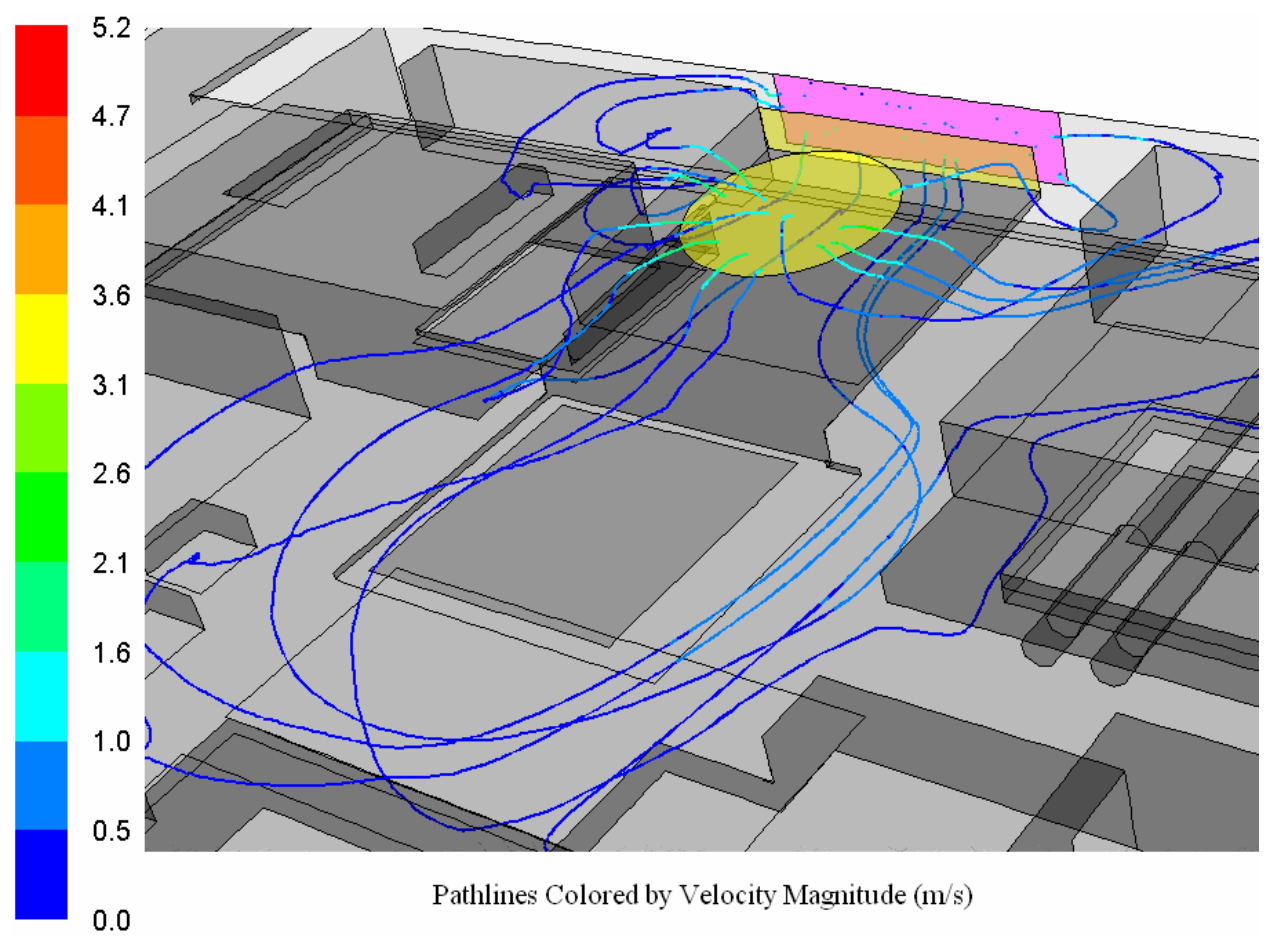

Figure 3.20 Path lines for secondary fan 


\section{CHAPTER 4}

\section{CONCLUSION}

In this study, the thermal management of a commercial notebook computer is numerically analyzed. A hybrid solution is used in the thermal management system of the notebook. There are two fans in the system: one of them is attached to a heat exchanger system -including heat pipes- for cooling the CPU, the other one is attached to a heat sink and dissipates heat from the graphics card and the south bridge.

The model of the system is formed with several simplifications and assumptions. Since the notebook computer has a very detailed component structure, it is not possible to model it exactly. The components which will not affect the flow are not modeled in this study. Most of the other components are simplified in the modeling process.

The heat exchanger in the system is modeled according to its real dimensions and geometry. In the numerical discussion part of the study, while discussing the mesh independency and the discretization scheme selection, a porous medium heat exchanger model is used to decrease the computational time.

A non-conformal tetrahedral grid structure is used in the mesh generation. The mesh size is chosen to be fine near the heat and momentum sources to increase the accuracy of the solution. The results of coarse and fine mesh size cases are compared. Due to the negligible difference between the cases, coarse mesh size is selected for the further analysis. 
The mesh generated in the heat exchanger has 3 cells in the air gaps between the fins and 1 cell in the fins, which is enough for a valid solution.

Incompressible laminar flow model is used for the solution neglecting the radiation heat transfer effects in the computational domain.

Selection of the discretization scheme is an important issue in computation fluid dynamics calculations. The solutions are obtained for the first order and the second order upwind discretization schemes, and compared.

Since there are some minor temperature differences between the two mesh size cases and discretization schemes, the coarse mesh configuration with the first order discretization scheme is used for the analysis.

The main heat transfer paths of the notebook computer are explained with the thermal resistance diagrams. In these diagrams, both the active and the passive heat transfer paths are presented. These diagrams make it easy to understand the main mechanisms in the heat dissipation of the components inside the notebook computer.

The system is analyzed for five different operating conditions. The results of this analysis are presented. In the fifth case, which is the worst case scenario, the design temperature limits for the HDD, the battery and the PCB are exceeded. However, this case is not likely to be reached by an average user.

The numerical results of the flow inside the domain are discussed in Section 3.4. The air away from the two fans in the system has very low velocities.

In the recent examples of the thermal management solutions used in the notebook computers, the heat dissipation plates, the heat sinks and the heat pipes are made up of copper instead of aluminum because of its higher thermal 
conductivity. The same thermal management system discussed in this study is also analyzed with the copper heat dissipation plates, heat sinks and heat pipes, and presented in Appendix C.

In summary, in this study the thermal management of a notebook computer is investigated by using CFD software. Although there are not any similar cases studied in the literature, when the temperature results for the components are compared with the average operating temperatures available, they seem reasonable.

Although the results seem reasonable, experimental analysis of the system may be useful to determine the accuracy of the numerical results. A higher accuracy can be achieved by modeling the system with experimentally measured heat dissipation values of the components. 


\section{REFERENCES}

[1] Intel Corporation, http://www.intel.com/support/processors/mobile/pentium4, Last visited on April 2008.

[2] A. Alisha Ali, "Design and Analysis of a Compact Two Phase Cooling System for a Laptop Computer", M.Sc. Thesis, Georgia Institute of Technology, June 2004.

[3] H. Xie, M. Aghazadeh, J. Toth, "The Use of Heat Pipes in the Cooling of Portables with High Power Packages”, IEEE Electronic Components and Technology Conference 1995, Proc., Vol. 45, pp. 906-913, 1995.

[4] N. K. R. Shankara, "What is Heat Pipe", 2004, http://www.cheresources.com/htpipes.shtml, Last visited on April 2008.

[5] B. V. Kosoy, "Heat Pipes, Theory and Practice", International Centre for Heat and Mass Transfer and Egik Inc. PTC-03 Short Course on Passive Thermal Control, pp. 33-54, October 2003.

[6] G. P. Peterson, "An Introduction to Heat Pipes", John Wiley \& Sons, 1994.

[7] M. S. Mahfoud, "Controlled Thermal Analysis Using Heat Pipe Technology”, Ph.D. Thesis, McGill University, May 1997.

[8] Transmeta, “TM5500/TM5800 Thermal Design Guide”, June 2002. 
[9] Aavid Thermalloy LLC., http://www.aavidthermalloy.com, Last visited on April 2008.

[10] T. Kobayashi, T. Ogushi, N. Sumi, M. Fujii, "Thermal Design of an Ultraslim Notebook Computer", IEEE Transactions on Components and Packaging Technologies, Vol. 23, No. 1, pp. 6-13, March 2000.

[11] M. Mochizuki, Y. Saito, K. Goto, T. Nguyen, P. Ho, M. Malcolm, M. P. Morando, "Hinged Heat Pipes for Cooling Notebook PC's", $16^{\text {th }}$ IEEE SEMI-THERM ${ }^{\mathrm{TM}}$ Symposium, Proc., pp. 64-72, 1997.

[12] H. Xie, A. Ali, R. Bhatia, "The Use of Heat Pipes in Personal Computers", InterSociety Conference on Thermal Phenomena, Proc., pp. 442-448, 1998.

[13] T. Nguyen, M. Mochizuki, K. Mashiko, Y. Saito, "Use of Heat Pipe / Heat Sink For Thermal Management of High Performance CPUs", $16^{\text {th }}$ IEEE SEMI-THERM ${ }^{\mathrm{TM}}$ Symposium, Proc., pp. 76-79, 2000.

[14] A. Karabuto, "HDD Diet: Power Consumption and Heat Dissipation", July 2004, http://www.digit-life.com/articles2/storage/hddpower.html, Last visited on April 2008.

[15] Intel Corporation, "Mobile Power Guidelines 2000”, Revision 0.8, September 1998.

[16] K. Hisano, H. Iwasaki, M. Ishizuka, "Thermal Analysis of Notebook Personal Computer", Proceedings of 1995 Japan International Electronic Manufacturing Technology Symposium, pp. 456-459, December 1995. 
[17] R. Viswanath, I. A. Ali, "Thermal Modeling of High Performance Packages in Portable Computers", IEEE Transactions on Components, Packaging, and Manufacturing Technology, Part A, Vol. 20, No. 2, pp. 230-240, June 1997.

[18] M. I. Baek, J. M. Lee, "Thermal Design for Notebook PC by Using Thermal Analysis", LG Electronics 9th International FLOTHERM User Conference, October 2000.

[19] E. Dallago, G. Venchi, "Thermal Characterization of Compact Electronic Systems: A Portable PC as a Study Case”, IEEE Transactions on Power Electronics, Vol. 17, No. 2, pp. 187-195, March 2002.

[20] E. Öztürk, "CFD Analysis of Heat Sinks for CPU Cooling with FLUENT", M.Sc. Thesis, Middle East Technical University, December 2004.

[21] SEPA Europe GmbH., http://www.sepa-europe.com, Last visited on April 2008.

[22] H. Schlichting, "Boundary Layer Theory", Seventh Edition, McGraw Hill Book Company, 1979.

[23] B. R. Munson, D. F. Young, T. H. Okiishi, "Fundamentals of Fluid Mechanics", Third Edition, John Wiley \& Sons, 1998.

[24] M. Nakanishi, W. Nakayama, M. Behnia, D. Soodphakdee, "A New Approach to the Design of Complex Heat Transfer Systems: Notebook Size Computer Design”, IEEE Inter Society Conference on Thermal Phenomena, Proc., pp 595-599, 2002. 
[25] F. P. Incropera, D. P. Dewitt, "Fundamentals of Heat and Mass Transfer", Fifth Edition, John Wiley \& Sons, 2002.

[26] Fluent Inc., "Fluent 6.3 User's Guide”, 2006. 


\section{APPENDIX A}

\section{HEAT PIPE THERMAL CONDUCTIVITY}

For the estimation of the thermal conductivity of heat pipes, thermal resistance modeling is used. The thermal resistance model of the heat pipe is shown in Figure A.1. Although there are ten resistances in the model, six of them are neglected due to their magnitude [11]. The total thermal resistance of the heat pipe is defined in Equations A.1 - A.5.

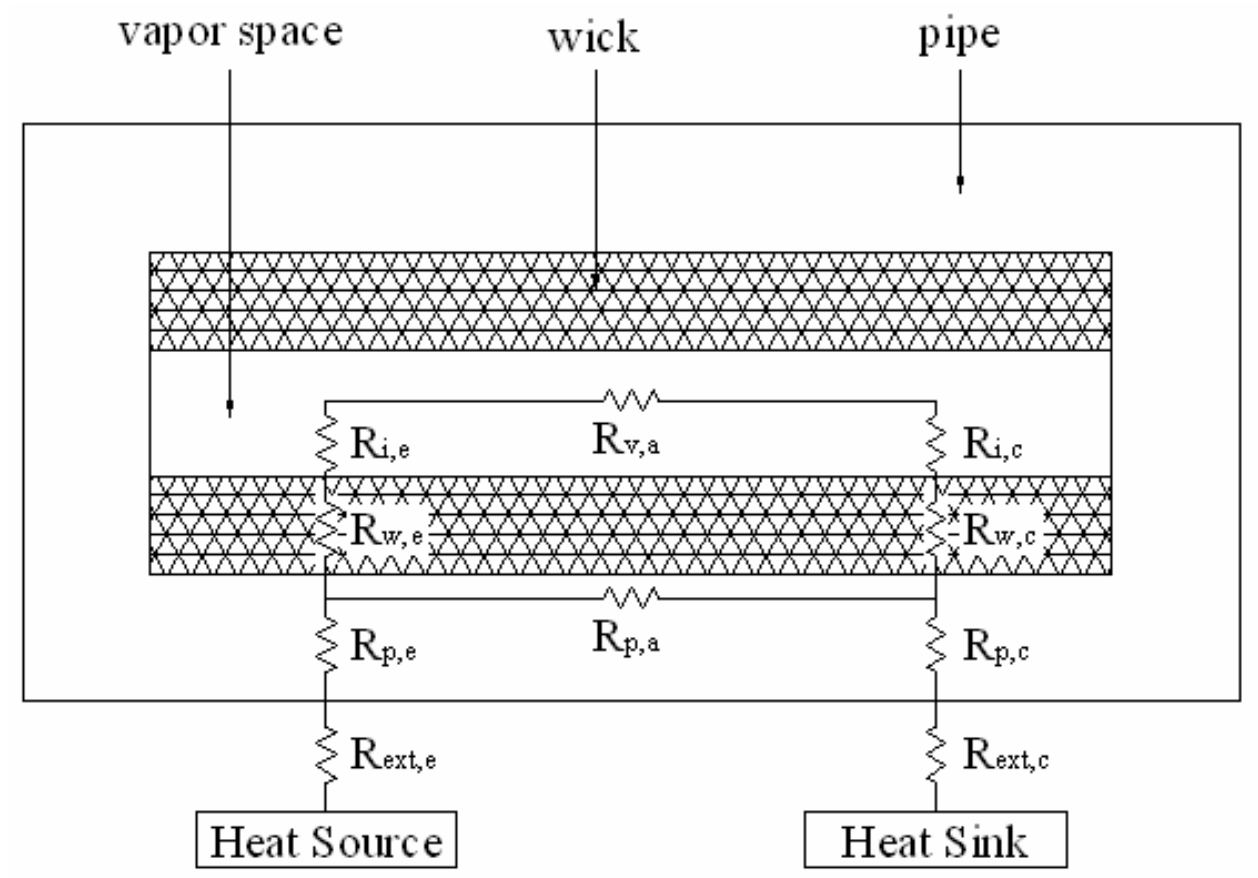

Figure A.1 Heat pipe thermal resistance model (adapted from [11]) 


$$
\begin{aligned}
& R_{t o t}=R_{p, c}+R_{p, e}+R_{w, c}+R_{w, e} \\
& R_{p, c}=\frac{t}{k_{p} \cdot A_{c}}=\frac{\ln \left(\frac{d_{o}}{d_{i}}\right)}{2 \cdot \pi \cdot L_{c} \cdot k_{p}} \\
& R_{p, e}=\frac{t}{k_{p} \cdot A_{e}}=\frac{\ln \left(\frac{d_{o}}{d_{i}}\right)}{2 \cdot \pi \cdot L_{e} \cdot k_{p}} \\
& R_{w, c}=\frac{1}{h_{c} \cdot \pi \cdot d_{i} \cdot L_{c}} \\
& R_{w, e}=\frac{1}{h_{e} \cdot \pi \cdot d_{i} \cdot L_{e}}
\end{aligned}
$$

where; $d_{o}$ is the heat pipe outside diameter, $d_{i}$ is the heat pipe inside diameter, $L_{c}$ is the condenser contacting length, $L_{e}$ is the evaporator contacting length, $k_{p}$ represents the heat pipe wall thermal conductivity. $h_{c}$ and $h_{e}$ are the estimated heat transfer coefficients for the condenser and the evaporator wick structures, respectively.

For the estimation of the axial thermal conductivity of the system only the last two terms in Equation A.1 are taken into account, therefore the equation reduces to:

$$
R_{\text {axial }}=\frac{1}{h_{c} \cdot \pi \cdot d_{i} \cdot L_{c}}+\frac{1}{h_{e} \cdot \pi \cdot d_{i} \cdot L_{e}}
$$

The effect of the thermal conductivity of the heat pipe in the thermal management of a notebook computer is discussed by comparing the average temperatures and the heat load on the heat transfer paths for three heat pipes with different thermal conductivities. The thermal conductivities used for these three heat pipes are $20000 \mathrm{~W} / \mathrm{mK}, 40000 \mathrm{~W} / \mathrm{mK}$ and $60000 \mathrm{~W} / \mathrm{mK}$. The system 
used in the comparison of these three heat pipes is the default operating condition with porous medium heat exchanger model discussed in the study.

The average temperature calculations for these three heat pipes are presented in Table A.1. As the thermal conductivity of the heat pipe increases, the average temperature of the component decreases. The difference between heat pipe 1 and 2 is higher than the difference between heat pipe 2 and 3. There is no significant difference in the average temperature values of the heat pipe 2 and 3.

Table A.1 Comparison of the average temperature values of the components

\begin{tabular}{|c|c|c|c|}
\hline Components & $\begin{array}{c}\text { Heat Pipe } 1 \\
\mathbf{T}\left({ }^{\circ} \mathrm{C}\right) \\
k=20000 \mathrm{~W} / \mathrm{mK}\end{array}$ & $\begin{array}{c}\text { Heat Pipe } 2 \\
\mathrm{~T}\left({ }^{\circ} \mathrm{C}\right) \\
k=40000 \mathrm{~W} / \mathrm{mK}\end{array}$ & $\begin{array}{c}\text { Heat Pipe } 3 \\
\mathrm{~T}\left({ }^{\circ} \mathrm{C}\right) \\
k=60000 \mathrm{~W} / \mathrm{mK}\end{array}$ \\
\hline CPU & 50.6 & 49.5 & 49 \\
\hline HDD & 46.4 & 46.2 & 46.1 \\
\hline BATTERY & 34.3 & 34.3 & 34.2 \\
\hline $\mathrm{GC}$ & 43.1 & 42.8 & 42.8 \\
\hline SB & 42.1 & 41.8 & 41.7 \\
\hline RAM & 41.7 & 41.4 & 41.3 \\
\hline PCMCIA & 39.5 & 39.3 & 39.3 \\
\hline PCB & 41.6 & 41.3 & 41.1 \\
\hline DVD & 34.8 & 34.7 & 34.7 \\
\hline
\end{tabular}

The average temperatures of the condenser and evaporator sections of the heat pipes are given in Table A.2. The average condenser temperatures are nearly the same for all heat pipes. The difference between the average evaporator temperatures shows the effectiveness of the heat pipes. 
Table A.2 Comparison of the average temperature values of the evaporator and the condenser section of the heat pipes

\begin{tabular}{|l|c|c|c|}
\hline Section & $\begin{array}{c}\text { Heat Pipe 1 } \\
\mathbf{T}\left({ }^{\circ} \mathbf{C}\right)\end{array}$ & $\begin{array}{c}\text { Heat Pipe 2 } \\
\mathbf{T}\left({ }^{\circ} \mathbf{C}\right)\end{array}$ & $\begin{array}{c}\text { Heat Pipe 3 } \\
\mathbf{T}\left({ }^{\circ} \mathbf{C}\right)\end{array}$ \\
\hline Evaporator & 38.8 & 37.5 & 36.9 \\
Condenser & 36 & 36 & 35.9 \\
\hline
\end{tabular}

The heat pipes which have lower thermal resistances, in other words higher thermal conductivities, carry bigger heat loads. The effect of changing heat pipe thermal conductivity on the heat transfer paths is given in Table A.3. Since the heat pipe is an element of active heat transfer path, the increase in thermal conductivity of the heat pipe increases the amount of heat dissipated by active methods.

Table A.3 Comparison of the heat loads on the heat transfer paths

\begin{tabular}{|l|c|c|c|}
\hline Type & Heat Pipe 1 (W) & Heat Pipe 2 $(\mathbf{W})$ & Heat Pipe 3 $(\mathbf{W})$ \\
\hline Passive & 6 & 5.8 & 5.8 \\
Active & 24 & 24.2 & 24.2 \\
\hline
\end{tabular}




\section{APPENDIX B}

\section{HEAT EXCHANGER GRID INDEPENDENCY}

The notebook computer model in which the heat exchanger modeled according to its real dimensions and geometry is used in the system. The mesh generated in the heat exchanger has 3 cells in the air gaps between the fins and 1 cell in the fins. A finer mesh with 176,838 additional elements, which has 4 cells in the air gaps between the fins and 2 cells in the fins, is generated in the heat exchanger to check the validity of the coarser mesh. In this finer mesh configuration, the entire system mesh is generated with 2,695,579 elements. The numerical results are compared for these two mesh configuration.

For the solution comparison of the two mesh configuration, a reference line is defined in the middle of the heat exchanger. The static temperature on this reference line is measured in both configurations and the results are plotted in Figure B.1. The temperatures on the reference line for the two mesh configuration are nearly the same. The fluctuations in the figure are caused by the temperature difference between the aluminum fins and the air between the fins. The former one is higher. The air temperature predicted by the fine mesh configuration is slightly lower than the coarse mesh configuration. The average temperature of the heat exchanger is $37.3{ }^{\circ} \mathrm{C}$ in the coarse mesh configuration solution and $37.4{ }^{\circ} \mathrm{C}$ in the fine mesh configuration solution. The difference is $0.1 \%$. 


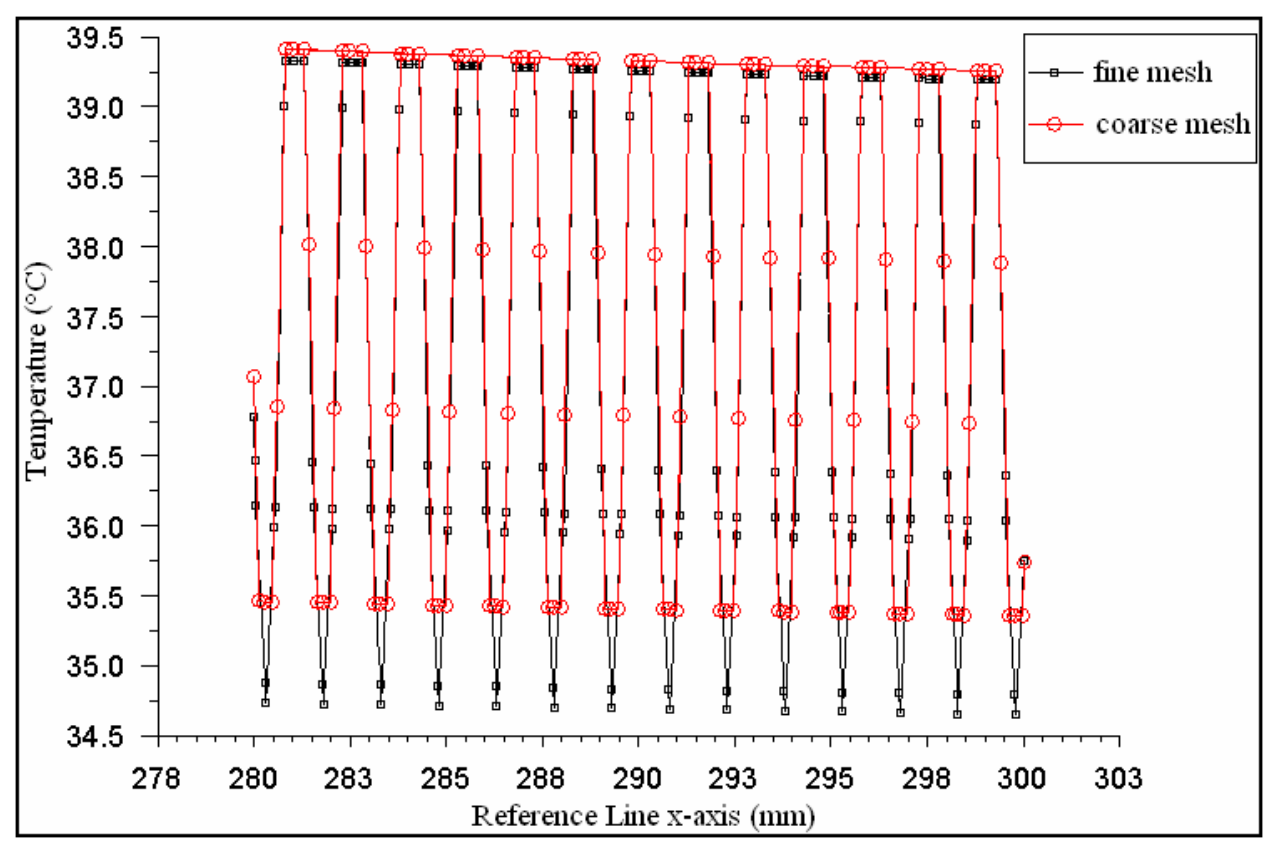

Figure B.1 Temperature plots on the reference line for the coarse and the fine mesh configurations

The average temperatures of the condenser and evaporator sections of the heat pipe for the coarse and fine mesh configurations are given in Table B.1. The average temperatures are nearly the same for the both configurations.

Table B.1 Comparison of the average temperature values of the evaporator and the condenser section of the heat pipe for the coarse and the fine mesh configurations

\begin{tabular}{|l|c|c|c|}
\hline Section & $\begin{array}{c}\text { Coarse Mesh } \\
\text { Average T }\left({ }^{\circ} \mathbf{C}\right)\end{array}$ & $\begin{array}{c}\text { Fine Mesh } \\
\text { Average T }\left({ }^{\circ} \mathbf{C}\right)\end{array}$ & $\begin{array}{c}\text { \% } \\
\text { Difference }\end{array}$ \\
\hline Evaporator & 41.7 & 41.5 & 0.3 \\
Condenser & 40.3 & 40.2 & 0.1 \\
\hline
\end{tabular}


In addition to these comparisons, Table B.2 gives average temperature calculations for the components for both of the mesh configurations. It can be seen that there is no significant change in the average temperatures of the components.

Since there is a considerable amount of difference between the two configurations, the coarse mesh configuration for the heat exchanger is acceptable.

Table B.2 Average temperature values of the components for the coarse and the fine mesh configuration

\begin{tabular}{|l|c|c|c|}
\hline Components & $\begin{array}{c}\text { Coarse Mesh } \\
\text { Average T }\left({ }^{\circ} \mathbf{C}\right)\end{array}$ & $\begin{array}{c}\text { Fine Mesh } \\
\text { Average T }\left({ }^{\circ} \mathbf{C}\right)\end{array}$ & $\begin{array}{c}\text { \% } \\
\text { Difference }\end{array}$ \\
\hline CPU & 53.5 & 53.4 & 0.1 \\
HDD & 47.9 & 47.8 & 0.1 \\
BATTERY & 34.9 & 35 & 0.1 \\
GC & 44.8 & 45 & 0.3 \\
SB & 43.8 & 43.9 & 0.1 \\
RAM & 43.2 & 43.2 & 0 \\
PCMCIA & 40.8 & 40.9 & 0.1 \\
PCB & 43.2 & 43.2 & 0 \\
DVD & 35.3 & 35.4 & 0.1 \\
\hline
\end{tabular}




\section{APPENDIX C}

\section{ENHANCEMENT IN THE THERMAL MANAGEMENT SYSTEM BY USING COPPER}

The notebook computer system analyzed in this study has a hybrid thermal management system in which aluminum plates are used to dissipate heat and cool down the components. In the recent notebook computer systems, copper is preferred to use in heat dissipation elements instead of aluminum.

The effect of the kind of material used in the heat dissipation plates, the heat sinks and the heat pipes in the thermal management solution of the notebook computer is discussed by comparing the maximum temperatures of the components. The comparison is done for materials: copper and aluminum. The system used in the comparison of these two cases is the default operating condition with the model discussed in the study.

The maximum temperature calculations for these two cases are presented in Table C.1. The temperatures of all the components decreased in the modified case except from the temperatures of the DVD and the PCMCIA card. As it can be seen in the Figure 2.1, the DVD and the PCMCIA card are on the left side of the notebook. The heat dissipation from the components on the right side and the middle of the notebook such as: the CPU, the hard disk, the graphics card and the south bridge chip is higher than the components on the left side. Since there are heat dissipation plates on the top and the bottom of the notebook, increasing the thermal conductivity of these plates results an increase in the temperatures of the components on the left side of the notebook. 
The maximum enhancement in the temperature values by using copper instead of aluminum is in the CPU temperature by $1.9 \%$.

Table C.1 Comparison of the maximum temperature of the components

\begin{tabular}{|l|c|c|c|}
\hline Components & $\begin{array}{c}\text { Standard (AI) } \\
\mathbf{T}\left({ }^{\circ} \mathbf{C}\right)\end{array}$ & $\begin{array}{c}\text { Modified }(\mathbf{C u}) \\
\mathbf{T}\left({ }^{\circ} \mathbf{C}\right)\end{array}$ & $\begin{array}{c}\% \\
\text { Difference }\end{array}$ \\
\hline CPU & 57.8 & 56.4 & 1.9 \\
BDD & 49.1 & 48.2 & 1.2 \\
BATTERY & 45 & 44.4 & 0.8 \\
SB & 45.2 & 44.7 & 0.7 \\
RAM & 44.2 & 43.6 & 0.8 \\
PCMCIA & 45.7 & 44.8 & 1.2 \\
PCB & 41.4 & 41.6 & 0.3 \\
DVD & 55.2 & 53.9 & 1.7 \\
\hline
\end{tabular}

